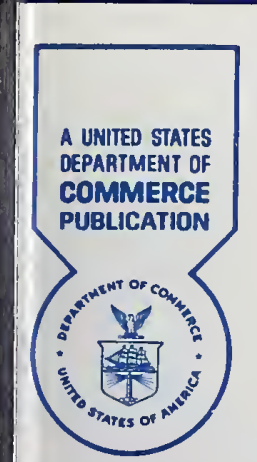

Nathonal Bureau of Standaras Library, E-01 Admin. Bidg. EEB $271970^{\text {BUILDING }}$ Referenc? taken from SCIENCE SERIES 22
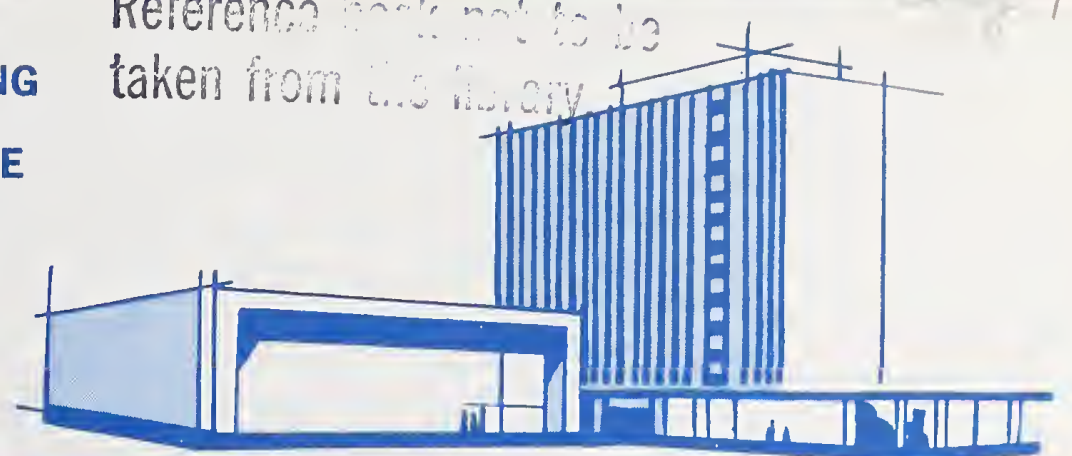

\title{
Investigation of Performance Characteristics for Sanitary Plumbing Fixtures
}




\section{Announcing-The Building Science Series}

The "Building Science Series" disseminates technical information developed at the Bureau on building materials, components, systems, and whole structures. The series presents research results, test methods, and performance criteria related to the structural and environmental functions and the durability and safety characteristics of building elements and systems.

These publications, similar in style and content to the NBS Building Materials and Structure Reports (1938-59), are directed toward the manufacturing, design, and construction segments of the building industry, standards organizations, officials responsible for building codes, and scientists and engineers concerned with the properties of building materials.

The material for this series originates principally in the Building Research Division of the NBS Institute for Applied Technology. Published or in preparation are:

BSS1. Performance of Buildings-Concept and Measurement. Man and His Shelter. (In press.)

BSS2. Interrelations Between Cement and Concrete Properties: Part 1, Materials and Techniques, Water Requirements and Trace Elements. 35 cents

BSS3. Doors as Barriers to Fire and Smoke. 15 cents

BSS4. Weather Resistance of Porcelain Enamels: Effect of Exposure Site and other Variables After Seven Years. 20 cents

BSS5. Interrelations Between Cement and Concrete Properties: Part 2, Sulfate Expansion, Heat of Hydration, and Autoclave Expansion. 35 cents

BSS6. Some Properties of the Calcium Aluminoferrite Hydrates. 20 cents

BSS7. Organic Coatings. Properties, Selection, and Use. $\$ 2.50$

BSS8. Interrelations Between Cement and Concrete Properties: Part 3, Compressive Strengths of Portland Cement Test Mortars and Steam-Cured Mortars, 55 cents.

BSS9. Thermal-Shock Resistance for Built-Up Membranes, 20 cents

BSS10. Field Burnout Tests of Apartment Dwelling Units, 25 cents

BSS11. Fire Resistance of Steel Deck Floor Assemblies. 25 cents

BSS12, Performance of Square-Edged Orifices and Orifice-Target Combinations as Air Mixers. 15 cents

BSS13. Shrinkage and Creep in Prestressed Concrete. 15 cents

BSS14. Experimental Determination of Eccentricity of Floor Loads Applied to a Bearing Wall. 15 cents

BSS15. Interrelations Between Cement and Concrete Properties: Part 4, Shrinkage of Hardened Portland Cement Pastes. 75 cents

BSS16. Techniques for the Survey and Evaluation of Live Floor Loads and Fire Loads in Modern Office Buildings. 40 cents

BSS17. Causes of Variations in Chemical Analysis and Physical Tests of Portland Cement. 40 cents

BSS18. Smoke and Gases Produced by Burning Aircraft Interior Materials. 35 cents

BSS19. Study of the Variables in the Saturating of Roofing Felts. 30 cents.

BSS21. Algorithms for Psychometric Calculations. (In press.)

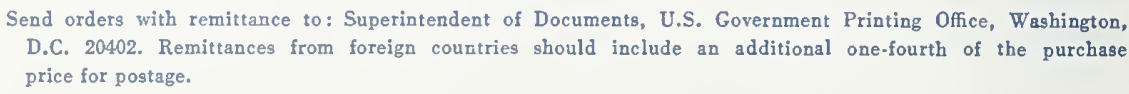


UNITED STATES DEPARTMENT OF COMMERCE - Maurice H. Stans, Secretary

\title{
Investigation of Performance Characteristics for Sanitary Plumbing Fixtures
}

\author{
Building Research Division \\ Institute for Applied Technology \\ National Bureau of Standards \\ Washington, D.C. \\ As requested by \\ Building Research Advisory Board \\ National Academy of Sciences-National Research Council \\ Washington, D.C.
}

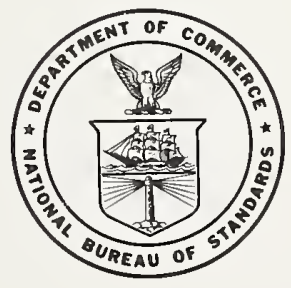

Building Science Series 22 ,

Nat. Bur. Stand. (U.S.), Bldg. Sci. Ser. 22, 72 pages (January 1970) CODEN: BSSNB

Issued January 1970 


\section{Project Staff}

The planning and execution of the various phases of this project were carried out principally by the following persons, who were members of the Building Research Division during the period of time over which the work was done.

D. Watstein, T. Reichard, and L. F. Skoda of the Structures Section; R. S. Wyly, R. W. Beausoliel, and C. J. Seay of the Environmental Engineering Section; D. G. Moore, J. C. Richmond, J. W. Pitts, and W. C. Wolfe of the Materials and Composites Section. P. R. Achenbach of the Division Office served as project director and coordinator. 


\section{Foreword}

Results are described from an investigation of performance characteristics for sanitary plumbing fixtures conducted at the National Bureau of Standards at the request of an ad hoc committee appointed by the National Academy of Sciences-National Research Council. The committee identified significant performance characteristics, coordinated the investigation, and developed its conclusions in part on the basis of the results of the investigation at NBS.

The findings and recommendations given herein have been prepared by NBS in a form suitable as supplemental information to appear as a chapter within the publication proposed for issue by the NAS-NRC. 


\section{Contents}

Project staff

Foreword

1.1. Statement of the problem

1.2. Initiation of project...............

1.3. Authorization and funding

1.4. Work to be performed . . . . . . . . .

1.5. Test specimens _....................

1.6. Specimen identification

1.7. Field surveys._. . .

1.8. Discussion of performance tests and performance requirements..........

1.9. Use of trade names for identifying instruments, materials, and equipment.....

1.10. Test titles Applicability of findings to various types of fixtures..................

1.12. Statistical limitations of findings

1.13. Units of measurement

2. Test procedures

2.1. Uniform loading (bathtub) (S101)
2.2 . Concentrated load, static (bathtub) (S102)

2.3. Rim load (bathtub) (S102A)

2.4. Concentrated dynamic load (bathtub) (S103)

2.5. Concentrated load, sump sidewall (bathtub) (S104)

2.6. Drain-fitting load (bathtub) (S105)

2.7. Watertight-joint potential (bathtub) (S106)

2.8. Surface inspection ( $\mathrm{M} 201)$

2.9. Water absorption (M202)

2.10. Abrasion resistance (M203)

2.11. Cleanability and soilability $(\overline{\mathrm{M}} \overline{\mathrm{O}} \overline{\mathrm{B}} \overline{\mathrm{A}})$
Page

ii

iii

1

2

2

3

4
2. Test procedures-Continued

Page

2.12. Surface-impact resistance (bathtub)

2.13. Dimensional stability (M205)

2.14. Bond maintenance (mechanical) (M206)

2.15. Surface slip resistance (bathtub or shower receptor) (M207) _..........

2.16. Scratch resistance (M208)

2.17. Drainability (bathtub) (M209)

2.18. Hot-water resistance (bathtub) (T302)

2.19. Cigarette-burn resistance (T303)

2.20. Radiant-heater resistance (T303A)

2.21. Resistance to thermal shock (T304)

2.22 . Resistance to household chemicals (C501)

2.23. Stain resistance (C502)

2.24. Color stability (C503)

2.25. Surface texture aging (C504)

2.26. Odor (C505)

2.27. Noise control (bathtub) (N401) and (N402)

2.28. Biological characteristics (B601) (B602) (B603)

3. Tests requiring further development

3.1. Cleanability and soilability $(\mathrm{M} 203 \mathrm{~A})$

3.2. Surface slip resistance (M207)

3.3. Resistance to thermal shock (T304) ....-

3.4. Other characteristics requiring test dedevelopment........................

4. References

Appendix A: Inspection of FRPE manufacturing processes, installed fixtures, and test facilities.-

Appendix B: Telephone survey of pressed-steel bathtubs 


\title{
Investigation of Performance Characteristics for Sanitary Plumbing Fixtures
}

\author{
Building Research Division \\ Institute for Applied Technology \\ National Bureau of Standards
}

\begin{abstract}
This report gives findings and recommendations developed during an investigation of performance characteristics for sanitary plumbing fixtures, conducted at the request of the Building Research Advisory Board of the National Academy of Sciences-National Research Council. The report describes the test methods that are recommended for the evaluation of 16 performance characteristics, and the nature of further work required to complete the development of four or five additional test procedures.

The suitability of various existing test methods for evaluating the functional and performance characteristics of sanitary plumbing fixtures was investigated in the laboratory. In addition, new or modified tests for certalin characteristics were developed. The laboratory work was performed only on bathtubs and flat specimens provided by industry through appropriate arrangements with the Building Research Advisory Board. Field inspection trips were made to provide the NBS project staff with up-to-date information on certain manufacturing processes and on installation and use problems. The complexities involved in the selection of valid performance levels are discussed, as well as the elements of judgment involved. A format that might be used in specifying performance is suggested for each test procedure, and the rationale underlying each suggested format is given.

Key words: Performance characteristics; sanitary plumbing fixtures; test methods; performance level; abrasion resistance; scratch resistance; stain resistance; cigarette-burn resistance; surface-impact resistance; chemical resistance; concentrated static-load capacity; cleanability and soilability.
\end{abstract}

\section{Introduction}

\subsection{Statement of the Problem}

The recent introduction into the market of new sanitary plumbing fixture materials, such as reinforced plastics, has emphasized the need for functional or performance criteria that would be applicable to all materials. It is probable that fixtures made of the new materials would have physical, chemical, and engineering properties different from those of the more conventional porcelain-enameled or vitreous-china fixtures. Furthermore, the more conventional fixtures may have higher levels of performance for some characteristics than are needed for satisfactory performance. Also, the tests in current use for porcelain-enameled or vitreous-china fixtures may not, in all cases, be suitable for use with a material such as a fiberglass-reinforced plastic. Obviously if meaningful performance criteria are to be developed for sanitary plumbing fixtures, not only is knowledge needed on the functional and technical performance characteristics of such fixtures, but it is also important to develop or select suitable test procedures for evaluating these characteristics. The investigation as herein described was concerned mostly with the testing procedures.

\subsection{Initiation of Project}

Recognizing the need for establishing realistic performance requirements for plumbing fixtures, the plumbing industry and agencies of the Federal Government requested the National Academy of Sciences-National Research Council, through its Building Research Advisory Board, to undertake the development of the essential performance requirements and methods for their evaluation. An ad hoc committee of the Building Research Advisory Board, consisting of persons from universities, government, and industry, was appointed to plan and direct the study.

The National Bureau of Standards was requested by the Building Research Advisory Board to carry out field and laboratory investigations, and the development of test procedures for sanitary plumbing fixtures, with the principal emphasis on bathtubs. The ad hoc committee of the 
Building Research Advisory Board and the subcommittees formed within it met with members of the staff of the National Bureau of Standards at selected intervals to review the progress of the program and to advise on its broad phases. By mutual agreement reached during the progress of the work, the actual testing was limited to flat specimens and bathtubs.

\subsection{Authorization and Funding}

The investigation undertaken by the National Bureau of Standards was authorized by the ad hoc committee in June 1964, in accordance with a proposal prepared by the Bureau. The work was financed jointly by multiple sponsors under the auspices of the Building Research Advisory Board and by the National Bureau of Standards.

\subsection{Work to be Performed}

By mutual, written agreement, the work to be performed by the National Bureau of Standards was to include the following:

1. Inspect manufacturing facilities, testing laboratories, and typical installations of fixtures to familiarize project personnel with current operations, use conditions, and test procedures.

2. Review existing test proceduress of ASTM, ASA, and other organizations, as well as commercial standards requirements, Federal specification requirements, and selected regulatory requirements ${ }^{1}$ for suitability, reproducibility of test results, and applicability to a wide range of construction materials. ${ }^{2}$

3. Identify, based on this review, existing test procedures that should be tried out on various materials; and develop new test procedures where needed.

4. Carry out trials of existing and new test procedures on flat specimens and bathtubs.

5. Prepare a final report to the ad hoc committee and include in this report (a) a description of the laboratory work that was performed on each property of interest, (b) a description of each recommended test procedure and apparatus, (c) the rationale for the recommended test procedure, and (d) a discussion of performance requirements that might be pertinent to sanitary fixtures.

Each of the properties of interest is discussed in the succeeding sections, based on the above-mentioned report. However, because of both time and budget limitations, it was not possible to recommend test procedures for all 28 properties that were judged important by the ad hoc committee. Those tests requiring additional work are discussed in the appropriate sections. It should be pointed out in this connection that the original

\footnotetext{
1 This language was intended to indicate plumbing code provisions. Several codes were reviewed.

2 This refers to the various materials that might be used in the manufacture of plumbing fixtures. Actual test development was carried out only on bathtubs and flat specimens.
}

project agreement did not require that test proce dures be recommended for all of the 28 properties

\subsection{Test Specimens}

Two types of test specimens were utilized: flat squares, either 4 -in $\times 4$-in or $41 / 4$-in $\times 41 / 4$-in ir size, and whole bathtubs. The specimens wert furnished by various manufacturers in accordance with arrangements made by the Building Research Advisory Board and the ad hoc committee. The plan adopted for specimen procurement called foj 100 squares from each of three or more manufac turers of vitreous-china, enameled-steel, enamelec cast-iron, fiberglass-reinforced polyester (FRPE) and stainless-steel fixtures, respectively. Fou whole bathtubs were to be furnished by each 0 three or more different manufacturers of enam eled-steel and enameled cast-iron fixtures, respec tively, and four whole bathtubs from each of foul or more manufacturers of fiberglass-reinforcec polyester fixtures.

This plan for specimen procurement was largel adhered to, except that (1) no stainless steel speci mens were obtained, (2) three brands of polyeste (FRPE) bathtubs rather than four were obtained (3) only two manufacturers provided flat FRPE specimens, and (4) two rather than three make of enameled steel flat specimens were provided. I is not believed that these changes in the origina plan for specimen procurement had any substan tial effect on the outcome of the investigation. Al specimens were furnished with a white finish ex cept for one FRPE bathtub, which was green, anc one lot of flat cast-iron specimens which was fur nished in five different colors. However, becaus these cast-iron specimens were received late in th investigation, it was not possible to include then in the testing work.

\subsection{Specimen Identification}

Each lot of bathtubs and each lot of flat speci mens were assigned identification numbers on ar rival in accordance with table 1.6-1. The reasol for including this table is to provide a more com plete identification of specimens referred to in thr tables and figures in later sections of the report

\subsection{Field Surveys}

Appendices A and B summarize the results o two limited surveys of bathtubs that had been in service for varying periods of time. Appendix A relates to fiberglass-reinforced polyester bathtub and Appendix B relates to porcelain-enameled steel bathtubs.

These surveys were made to acquaint the proj ect staff with typical manufacturing, installation and use conditions, and to provide some guidanc in arriving at realistic test conditions. Referenc to Appendices $A$ and $B$ at this point will be help 
TABLE 1.6-1. Identification of specimens

\begin{tabular}{|c|c|c|c|}
\hline Specimen Nos. & Manufacturer & Type of material & Type of specimens \\
\hline $\begin{array}{l}\mathrm{A}-1 \text { to } 101 \\
\mathrm{~B}-1 \text { to } 4 \\
\mathrm{C}-1 \text { to } 4 \\
\mathrm{D}-1 \text { and } 2\end{array}$ & $\begin{array}{l}\mathrm{A} \\
\mathrm{B} \\
\mathrm{A} \\
\mathrm{C} \\
\mathrm{D}\end{array}$ & $\begin{array}{l}\text { Glass-fiber-reinforced polyester (F RPE) } \\
\text { FRPE } \\
\text { FRPE } \\
\text { FRPE } \\
\text { Porcelain-enameled steel. }\end{array}$ & $\begin{array}{l}\text { 41/1 } \times 41 / 1 / \text {-in flats. } \\
\text { Bathtubs. } \\
\text { Bathtubs. } \\
\text { Bathtubs. } \\
\text { Bathtubs. }\end{array}$ \\
\hline 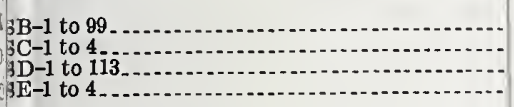 & $\begin{array}{l}\mathbf{E} \\
\mathbf{F} \\
\mathbf{G}\end{array}$ & $\begin{array}{l}\text { Porcelain-enameled steel } \\
\text { Porcelain-enameled steel } \\
\text { Porcelain-enameled steel } \\
\text { Porcelain-enameled steel }\end{array}$ & $\begin{array}{l}\text { 4 x 4-in flats. } \\
\text { Bathtubs. } \\
4 \times 4 \text {-in flats. } \\
\text { Bathtubs. }\end{array}$ \\
\hline 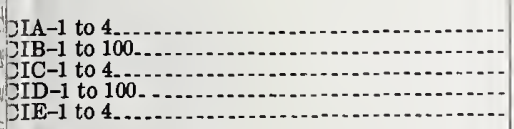 & $\begin{array}{l}\mathrm{H} \\
\mathrm{K} \\
\mathrm{L} \\
\mathrm{L} \\
\mathrm{M}\end{array}$ & 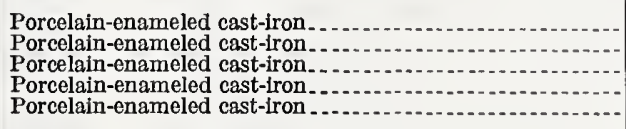 & $\begin{array}{l}\text { Bathtubs. } \\
4 \times 4 \text {-in flats. } \\
\text { Bathtubs. } \\
4 \times 4 \text {-in flats. } \\
\text { Bathtubs. }\end{array}$ \\
\hline $\begin{array}{l}\text { GIF-1 to } 100 \\
\text { YCA-1 to } 101 \\
\text { YCB-1 to } 104\end{array}$ & $\begin{array}{l}\mathrm{N} \\
\mathrm{O} \\
\mathrm{P} \\
\mathrm{R}\end{array}$ & 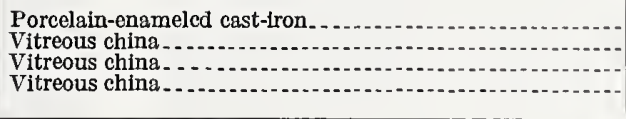 & $\begin{array}{l}4 \times 4 \text {-in flats. } \\
4 \times 4 \text {-in flats. } \\
4 \times 4 \text {-in flats. } \\
4 \times 4 \text {-in flats. }\end{array}$ \\
\hline
\end{tabular}

ful in understanding various sections of this report.

Originally it had been expected that an extenive field survey would be made to obtain statisically significant results relating to various use factors, physical properties, length of service, etc. However, this survey was not undertaken, prinipally because competent statisticians advised that a meaningful survey would be prohibitive in cost.

\subsection{Discussion of Performance Tests and Performance Requirements}

For a piece of equipment as intimately involved in family living as a bathtub, the desirable funcional characteristics include not only requirements such as water-tightness, drainage characteristics, strength, and safety, but also the more subjective soncepts such as ease of cleaning, appearance, durability, resistance to staining, burn resistance, and esistance to chemical attack. These latter subjecive requirements are likely to be expressed in qualitative terms involving such phrases as "ac"ceptable appearance," "normal service life," and "typical use conditions," that have no precise definition in physical terms.

Developing test methods that are meaningful requires conception of a test procedure that simutates to an acceptable degree the kinds of physical, shemical, and mechanical exposure received by the fixtures in actual use. While simulative service isting is not new, simulation of the interaction between human beings and household fixtures in a way that will provide a basis for fair competition among materials of unlimited variety presents additional complexities. It involves careful analysis of the important processes of use, wear, and deteripration that are brought to bear on the fixtures in service, and translation of these processes into a piece of laboratory equipment that can be described and reproduced and that can measure the ffiects of these processes in quantitative terms.
Once an acceptable test procedure and a test apparatus have been developed, the performance of typical fixtures can then be measured under the selected test conditions. Although fixtures or specimens of materials prepared especially for test purposes can sometimes be obtained on which to collect quantitative data, more frequently only commercial items are available for testing. In this latter case, test results on the commercial items must be used for comparison with user requirements.

The selection of acceptable performance levels involves evaluation of human aesthetic reaction as well as the frequency and duration of exposure to a variety of human activities. In the case of properties that may be expected to deteriorate gradually with use over a period of years, valid performance levels cannot be set without extensive statistical data on use conditions, and on users' concepts of long-term acceptability.

Such statistical data are usually not available because of the prohibitive cost of obtaining them. Where the measured values of a given property vary over a wide range for various materials using a selected test method, it may not al ways be logical to set a single performance level for all materials.

The factors of use conditions and tolerance level of users are intimately related to standard of living, psychology, and the effect of long experience with conventional materials, Thus, a given performance level might be acceptable in the view of some users, but entirely unacceptable to others. Similarly, after a period of experience with a new material, users might come to accept or require a different level of performance than formerly. For example, it is not difficult to imagine the attitude of users toward the introduction of glass for windows if the material previously used had been a transparent resilient material such as plexiglas. It might take many years to obtain consumer acceptance of the low impact resistance of glass under these conditions.

In the absence of adequate statistical data on use conditions and tolerance of users, one practical 
approach to performance levels is to select levels that either upgrade, downgrade, or maintain the existing quality of a class of products in current use, based on the measured performance of a suitable comprehensive sampling of contemporary products. Decisions with respect to upgrading, downgrading, or maintaining present quality require the studied judgment of experienced persons acting together. Performance levels arrived at in this way would, of course, be subject to later adjustment as more extensive service data or user reaction became available.

Recommended performances levels are not included herein. However, comments on performance requirements have been added at the end of each section in the hope that these comments may be helpful to code and specifications groups who may wish to set performance levels that are based on the recommended test procedures.

\subsection{Use of Trade Names for Identifying Instruments, Materials, and Equipment}

Certain commercial instruments, materials, and equipment are indentified in order to specify the experimental procedure adequately. In no case does such identification imply recommendation or endorsement by the National Bureau of Standards, nor does it imply that the instruments, materials, or equipment identified are necessarily the best available for the purpose, nor that items not identified but having the necessary characteristics cannot be used.

\subsection{Test Titles}

The test procedures to be discussed in what follows are titled in a fashion consistent with the identification system used by the ad hoc committee. The word "bathtub" in parentheses indicates that the test is limited to bathtubs in its present state of development. If the word "bathtub" does not appear in parentheses in the test title, this signifies the test is applicable to fixtures in addition to bathtubs. The number in parentheses signifies the test classification adopted by the ad hoc committee. For example, S101 means test No. 101 in the Structural Series, M203 means test No. 203 in the Mechanical Series, T303 means test No. 303 in the Thermal Series, etc.

\subsection{Applicability of Findings to Various Types of Fixtures}

Since no test development was conducted in this investigation on actual fixtures other than bathtubs, some of the recommended tests must be limited to bathtubs. In these instances, further work will be necessary to adapt the tests to other fixtures. However, a number of the tests are applicable to more than one fixture type, because certain per- formance characteristics are primarily related to the material and are affected little or none by the type of fixture the material is used in.

\subsection{Statistical Limitations of Findings}

Many of the test procedures discussed herein should be looked upon as in need of further refinement. This is particularly pertinent from statistical considerations. For example, some tests are obviously affected by several sources of variation. but limitations on the amount of work that could be performed in the present investigation precluded the collection of adequate statistical data for the computation of the variances corresponding to these various sources. Among the general problems that need further attention in applications of the work reported are (1) required number of test specimens and replicate tests, (2) sampling procedures, and (3) effects of variation among observers, equipment, and laboratories. In summary, the problem is: How much testing is required as a minimum to assure a just acceptance or rejection of a single fixture or a lot of fixtures? This is particularly important where the measured performance by one or a few measurements is close to specified minimum performance levels.

The selection of fixtures and flat specimens for use in test development was handled by the manufacturers through the auspices of the Building Research Advisory Board. The National Bureau of Standards made no study regarding the extent to which these fixtures and specimens represented current production, and therefore makes no claim in this respect.

Thus, in any application of the findings of the present investigation, it is important to recognize the statistical limitations described above, and to recognize that a very considerable amount of additional work will be required to obtain an altogether correct solution to the statistical problems.

\subsection{Units of Measurement}

Results of this investigation are reported in terms of conventional units, for the most part. This was done for two reasons : First, conventional units are ordinarily used by those groups most concerned with the results. Second, most of the existing standards and test methods extensively referenced and evaluated herein utilize conventional units.

However, because of the increasing importance of international standards in foreign commerce it is strongly recommended that groups which utilize the results of this investigation in the promulgation of standards and specifications as. sume the responsibility for appropriate conversion to International Standard (SI) units. For example, 0.500 in equals $1.27 \mathrm{~cm}, 2.1 \mathrm{lb}$ equals $0.9 \mathrm{E}$ $\mathrm{kg}, 120^{\circ} \mathrm{F}$ equals $48.9^{\circ} \mathrm{C}$, etc. 


\section{Test Procedures}

\subsection{Uniform Loading (Bathtub) (S101)}

No test method exists for the uniform loading of bathtubs and no test method is recommended. This type of loading would be the result of the weight of the bath water. The amount of water necessary to fill each of eight different bathtubs to the overflow outlet hole was measured. The average weight of water was found to be $339 \mathrm{lbs}$. A 300-lb concentrated load at the center of the sump ${ }^{3}$ would usually be more severe than a uniform load of $339 \mathrm{lbs}$. Therefore, if the recommended concentrated static-load test (Sec. 2.2) is used a uniform-load test would not be needed.

Although a uniform-load test was not considered essential, some data were obtained on sump deflections from a type of load similar to that imposed by a person sitting or standing in a bathtub partially filled with water. Load-deflection tests were made on three FRPE tubs using $150 \mathrm{lbs}$ of water and three 50-lb cast-iron weights centrally placed in the sump. Deflections with time were measured by using the procedure recommended for the concentrated static-load test (sec. 2.2). These data, for hot and cold water, were obtained for general information only.

Figure 2.1-1 presents the results of two tests on one of the FRPE tubs. The three rectangular weights covered a combined area of approximately 132 in $^{2}$ in both tests, but were placed slightly differently in the two tests. In Test 1, the weights were placed end-to-end along the longitudinal centerline of the tub, but were placed side-by-side

3 The "sump" of a bathtub will be deflned as the receptor comprising the inside walls and bottom of the bathtub.

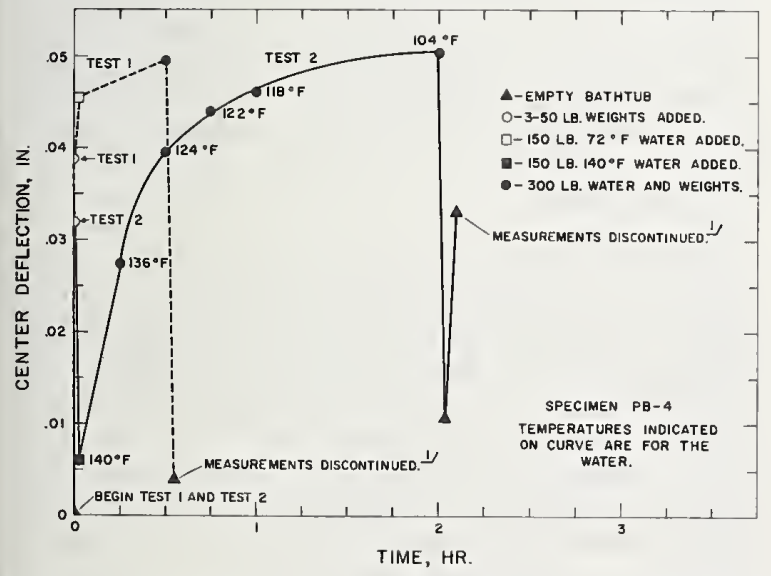

${ }^{1}$ Data in section 2.18 on other tubs subjected to hot-water loading show that residual center deflections decreased substantially with time after load removal and loading.

Figure 2.1-1. Effect of time on the center deflection of an FRPE tub with warm- and coldwater loads. with their lengths transverse to the longitudinal centerline of the tub in Test 2.

Room temperature $\left(72^{\circ} \mathrm{F}\right)$ water was added for Test 1 and hot $\left(104^{\circ} \mathrm{F}\right)$ water for Test 2.

For Test 1 the three 50-lb weights produced a center deflection ${ }^{4}$ of 0.039 in and the addition of the $150 \mathrm{lb}$ of cool water produced an immediate additional deflection of $0.007 \mathrm{in}$.

For Test 2 the three 50-lb weights produced a center deflection of $0.032 \mathrm{in}$, but the addition of the $150 \mathrm{lb}$ of hot water caused an immediate upward movement of $0.026 \mathrm{in}$ at the center of the sump (indicated by a downward movement on graph). It should be noted that the immediate upward movement of the sump from the hot-water load was about four times the downward movement from the cool water in Test 1 . However, with time the center deflections for both tests approached the same value.

Immediately upon removal of the load in Test 2 the expected upward movement occurred. However, as the tub cooled the thermal gradients caused a downward movement. It is unfortunate that measurements were not continued for a longer period, but from other test results there is not much doubt that the sump would gradually return to a position close to the original.

\subsection{Concentrated Load, Static (Bathtub) (S102)}

\section{a. Purpose and Scope}

The purpose of this test is to determine if a bathtub will support a 300-lb concentrated load at the bottom center of the tub without excess deflections or surface damage. The service load simulated is that of a heavy person standing in the tub.

\section{b. Recommended Test Method}

\section{(1) Equipment Required for Test}

1. Three micrometer dial gages graduated to $0.001 \mathrm{in}$.

2. A loading device for applying a 300-1b test load without shock to the center of the tub bottom.

Note: Either calibrated weights or a suitable mechanical or hydraulic load applicator may be used.

3. A distribution pad to distribute the load over a 5- $\times 10$-in area. The pad shall consist of a sheet of $3 / 4$-in-thick sponge rubber (Shore Durometer Hardness of 8 to 14) topped with a plate of plywood or stiffer material having a minimum thickness of $3 / 4$ in. This plate shall be of sufficient thickness so that there is no more than 0.01 in deflection of the ends when the $300-1 b$ load is applied during the test.

"The "center deflection" is deflned, as the deflection at the mid-point of the longitudinal centerline of the sump. 


\section{(2) Support of Specimen During Test}

The bathtub shall be mounted for test in a wood frame simulating normal installation. Design of the supporting frame shall be such as to allow for clearance under the tub for deflection-measuring dial gages. The manufacturer's installation instructions when obtainable shall be used in spacing the 2- $\times 4$-in stud of the frame and in fastening the tub to the frame. In lieu of explicit manufacturer's instructions the tub shall be fastened along the water bead to each stud of the test frame by $11 / 2$-in long No. 6 steel wood screws using $3 / 8$-in steel washers. The spacing of the studs in the supporting frame shall be no greater than 16 in on centers.

The top of the supporting frame shall be at least 12 in higher than the top of the installed tub.

If legs or other component parts of the tub are within $1 / 8$ in of the floor line, after installation, rigid vertical support shall be provided for these components.

The front apron shall be supported in a continuous bed of plaster of paris.

For tubs without integral wall surrounds the back ledge of the tub shall be supported by a continuous horizontal $2-\times 4$-in wood framing member that is fastened securely to the studs.

\section{(3) Test Procedure}

Maintain the temperature of the testing laboratory and bathtub at $75 \pm 5^{\circ} \mathrm{F}$. Before starting the test, inspect the finished surface of the bathtub in accordance with section 2.8 of this report. Note all defects detected.

Center the distribution pad over the horizontal center lines of the sump with the 10-in dimension along the length of the sump. Determine the sump center lines by using the average length and width of the sump.

Place the three micrometer dial gages on a rigid base beneath the longitudinal center line of the sump, with one directly beneath the center of the distribution pad and the other two within 2 in of each end of the bottom of the sump.

NoTE: The areas where the tips of the dial gage bear on the tub must be flat and smooth so that a small lateral movement of the tub will not change the gage reading by more than 0.001 in. These bearing areas can be prepared either by grinding the under surface or by rigidly fastening a small flat, level plate to the tub. In case the drain hole of the bathtub should interfere with the placement of a gage, a standard drain-fitting spud can be inserted in the drain-outlet hole and a flat area on the spud used for the dial-gage bearing.

Preload the specimen by applying the test load of $300 \mathrm{lb}$ at the center of the distribution pad and leaving the load in place for $5 \mathrm{~min}$. Then remove the load and make the initial dial-gage readings.

Reload the tub and make the gage readings immediately following load application and also 5 min later. Finally, remove the load and make the dial readings immediately after removal and again 10 min later.
Determine the average settlement of the tub and supports by averaging the deflections measured by the two end gages. Determine the center deflection of the sump by subtracting this a verage settlement from the deflection measured by the center gage.

After load removal, inspect the surfaces of the tub for cracks and spalls in accordance with section 2.8. Note any other damage that develops from the testing.

\section{(4) Information To Be Reported}

Include the following in the test report:

1. Specimen identification;

2. Description of specimen including overall height, width, and length;

3. Description of test frame;

4. Method of suporting and fastening bathtub in test frame;

5. Defects, if any, prior to test;

6. Defects, if any, after test;

7. Deflection at the center of sump;

a. Immedicately after application of load;

b. Five minutes after application of load:

c. Immediately after removal of load;

d. Ten minutes after removal of load.

\section{c. Test Results and Discussion}

\section{(1) Discussion of Existing Methods}

A test method for evaluating the structural integrity of FRPE bathtubs is described in the August 1964 proposed revision of Commercial Standard CS221-59, hereafter referred to as the "proposed revision of CS 221-59" [1] $]^{5}$. This test method requires that a full-size unit be installed according to manufacturer's directions and an applied load of $300 \mathrm{lb}$ be distributed over a 3-indiam area near the center of the bottom of the bathtub. The applied load is allowed to remain on the tub for not less than one nor more than two minutes. The maximum allowable deflection under the load point is $0.150 \mathrm{in}$. The residual deflection which is determined 10 min after removal of the applied load is not to exceed $0.008 \mathrm{in}$.

\section{(2) Test Data}

The relationship between the applied loads and defiections are shown in figure 2.2-1. Each pair of curves represents the maximum and minimum deflections observed during tests of bathtubs manufactured from the materials designated. The observed deflections for individual units tested appear in table 2.2-1. Table 2.2-1 also includes the results of tests performed on units using a 3-indiam disk as the applied load area. As can be expected, the measured deflections are larger for these tests.

Table 2.2-2 is a summary of static load tests to destruction. The table includes results of tests on

\footnotetext{
5 Figures in brackets indicate the literature references at the end of this publication.
} 
three FRPE units, one enameled-steel tub, and one cast-iron tub. The table is self-explanatory and is presented for information only. Table 2.2-3 is a compilation of various dimensions of all tubs used in these tests and is presented for information only.

An examination of table 2.2-1 shows that all tubs tested had center deflections of less than 0.125 in, and had residual deflections 10 min after load removal of less than $0.003 \mathrm{in}$.

\section{(3) Rationale for Test Selection}

The basic concepts of the proposed revision of the Commercial Standard were preserved in the recommended test; however, several modifications were incorporated. The first was to enlarge the distribution pad from a 3-in-diam circular area to a 5 - $\times 10$-in rectangular area. This change was

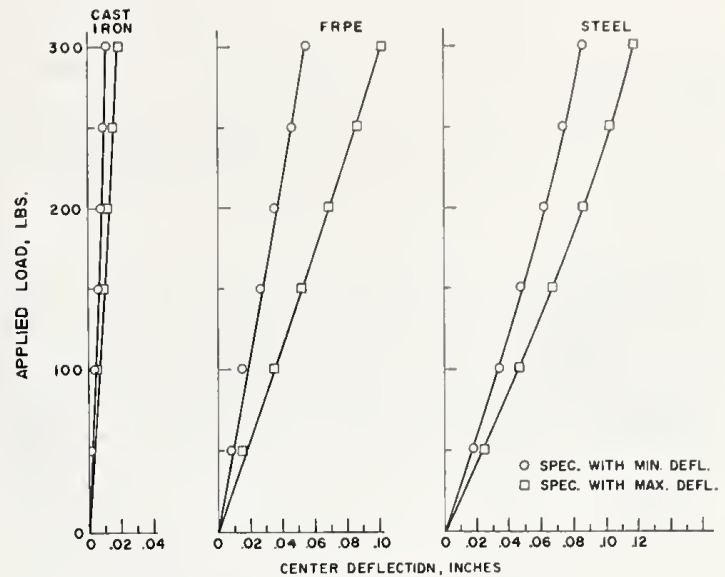

Figure 2.2-1. Conccntrated load test (static), 50 square inches area.

TABLE 2.2-1. Center deflections (300-lb concentrated static load)

\begin{tabular}{|c|c|c|c|c|c|c|c|c|}
\hline \multirow[b]{2}{*}{ Specimen No. } & \multirow[b]{2}{*}{ Material } & \multicolumn{4}{|c|}{$5-x$ 10-in loaded area } & \multicolumn{2}{|c|}{3 -in round loaded area } & \multirow{2}{*}{$\begin{array}{l}\text { Ratio } 3 \text {-in } \\
\text { round to } \\
5 \times 10 \text {-in } \\
\text { areas imme- } \\
\text { diately after } \\
\text { loading }\end{array}$} \\
\hline & & $\begin{array}{c}\text { Immediately } \\
\text { after } \\
\text { loading }\end{array}$ & $\begin{array}{l}5 \text { min after } \\
\text { loading }\end{array}$ & $\begin{array}{l}\text { Immediately } \\
\text { after } \\
\text { removal } \\
\text { of load }\end{array}$ & $\begin{array}{l}10 \text { min after } \\
\text { removal } \\
\text { of load }\end{array}$ & $\begin{array}{c}\text { Immediately } \\
\text { after } \\
\text { loading }\end{array}$ & $\begin{array}{l}\text { Immediately } \\
\text { after } \\
\text { removal } \\
\text { of load }\end{array}$ & \\
\hline $\begin{array}{l}\text { PD-1.. } \\
\text { PC-1. - } \\
\text { PB-4.- }\end{array}$ & $\begin{array}{l}\text { FRPE } \\
\text { FRPE } \\
\text { FRPE }\end{array}$ & $\begin{array}{r}\text { in } \\
0.055 \\
.083 \\
.102\end{array}$ & $\begin{array}{r}\text { in } \\
0.056 \\
.084 \\
.104\end{array}$ & $\begin{array}{r}\text { in } \\
0.002 \\
.003 \\
.005\end{array}$ & $\begin{array}{r}\text { in } \\
<0.001 \\
.001 \\
.001\end{array}$ & $\begin{array}{r}\text { in } \\
0.061 \\
.111\end{array}$ & $\begin{array}{r}i n \\
0.001 \\
.004 \\
0\end{array}$ & $\begin{array}{l}1.11 \\
1.38 \\
-. .\end{array}$ \\
\hline $\begin{array}{l}\text { SE-2 } \\
\text { SA-4 } \\
\text { SC-2... }\end{array}$ & $\begin{array}{l}\text { Steel..... } \\
\text { Steel..... } \\
\text { Steel...-. }\end{array}$ & $\begin{array}{l}.086 \\
.109 \\
.107\end{array}$ & $\begin{array}{l}.086 \\
.109 \\
.107\end{array}$ & $\begin{array}{r}<.001 \\
<.001 \\
.001\end{array}$ & $\begin{array}{l}<.001 \\
0 \\
<.001\end{array}$ & $\begin{array}{l}.107 \\
.126 \\
.128\end{array}$ & $\begin{array}{l}.001 \\
.007 \\
.004\end{array}$ & $\begin{array}{l}\text { 1. } 24 \\
\text { 1. } 16 \\
1.20\end{array}$ \\
\hline $\begin{array}{l}\text { CIE-4 } \\
\text { CIC-4 } \\
\text { CLA-1 }\end{array}$ & $\begin{array}{l}\text { Cast Iron } \\
\text { Cast Iron }- \\
\text { Cast Iron }\end{array}$ & $\begin{array}{r}.012 \\
.015 \\
.019\end{array}$ & $\begin{array}{l}.012 \\
.015 \\
.019\end{array}$ & $\begin{array}{l}-.001 \\
0 \\
0\end{array}$ & $\begin{array}{l}<.001 \\
0 \\
0\end{array}$ & $\begin{array}{l}.013 \\
.017 \\
.022\end{array}$ & $\begin{array}{l}0 \\
0 \\
0\end{array}$ & $\begin{array}{l}1.08 \\
1.13 \\
1.16\end{array}$ \\
\hline
\end{tabular}

made to more closely simulate the area covered by a person standing in a bathtub. The larger area also permits the use of dead weights for load application.

The test as described in the proposed revision of CS 221-59 made no provision for correcting for settlement of the tub in the frame when the load was applied. The present test procedure considers the possibility of error from this source and corrects for it through use of three gages rather than one.

The length of time for the applied load to remain on the bathtub was increased to $5 \mathrm{~min}$. to coincide more nearly with service use.

\section{d. Comments on Performance Requirements}

(1) Suggested Format for a Performance Level

The bathtub shall show no damage to either the visible or nonvisible surfaces from the testing. In addition, the center deflection $5 \mathrm{~min}$ after the load is applied shall not be greater than in nor shall the residual center deflection $10 \mathrm{~min}$
TABLE 2.2-2. Static load tests to destruction $(5-\times 10-i n$ area)

\begin{tabular}{|c|c|c|}
\hline $\begin{array}{l}\text { Specimen } \\
\text { No. and } \\
\text { material }\end{array}$ & $\begin{array}{l}\text { Ultimate } \\
\text { load, lb }\end{array}$ & Results \\
\hline $\begin{array}{l}\text { PB-4 } \\
\text { F RPE }\end{array}$ & 4,000 & $\begin{array}{l}\text { At } 3,000 \mathrm{lb} \text {, center longitudinal reinforcing mem- } \\
\text { ber broken. Failure in top-flange screw con- } \\
\text { nections to studding and transverse crack in } \\
\text { sump between applied-load pad and front wall } \\
\text { at ultimate load. }\end{array}$ \\
\hline $\begin{array}{l}\text { PC-1 } \\
\text { FRPE }\end{array}$ & 5,100 & $\begin{array}{l}\text { At } 2,550 \mathrm{lb} \text {, center reinforeing member broken. } \\
\text { At } 3,630 \text { lb, head-end reinforcing member } \\
\text { broken. At 4,090 lb, drainend reinforcing } \\
\text { member broken. Transverse cracking of fixture } \\
\text { across sump at maximum load. }\end{array}$ \\
\hline $\begin{array}{l}\text { PD-1 } \\
\text { F RPE }\end{array}$ & 18,000 & $\begin{array}{l}\text { Audible cracking of reinforcing member began } \\
\text { at } 2,350 \mathrm{~b} \text {. No visible damage to coating. } \\
\text { Reinforcing under sump splintered. Test } \\
\text { discontinued at } 8,000 \text { lb. } 1\end{array}$ \\
\hline $\begin{array}{l}\text { SA-4 } \\
\text { Steel }\end{array}$ & 5,500 & $\begin{array}{l}\text { At } 3,550 \mathrm{lb} \text {, spalling around rim. Primary struc- } \\
\text { tural failure from buckling of flange at head } \\
\text { end. Spalling of coating in bottom of sump } \\
\text { near center and permanent set of about } 1 \text { in at } \\
\text { point of application of load. }\end{array}$ \\
\hline $\begin{array}{l}\text { CIA-4 } \\
\text { Cast Iron }\end{array}$ & 6,900 & $\begin{array}{l}\text { Crack in fixture along longitudinal center line } \\
\text { of sump about one-half the length of the bottom } \\
\text { at maximum load. }\end{array}$ \\
\hline
\end{tabular}

1 Loading discontinued, because 8,000-1b load caused sump bottom to bear on reinforcing structure. 
TABLE 2.2-3. Bathtub dimensions and weights

\begin{tabular}{|c|c|c|c|c|c|c|c|c|c|}
\hline \multirow[t]{2}{*}{ Material } & \multicolumn{3}{|c|}{ FRPE } & \multicolumn{3}{|c|}{ Pressed Steel } & \multicolumn{3}{|c|}{ Cast Iron } \\
\hline & 1 & 2 & 3 & 1 & 2 & 3 & 1 & 2 & 3 \\
\hline Weight, lb. . & 141 & 100 & 80 & 83 & 96 & 94 & 268 & 293 & 318 \\
\hline $\begin{array}{l}\text { Outside Dimensions: } \\
\text { (a) Length, in } \\
\text { (b) Width, in } \\
\text { (c) Rim Height, in } \\
\text { (d) Top to Floor, in } \\
\text { (e) Water Bead, in }\end{array}$ & \begin{tabular}{r|}
60 \\
$331 / 4$ \\
$16^{3} / 8$ \\
$787 / 8$ \\
$11 / 2$
\end{tabular} & \begin{tabular}{r|}
$5915 / 16$ \\
$343 / 6$ \\
$167 / 8$ \\
$745 / 8$ \\
$13 \%$
\end{tabular} & $\begin{array}{l}605 / 16 \\
311 / 2 \\
14 \% 8 \\
20 \\
11 / 4\end{array}$ & $\begin{array}{l}601 / 6 \\
301 / 16 \\
16 \\
163 / 4 \\
3 / 4\end{array}$ & $\begin{array}{l}60^{3} / 16 \\
31 \\
1515 / 16 \\
16^{15} / 16 \\
1\end{array}$ & $\begin{array}{l}601 / 6 \\
301 / 16 \\
15 \\
157 / 8 \\
7 / 6\end{array}$ & $\begin{array}{l}601 / 6 \\
30316 \\
141 / 4 \\
145 / 8 \\
3 / 8\end{array}$ & $\begin{array}{l}5913 / 16 \\
301 / 8 \\
141 / 8 \\
145 / 8 \\
1 / 2\end{array}$ & $\begin{array}{l}599 / 16 \\
2915 / 16 \\
141 / 8 \\
143 / 4 \\
6 \\
6\end{array}$ \\
\hline $\begin{array}{l}\text { Sump dimensions: } \\
\text { (a) Depth, in. } \\
\text { (b) Depth, in.b } \\
\text { (c) Length, in. }{ }^{\circ} \\
\text { (d) Width, at widest point, in.d } \\
\text { (e) Width at drain, in.d.- } \\
\text { Rim width: }\end{array}$ & $\begin{array}{l}125 / 6 \\
125 \% 16 \\
531 / 2 \\
231 / 2 \\
21\end{array}$ & $\begin{array}{l}141 / 16 \\
139 / 16 \\
49 \\
221 / 6 \\
211 / 8\end{array}$ & $\begin{array}{l}121 / 4 \\
111 / 2 \\
491 / 4 \\
221 / 6 \\
211 / 2\end{array}$ & $\begin{array}{l}127 / 8 \\
12 \% / 6 \\
501 / 2 \\
223 / 6 \\
201 / 8\end{array}$ & $\begin{array}{l}139 / 16 \\
13 \\
53 \\
22^{1} 1 / 16 \\
22^{1} 1 / 16\end{array}$ & $\begin{array}{l}123 / 4 \\
123 / 6 \\
54 \\
237 / 16 \\
213 / 4\end{array}$ & \begin{tabular}{l|}
$121 / 2$ \\
12 \\
$501 / 4$ \\
$217 / 6$ \\
$183 / 6$
\end{tabular} & $\begin{array}{l}121 / 2 \\
113 / 4 \\
50 \\
227 / 6 \\
185 / 16\end{array}$ & $\begin{array}{l}1211 / 16 \\
123 / 16 \\
483 / 4 \\
213 / 8 \\
203 / 4\end{array}$ \\
\hline $\begin{array}{l}\text { Rim width: } \\
\text { at center, in }\end{array}$ & $67 / 6$ & $41 / 16$ & $43 / 4$ & $33 / 4$ & $53 / 16$ & $31 / 2$ & $3^{11 / 16}$ & $41 / 4$ & $51 / 16$ \\
\hline
\end{tabular}

after the load is removed be greater than in. Note: Damage to the visible surfaces of the bathtub shall be construed as the appearance of any of the defects described in section 2.8, while damage to nonvisible surfaces shall be construed as cracking or separation of reinforcing members or any similar deterioration of the structural properties of the bathtub.

\section{(2) Rationale for Suggested Format}

There are two reasons for limiting the center deflection of the bathtub. The first is to insure that the bath or shower water will drain completely from the tub even though the bather remains in the tub. The second reason is that large deflections may instill a feeling of insecurity in many users.

The reason for limiting the residual deflection after load removal is to provide some assurance against accumulative permanent set from repeated loadings, which might eventually make the fixture unusable.

\subsection{Rim Load (Bathtub) (S102A)}

\section{a. Purpose and Scope}

The purpose of this test is to determine if a bathtub will withstand a 300-lb. load applied at the center of the front rim without damage. The service load simulated is that of a person sitting or standing on the bathtub rim.

\section{b. Recommended Test Method}

\section{(1) Equipment Required for Test}

1. The load-application method shall be as specified in section 2.2.b(1).

2. The load-distribution pad shall be as specified in section 2.2.b(1) except that the area of the pad shall be $7-\times 7$-in.

\section{(2) Preparation of the Test Specimen}

The bathtub shall be mounted and supprorted for test as specified in section 2.2.b(2). The inside surfaces of the tub shall be inspected in accordance with the procedure described in section 2.8 .

\section{(3) Test Procedure}

Maintain the temperature of the testing laboratory and bathtub at $75 \pm 5^{\circ} \mathrm{F}$. Apply the test load through the distribution pad at the center of the front rim. Apply the center of the load to the center of the pad, and leave in place for $5 \mathrm{~min}$. After removal of the load, inspect the finished surfaces of the bathtub for damage.

\section{(4) Information to be Reported}

Include the following in the test report:

1. Specimen identification;

2. Method of supporting and fastening specimen in frame;

3. Description of test frame;

4. Damage noted prior to test;

5. Damage noted after test.

\section{c. Test Results and Discussion}

\section{(1) Discussion of Existing Methods}

Commercial Standard CS 221-59 [2] requires that a load of $300 \mathrm{lb}$ be placed on the deck cormers and at the mid-point of the rolled-over edge of the bathtub. The load which is applied through a pad of suitable soft material is left in position for 1 to $10 \mathrm{~min}$. The loaded area is 7 in by the width of the rim. No permanent deformation nor any cracking or crazing is allowed. The proposed revision of CS 221-59 [1] is essentially the same except that the no-permanent-deformation requirement was removed.

The proposed revision also specified that the mid-point and one end of the rim should be loaded 
through a 3 -in round pad. No provision was made for loading other areas.

\section{(2) Test Development}

The basic features of the proposed revision of CS 221-59 were considered to be satisfactory. During test development, the 300 -lb test load was applied at various positions about the rims of the tubs. Deflection measurements of the rim as well as lateral movements of the front apron were made. Table 2.3-1 describes some of the lateral-movement measurements made on the various tubs. Since deflections of the rim and lateral movements of the apron due to an applied load are partly dependent on the restraints imposed on the tub as a result of installation, none of the measurements was considered significant. The data presented in table 2.3-1 are for information only and are not intended for use in evaluating the tubs. No surface damage attributable to the $300-1 b$ test load was observed on any of the tubs tested.

\section{(3) Rationale for Test Selection}

The recommended test procedure is similar to that outlined in CS 221-59 [2], with one exception. The single test area, chosen as the center of the front rim, subjects the tub to the greatest possible flexural load and therefore is the most desirable location for applying the test load.

The rim load is recommended as simulating the service load from a heavy person sitting or standing on the rim. The test is needed to evaluate the resistance to surface damage that possibly could result from high flexural stresses.

\section{d. Comments on Performance Requirements}

\section{(1) Suggested Format for a Performance Level}

Surface finish damage that can be attributed to the test shall not be allowed. The inspection procedure prescribed in section 2.8 shall be used for evaluation of damage.
(2) Rationale for Suggested Format

No limit on deflection or lateral movement is included in the suggested format since the structural rigity of the tub can be determined by performance requirements for the static load test (sec. 2.2).

In addition, lateral movement and resultant forces in service are affected by the degree of restraint offered by the method of installation, both of which may vary widely. The 300-lb load recommended approximates the weight of a very large person. It seems reasonable to expect a bathtub to withstand a service loading of this magnitude without surface damage.

\subsection{Concentrated Dynamic Load (Bathtub) (S103)}

\section{a. Purpose and Scope}

The purpose of this test is to determine if the bathtub will withstand, without visible damage, an impact load simulating a person falling or jumping into a bathtub.

\section{b. Recommended Test Method}

\section{(1) Apparatus}

The falling-body test load shall consist of lead shot in a leather bag. The total weight of the falling body shall be $150 \mathrm{lb}$ ( $\pm 1 \mathrm{lb}$ ).

The bag shall be cylindrical, 9 in in diameter by about 18 in high. The leather shall be similar to that described in Federal Specification $\mathrm{KK}-\mathrm{L}-$ 201 e for lacing leather. It shall be made from at least two pieces of leather so that the bottom, striking, surface will be seamless. A method for closing the top opening of the bag shall be provided to prevent.loss of lead shot.

Note: As the bursting force is high, the sewing of the seams is critical. The size of thread used should be as large as practical to reduce the tendency of the thread to cut the leather.

TABLE 2.3-1 Rim-load lest results

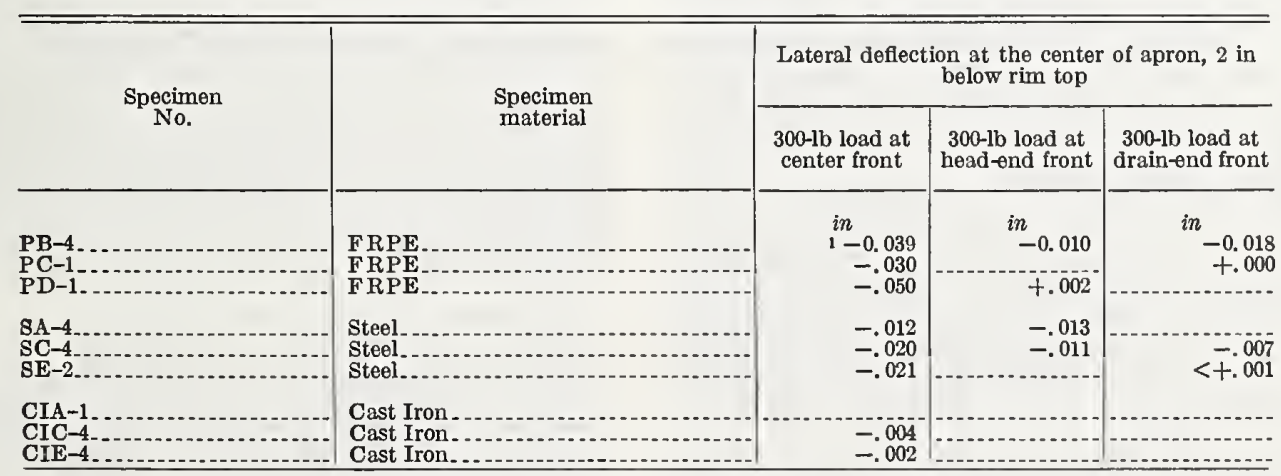

1 Negative deflections indicate movement away from sump. 
The method of hanging and releasiring the bag shall be such that the center of the point of impact in the tub can be estimated to within 0.5 in and the height-of-drop can be adjusted to within $0.1 \mathrm{in}$.

NoTE: The buckle from an automotive safety seat belt is satisfactory for a release mechanism.

\section{(2) Preparation of Test Specimen}

The bathtub shall be mounted and prepared for test as specified in section 2.2 The center of the sump shall be determined as in paragraph 2.2 b(3), and marked.

\section{(3) Test Procedure}

Maintain the temperature of the testing laboratory and bathtub at $75 \pm 5^{\circ} \mathrm{F}$. Drop the bag successively from heights of 5,10 , and 15 in, measured vertically from the center of the bottom surface of the bag to the point marked as the center of the sump. Make one drop at each height. Make certain that the center of the bag strikes within 0.5 in of the center of the sump. After the final 15-in drop, inspect the finished surface of the bathtub for defects in accordance with section 2.8 .

\section{(4) Information to be Reported}

Include the following in the test report:

1. Specimen identification;

2. Method of supporting and fastening specimen in test frame;

3. Description of test frame;

4. Defects noted prior to test;

5. Defects noted after test.

\section{c. Test Results and $\stackrel{\oplus}{\text { Discussion }}$}

\section{(1) Test Development}

A review of the literature revealed no existing standard test method that would produce the required conditions. Therefore, a simple falling-body test was developed to simulate the type of dynamic loading that might occur in service. A variety of containers, weights, support conditions, shockabsorbing pads, and heights-of-drop was tried prior to selection of the recommended dynamic test. Metal containers proved to be too difficult to control after impact. Sand-filled bags were too bulky and also difficult to control. Lead shot in canvas bags burst the canvas when dropped. Finally a leather bag was obtained which would withstand the force from the impact.

Initially a 300-lb falling body was used. However, this was found to produce severe damage to some of the bathtubs except at unrealistically small heights-of-drop. The 300-lb test was abandoned as unrealistic, as field information indicated very little or no damage from service-inflicted loads of this type.

Electronic instrumentation was devised to record the duration of impact and also the deflec- tions. However, this was deemed too refined, costly, and time-consuming for the information obtained.

The results of the development work indicated that a weight of $150 \mathrm{lbs}$ in a supple leather bag dropped in increments of 6 in or less should constitute an adequate test.

A relatively simple method was devised to measure deflections to 0.01 in by supporting a 6 -in scale in a friction-clamping device. The scale was put into contact with the underside of the bottom of the tub prior to application of the load and the initial leading made. The deflection device had to be reset prior to each drop. As for the concentrated static-load tests (sec. 2.2), three deflection devices were used so that the observed center deflections could be corrected for tub and support movement.

The relationships between heights-of-drop and deflections are shown in figure 2.4-1. Each pair of curves represents the maximum and minimum observed values for each type of bathtub tested. These data are presented for information only and are not intended for use in evaluating the dynamic properties of the various units. However, they do illustrate a reason for not including deflection as a performance requirement. For example, for a 24-in drop, the center deflection for the cast-iron tubs was between 0.1 and $0.2 \mathrm{in}$, but, for the FRPE tubs, the deflections ranged from about 0.4 to 0.75 in. It does not seem to be practical to use a limiting deflection as a performance requirement because of the wide variations in test results between materials and specimens.

The data presented in table 2.4-1 show that damage to one steel tub was observed after an 18in drop. It should be noted that damage was observed only for the steel tubs. As the tubs were tested in height-of-drop increments of 6 in, it is not known if the observed damage would have occurred had the weight been dropped once only from a height of 18 or 24 in.

Originally there had been some thought that, in lieu of a dynamic test, a heavier, static concentrated loading might be used. However, the data shown in figure 2.4-2 indicate that, if only deflections are considered, the relationship between the two types of tests is rather obscure for heights-ofdrop above $12 \mathrm{in.}$

Furthermore, if the static load corresponding to the first-observed damage reported in table 2.2-2 for the destruction tests is considered, it will be noted that the damage occurred at $3550 \mathrm{lbs}$ for the steel tub. This static load is well above the eqiuvalent static load indicated in figure 2.4-2 for the 18 - or 24 -in drop which produced damage in the dynamic test.

\section{(2) Rationale for Test Selection}

The recommended test was selected because it represents qualitatively the type of dynamic loading which might result from a person falling in, or jumping into, a bathtub. 


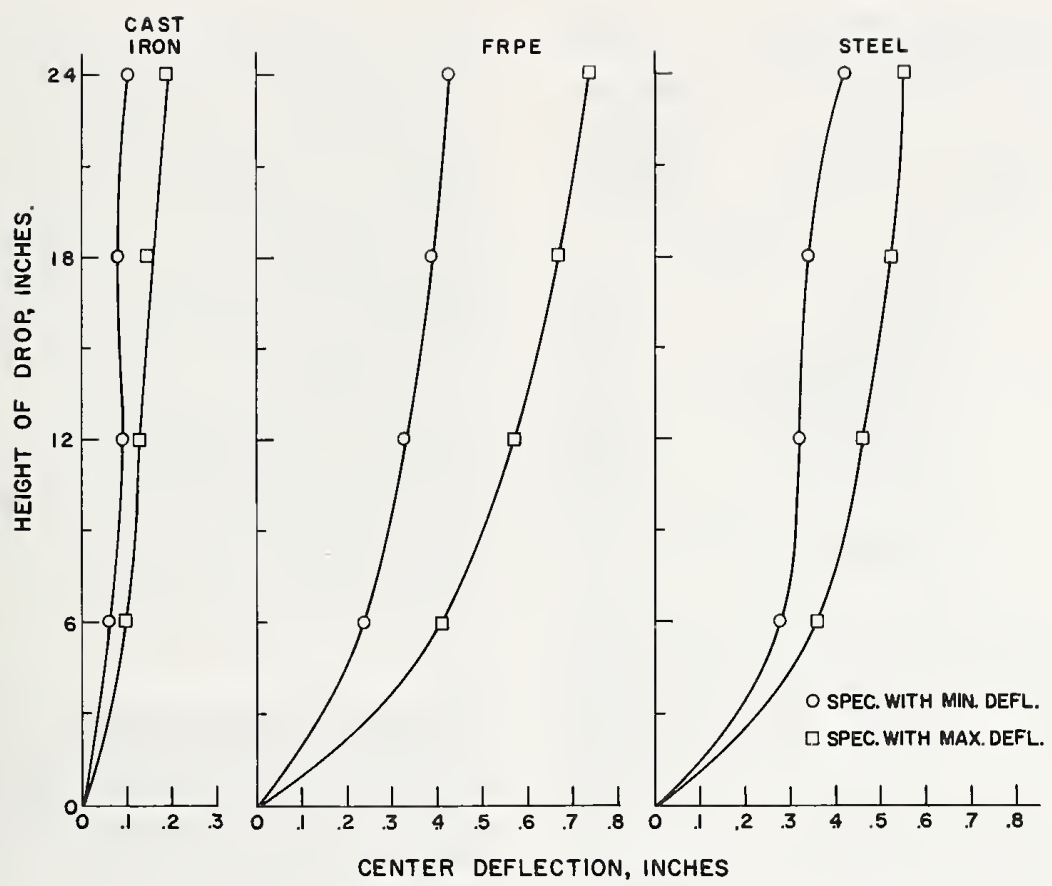

FIGURE 2.4-1. Concentrated load test (dynamic), 150-lb leather bag.

The possibility of using a heavier static load in lieu of the dynamic load was discarded for the reason stated in paragraph $2.4 \mathrm{c}(1)$.

\section{d. Comments on Performance Requirements}

\section{(1) Suggested Format for a Performance Level}

The bathtub shall withstand without damage the test conditions specified in paragraph $2.4 \mathrm{~b}(3)$ when the 150-lb weight is dropped from a height of ___ in. Damage shall be construed as the appearance of any surface defects in the bathtub, visible damage to the reinforcing structure, or other deterioration of structural properties as a result of testing.

\section{(2) Rationale for Suggested Format}

It is believed that the following information might be helpful in arriving at a realistic performance level :

1. Field information (Appendix B) was obtained that showed a negligible incidence of damage to pressed-steel bathtubs from falls. Since some falls did occur, it can be inferred that the present tub designs are sufficiently strong to withstand this service condition. The pressed-steel tubs that were tested showed no damage at heights-ofdrop of 12 in or less, and only one showed damage at 18 in.

2. A person falling in a tub would normally strike the tub bottom near the end opposite the drain, where the tub has enhanced structural stability rather than near the center, where structural stability is near a minimum. Thus, a per-

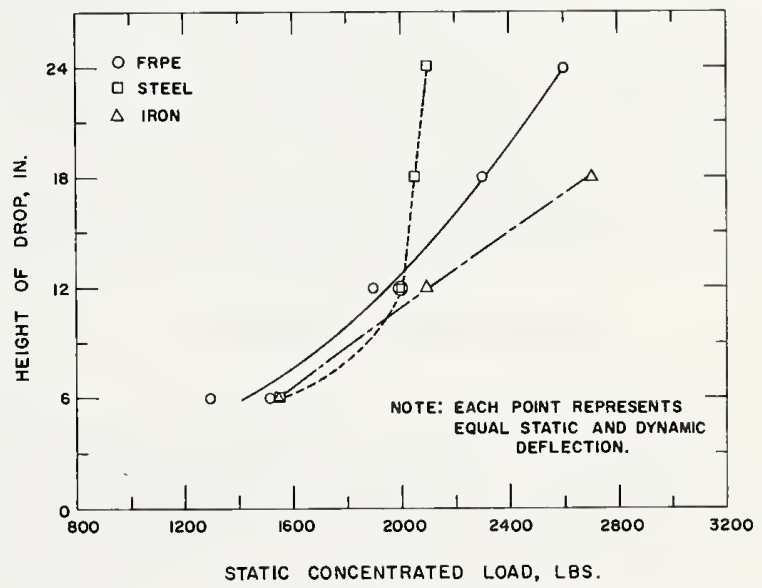

FIGURE 2.4-2. Correlation between height of drop in dynamic test and load in static destructive test.

formance requirement based on impact at the center would be more severe than if based on impact near one end. Also, the leather bag filled with lead shot is probably more rigid than the human body and, for this reason, could produce more stress in the fixture at the instant of impact. Thus a given height of fall of the 150-1b test weight would simulate a greater height of fall for a 150-1b person. The data in table 2.4-1 show failures in steel tubs at heights-of-drop of 18 and 24 in, but no damage was observed at $12 \mathrm{in}$.

3 . The use of successive heights-of-drop (5-, 10-, and 15-in) in the recommended test is believed to be desirable since there is a lack of information on 
TABLE 2.4-1. Results of concentrated dynamic load test with the 150-lb weight

\begin{tabular}{|c|c|c|c|c|}
\hline Specimen & Material & $\begin{array}{l}\text { Maximum } \\
\text { height-of- } \\
\text { drop }\end{array}$ & Defects noted & $\begin{array}{l}\text { Center de- } \\
\text { flection at } \\
\text { maximum } \\
\text { height-of- } \\
\text { drop }\end{array}$ \\
\hline & & in & & in \\
\hline $\begin{array}{l}\mathrm{PB}-4 \\
\mathrm{PC}-1\end{array}$ & $\begin{array}{l}\text { FRPE } \\
\text { FRPE }\end{array}$ & $\begin{array}{l}24 \\
24\end{array}$ & $\begin{array}{l}\text { None } \\
\text { None }\end{array}$ & $\begin{array}{r}0.74 \\
.59\end{array}$ \\
\hline PD-1. & FRPE & 24 & None. & .43 \\
\hline $\mathrm{SA}-4$ & Steel .. & 24 & Transverse crazing & .37 \\
\hline $\mathrm{SC}-2$ & Steel_.... & 18 & Star crazing at & .47 \\
\hline SE-2_ & Steel_. & 24 & $\begin{array}{l}\text { Star crazing at } \\
\text { both legs. }\end{array}$ & .35 \\
\hline CIA-1. & Cast iron & 24 & None & .18 \\
\hline & Cast iron.- & 24 & None & .25 \\
\hline CIE-4. & Cast iron. & 24 & None & .10 \\
\hline
\end{tabular}

the cumulative effects of impact loading; i.e., successive impacts of increasing magnitude might possibly lower the impact resistance of the fixture.

\subsection{Concentrated Load, Sump Sidewall (Bathtub) (S104)}

\section{a. Purpose and Scope}

The purpose of this test is to determine if the sidewalls of the sump of a bathtub can withstand highly concentrated loads of relatively small magnitude without excessive deflection, denting, indentation, or other damage. The service load simulated would be the pressure exerted by a person bracing himself against the side of a bathtub, or other similar load applications during normal use.

\section{b. Recommended Test Method}

\section{(1) Apparatus}

The load-application and deflection-measuring devices shall be essentially as shown in figure 2.5-1. The 1-in-diam steel ball shall be cemented to the arm. The lengths of the lever arms for the loading device shall be equal to within 0.01 in to provide for a one-to-one transfer of the load. The counter balance shall be adjusted so that the level system is balanced without the weight hanger.

The tripod used for holding the 0.001-in dial gage shall have thin rubber pads mounted on its feet and shall have sufficient stiffness and weight to prevent movement of the tripod during test.

The hanger for the loading weight shall weigh $0.5 \pm 0.1 \mathrm{lb}$, and the test load weight shall be $25.0 \pm 0.1 \mathrm{lb}$ including the hanger. The load may be applied in increments.

\section{(2) Test Procedure}

Mount and prepare the bathtub for test as specified in section 2.2. Inspect the finished surfaces for defects and damage in accordance with section 2.3 prior to test. Maintain the temperature of the testing laboratory and bathtub at $75 \pm 5^{\circ} \mathrm{F}$.

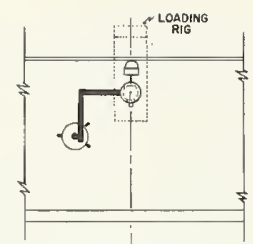

DEFLECTOMETER

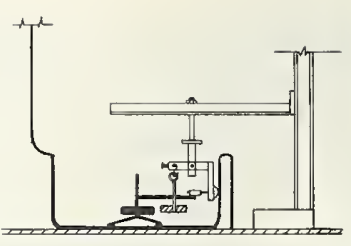

VIEW OF LOADING RIG

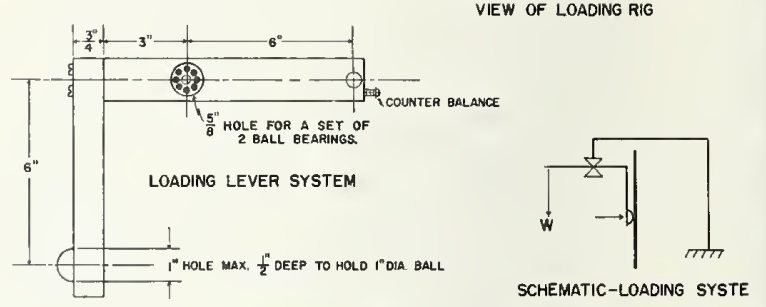

FTGURe 2.5-1. Deflection test for unsupported area.

Apply the test load of $25 \mathrm{lb}$ to the sidewall of the sump at midheight. Test four positions, including two near the midlength of the front and rear side walls. The other two positions are to be about 12 in horizontally from the original positions and on nearly vertical walls. Read the dial gage immediately after loading.

When setting up the testing device shown in figure 2.5-1, take special care to ensure that:

1. The level arm with the load-application ball is parallel to the surface being tested.

2 . The stem of the dial gage over the load-application point is directly on the centerline of the ball.

3. The stem of the dial gage is normal to the surface on which it is resting.

The loading procedure is as follows:

1. Apply the hanger and observe initial deflection reading on the dial gage.

2. Apply test load and observe the deflection reading.

3. Inspect the tested surface in accordance with section 2.8, following removal of load. Take special care to determine if indentation of the surface at the load point has occurred.

\section{(3) Information to be Reported}

Include the following in the test report:

1. Specimen identification;

2. Description of test frame and method of supporting and fastening;

3. Defects and damage noted prior to test;

4. Damage noted after test;

5. Positions of test areas;

6. Deflection readings made at each position.

\section{c. Test Results and Discussion}

\section{(1) Discussion of Existing Methods}

Commercial Standard CS 221-59 [2] includes a requirement for a deflection test for unsupported areas. A load of $10 \mathrm{lb}$ is applied through a 1-in 
round steel bar rounded to a $1 / 2$-in radius at the and in contact with the bathtub. The maximum deflection allowed under this load is $1 / 8 \mathrm{in}$. No permanent deflection is allowed. The proposed revision of CS 221-59 [1] is essentially the same except that the deflection is to be determined with a 0.001 in deflectometer and the no-permanentdeflection requirement was withdrawn. In addition, the proposed revision specified that surface cracking as a result of the test shall constitute failure.

Neither version of the Commercial Standard specified methods for applying the load or for measuring deflection.

There are no other known standard test methods which are similar in purpose to that recommended here.

\section{(2) Test Development}

Initially a simple hand-held instrument that would overcome the drawbacks in the method outlined in CS 221-59 was considered. A preliminary design was developed for an instrument similar in principle to the rubber-hardness-testing durometer. As time was of the essence, this idea was dropped and the simple lever-dial-gage arrangement shown in figure 2.5-1 was adopted for the test.

The device used in the test work was the same as shown in the drawing except that an additional dial gage was added to measure deflections $41 / 2$ in from the load point. It was thought that this additional deflection measurement could be used to judge the extent of the cupping effect when the load was applied.

The load of $10 \mathrm{lb}$ specified in CS 221-59 was thought to be unrealistically low. After preliminary tests indicated that no surface damage should be expected, the load was increased to $25 \mathrm{lb}$ for the test work.

Table 2.5-1 presents the deflection data from both gages for all bathtubs tested. The ratio of the two deflections can be used to judge the extent of the cupping for flat areas without reinforcing members or back-up material. The more flexible FRPE tubs had stiffening ribs or back-up materials which affected the deflection ratios greatly.

For this reason the measurement of deflections $41 / 2$ in from the load point is not recommended.

The measured deflections at the 25 -lb load point varied considerably, especially for the $\mathrm{PB}-4$ tub. This bathtub had a $3 / 8$-in stiffener cemented to the backwall, but none on the front wall. The wall thickness varied considerably on the FRPE tubs, so some variation in deflections was expected. No visible surface damage, denting or indentation was caused by the testing.

Table 2.5-2 summarizes the deflections observed when a 10-lb load, as prescribed in CS 221-59, was imposed on the sidewalls. The maximum observed deflection on any specimen was slightly less than half that permitted by the Commercial Standard.
TABLE 2.5-1. Deflections of unsupported areas with 25-lb load

\begin{tabular}{l|l|c|c|c|c|c}
\hline \hline Spccimen & $\begin{array}{l}\text { Front } \\
\text { center }\end{array}$ & $\begin{array}{c}\text { Back } \\
\text { ecnter }\end{array}$ & $\begin{array}{c}\text { Front } \\
\text { head } \\
\text { end }\end{array}$ & $\begin{array}{c}\text { Front } \\
\text { drain } \\
\text { end }\end{array}$ & $\begin{array}{c}\text { Back } \\
\text { head } \\
\text { end }\end{array}$ & $\begin{array}{c}\text { Back } \\
\text { drain } \\
\text { end }\end{array}$ \\
\hline
\end{tabular}

Deflections at load point for various positions, in a

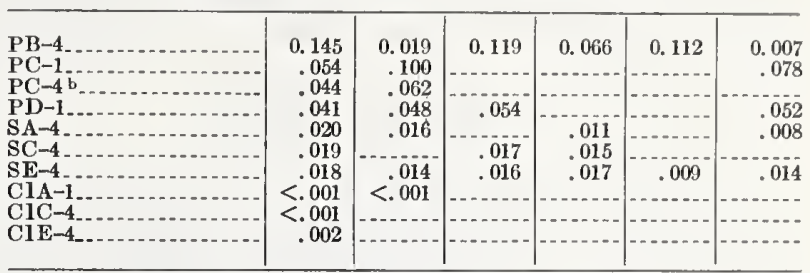

Deflections at $4 \frac{1}{2}$ in from load point

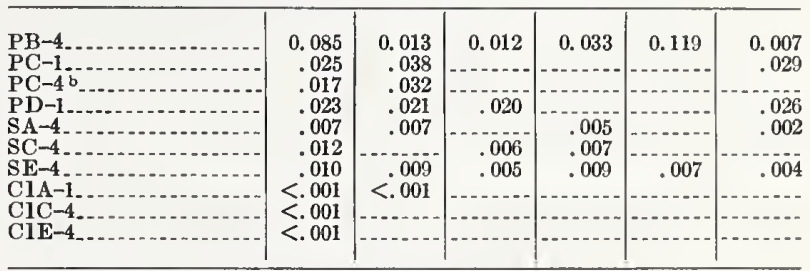

aAll test areas were at midheight of sump.

b This specimen tested after betng subjected to 100 -hr boil test described in section 2.18 .

TABLE 2.5-2. Deflections at load point with 10-lb (CS 22159) load, in ${ }^{\text {s }}$

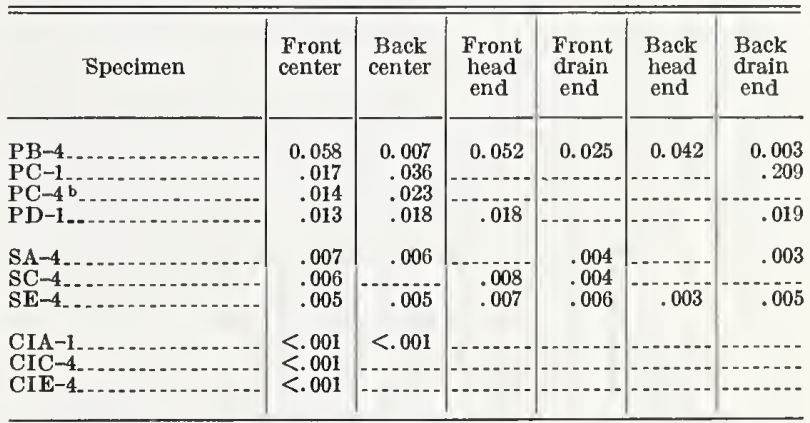

${ }^{-}$Tested in accordance with section $2.5 \mathrm{~b}$

b This specimen tested after being subjected to $100 . \mathrm{hr}$ boll test described in section 2.18 .

\section{(3) Rationale for Test Selection}

The basic principles outlined in CS 221-59 were preserved, but methods for applying the load and measuring the deflection were incorporated. It was felt that these methods should not be left to each testing laboratory to develop.

Commercial Standard CS 221-59 originally required that there be no permanent deflection. $\mathrm{A}$ requirement for no permanent deflections seems unnecessary because the small permanent deflections resulting from the test have no aesthetic or functional significance. These very small deflections are difficult to measure and the lack of precision in measuring them might lead to difficulties in interpretation of test results. For determining the presence of any relatively large permanent indentations, or denting, the use of the surface inspection routine of section 2.8 is satisfactory. 


\section{d. Comments on Performance Requirements}

(1) Suggested Format for a Performance Level

Visible surface-finish damage including denting or indentations shall not be present at any of the four test positions after removal of the 25-lb load. In addition, the deflection at any of the four test points shall not be greater than __ in during load application.

\section{(2) Rationale for Suggested Format}

The reason for suggesting a limiting value for the deflection under the load point is to limit the flexibility of the sidewall material. A requirement for no surface damage under a reasonable loading is desirable, since concentrated loads are sometimes applied to sump sidewalls in service.

It can be seen from the data in table 2.5-1 that the sidewall deflections of the tubs tested were all less than $0.200 \mathrm{in}$.

\subsection{Drain-Fitting Load (Bathtub)}

$(\mathrm{S} 105)$

\section{a. Purpose and Scope}

The purpose of-this test is to determine if a bathtub will withstand without damage to the finished surface a bending moment applied to the waste-drain fitting. The service load simulated by this test is that produced by differential movement between the waste-drain fitting and the vertical, waste or soil stack as a result of shrinkage of the floor joists supporting the bathtub. A similar service load could be caused by thermal expansion of the waste or soil stack under certain conditions. The recommended test applies to bathtubs only.

\section{b. Recommended Test Method}

\section{(1) Equipment Required for Test}

The apparatus required for this test shall be as shown in figure 2.6-1. The apparatus consists of a rigid steel connecting device (adjustable to fit var-

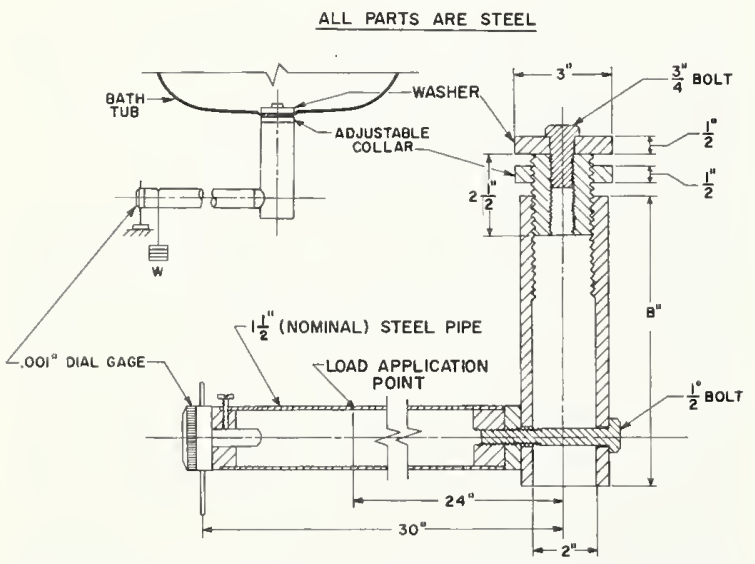

FraUre 2.6-1. Apparatus for drain-fitting load test. ious configurations of the drain-hole outlets), a detachable lever arm, and a micrometer dial gage mounted so as to measure movement of the lever arm when a bending moment is applied.

The lever arm, with the gage mounted, shall weigh $7.25 \mathrm{lb}$ to produce an initial moment of 10 $\mathrm{ft}-\mathrm{lb}$. The weights and hanger shall weigh a total of $20 \mathrm{lb}$ to produce an additional moment of 40 ft-lb. Four, or more, weights of approximately equal mass shall be provided.

\section{(2) Preparation of Test Specimen}

Mount the bathtub and prepare for test as specified in section 2.2. Take special care to fasten the specimen securely to the frame. As an additional precaution, add at least $100 \mathrm{lb}$ of weight distributed over the bottom of the sump so as to approximately cancel out the overturning moment of the test load.

When assembling the connecting device to the bathtub drain hole, adjust the collar so that there will be no physical contact between the top washer and the tub. Place a bedding of freshly mixed plastic of Paris around the connection as illustrated in figure 2.6-2. Plumb the vertical member of the connecting device when the plaster is placed. When the plaster is partially set remove excessive plaster so that no plaster extends beyond the 3-indiam washer and collar.

Finally, when the plaster is hardened the horizontal lever arm shall be attached to the connecting device and the deflection-measuring dial gage shall be adjusted for indication of vertical movement.

\section{(3) Test Procedure}

1. Before beginning the test, inspect the inside surfaces of the bathtub for damage and defects in accordance with section 2.8. Maintain the temperature of the testing laboratory and bathtub at $75 \pm 5^{\circ} \mathrm{F}$.

2. Make the test in at least two radial directions $90^{\circ}$ apart, including one for which the lever arm is parallel to the long direction of the bathtub.

3. With the lever arm in place, record the initial dial-gage reading. Place the weights individually on the arm, and record deflection for each increment of load. Continue loading until the indicated deflection is equal to or greater than $1.25 \mathrm{in}$, or until an additional load of $20 \mathrm{lb}$ (40 ft-lb of moment) has been applied.

4. After application and removal of the load, again inspect the inside surfaces of the tub for damage attributable to the test in accordance with the inspection procedure prescribed in section 2.8 .

\section{(4) Information to be Reported}

Include the following in the test report:

1. Specimen identification;

2. Description of test frame and method of supporting and fastening specimen in frame; 


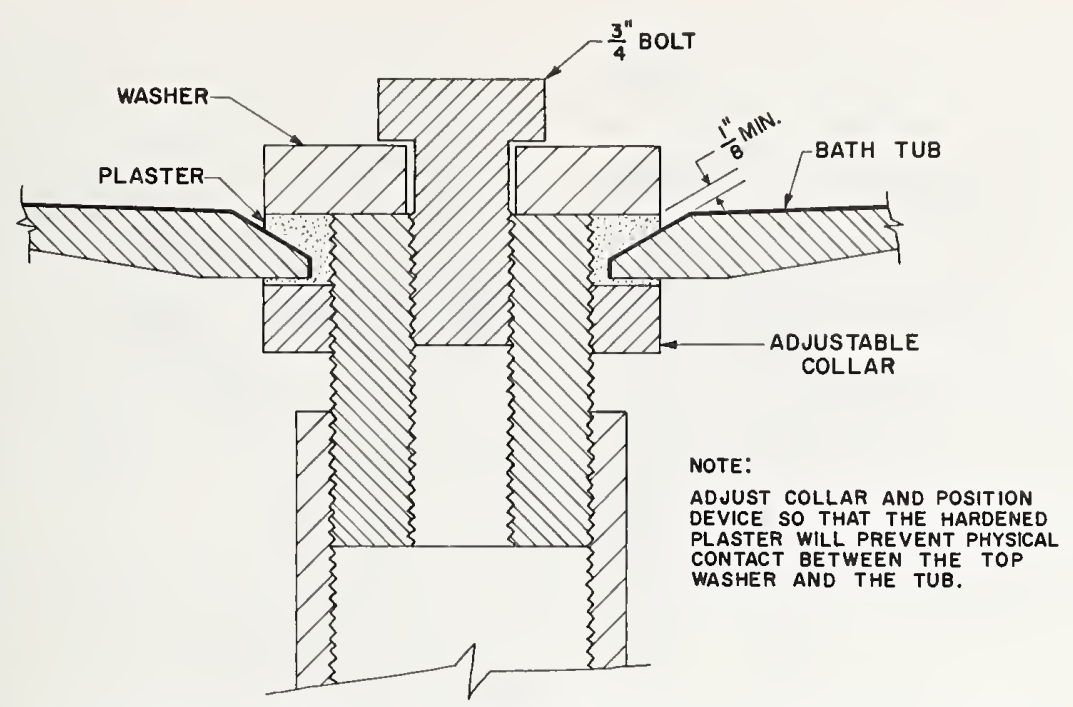

FIgURE 2.6-2. Installation of connecting device for drain-fitting load test.

3. Damage and defects noted prior to test;

4. Damage noted after test;

5. Radial direction of lever arm for each test position;

6. The deflections for each load increment at each test position;

7. The weight added at each increment (including the weight hanger).

\section{c. Test Results and Discussion}

\section{(1) Discussion of Existing Methods}

A drain-fitting-connection test is described in Commercial Standard CS 221-59 [2]. This test method requires that a 25 -lb weight be applied by means of a lever arm two ft in length connected to the drain fitting extending horizontally in a plane parallel to the rim of the tub. The arm and weight are placed in three radial positions, two of which are approximately $180^{\circ}$ apart. The performance requirement for this test is that no visible cracks in the bathtub surface shall be evident when inspected with the fitting in place using a standard ink test. In the proposed revision of CS 221-59 [1], the test was changed to require the application of a 50-lb weight through a 2 -ft lever arm. The performance requirement was not changed in the proposed revision.

\section{(2) Test Development}

The test as described in CS 221-59 applies the load through a "drain fitting connection." After examining several drain fitting connections produced by different manufacturers it was obvious that the rigidity of the fittings themselves would be a factor to be considered in the test. In order to standardize the test it was necessary to design a "standard" drain fitting connection so that the same test conditions would apply to all tubs. The recommended apparatus for the drain fitting test is shown in figure 2.6-1.

After the apparatus was designed, it was necessary to consider the magnitude of service loads and/or movements which would be encountered by a bathtub in service. The applied load in service would usually result from the restraint offered by the soil or waste stack to the downward movement of a bathtub supported by framing members undergoing drying shrinkage. If lumber is not dried before installation, the shrinkage of $2-x 10$ in joists can be as much as $1 / 2$ in in the 10 -in direction.

An auxiliary test was performed in order to determine how much of this movement might be transferred to the bathtub as bending moment through the connecting assembly. This test was made with a cast-iron tub placed upside down on the floor and weighted at each corner to offset overturning moments. Two different drain-fitting assemblies, complete with overflows and traps were obtained for this test. One assembly included a cast-iron trap and the other a 17-gage brass-tubing trap. Otherwise the assemblies were similar. Each assembly was installed on the inverted bathtub and loads were applied to a pipe extension of the trap outlet as shown in figure 2.6-3. The distance from the drain outlet to the point at which the load was applied was chosen as the shortest possible between the drain and the stack. This would simulate the most severe condition occurring in service as a result of relative vertical movement. The movement of the outlet end of the trap was measured by a 0.001 in dial gage supported on the floor. The results of the tests made in this way are shown in figure 2.6-4 and indicate that a load of about $50 \mathrm{lbs}$ applied at a distance of $11 \frac{1}{4}$ in from the centerline of the drain caused a relative movement of about $1 / 2$ in at the point of deflection measurement. 


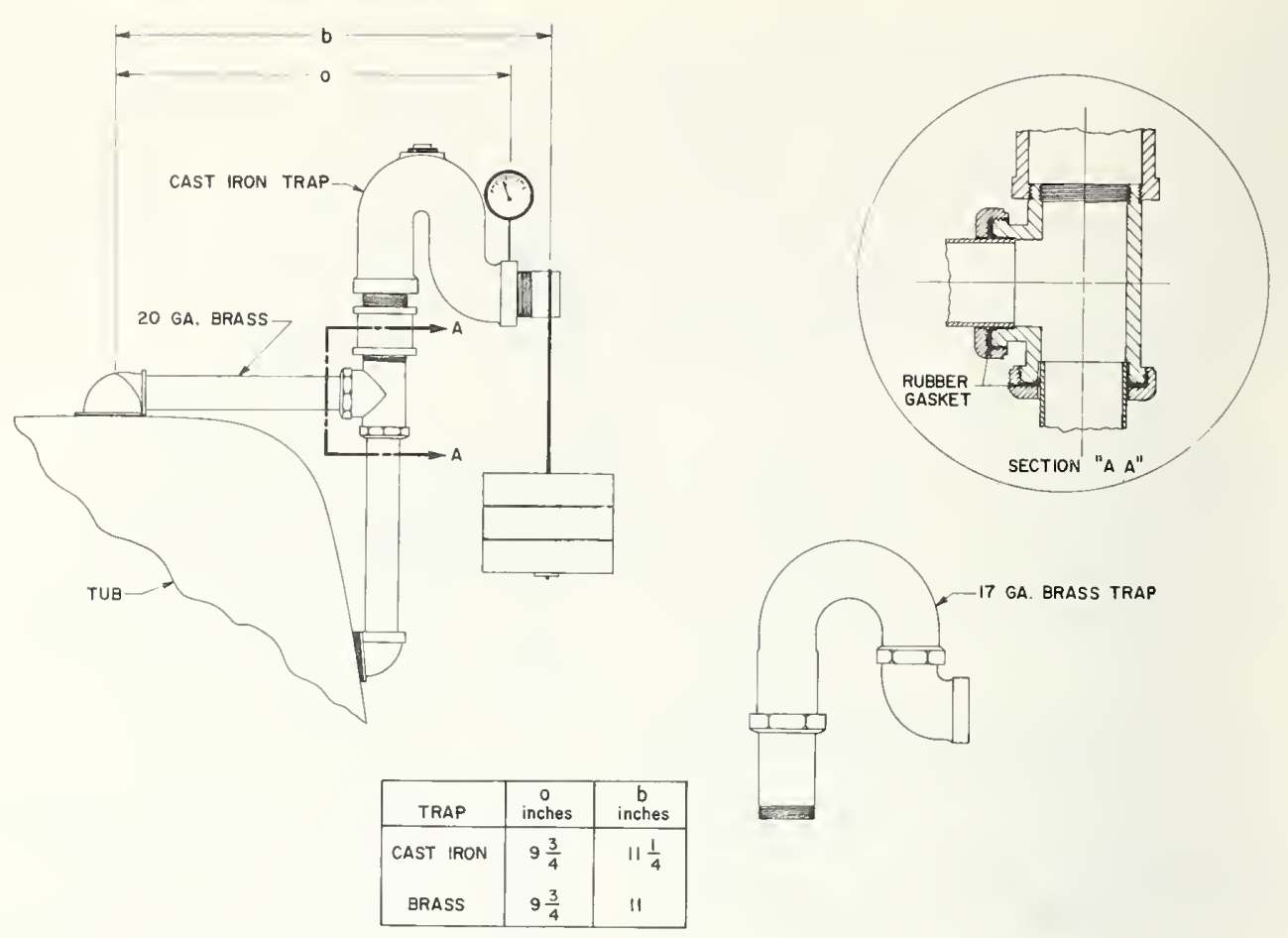

FIGURE 2.6-3. Test arrangement for evaluating rigidity of commercial arain-fitting assemblies.

Using these data as a guide the drain-fitting-load test was performed on one specimen of each available bathtub sample. The test procedure was as recommended in $2.6 \mathrm{~b}$ and the data are presented in table 2.6-1. Figure 2.6-5 presents some typical moment-deflection data obtained for one specimen. As is indicated in this figure the initial deflection readings were with the $10 \mathrm{ft}-\mathrm{lb}$ of moment contributed by the weight of the lever arm. Because the deflection caused by this moment was not measured directly the moment-deflection curves for each specimen were graphically extended back

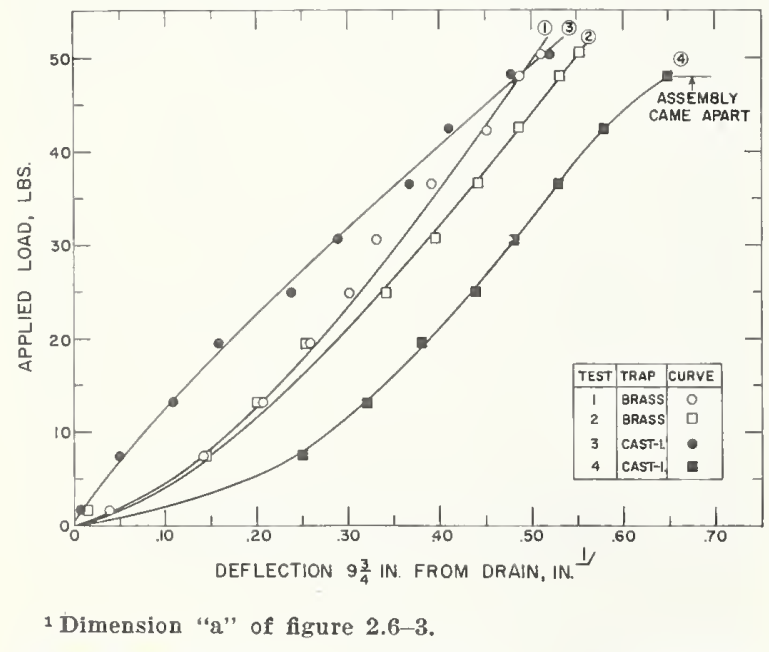

FIgure 2.6-4. Test for rigidity of arain-fitting assemblies. to zero-moment. Deflections determined by this method are entered in table 2.6-1 as the "zero-offset." The zero-offset data are considered to be approximate because of the curvature of some moment-deflection curves.

\section{(3) Rationale for Test Selection}

The service load which this test method is intended to simulate is that resulting from a differential vertical movement between the tub and waste or soil stack. The material of the tub around the drain outlet hole should be either (a) flexible

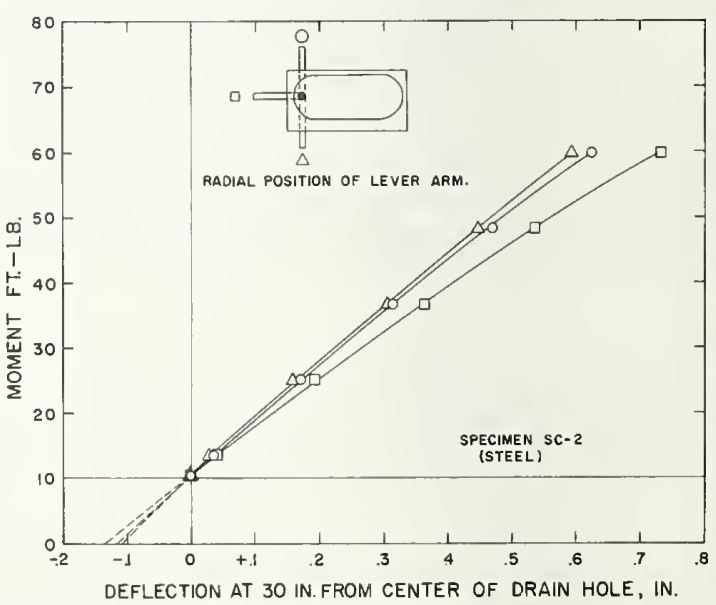

Figure 2.6-5. Typical moment-deflection data for drain-fitting-load test. 
TABLE 2.6-1. Drain-fitting-load test results

\begin{tabular}{|c|c|c|c|c|c|c|}
\hline \multirow{3}{*}{ Specimen } & \multirow{3}{*}{$\begin{array}{l}\text { Direction } \\
\text { of loaded } \\
\text { end of } \\
\text { lever arm }\end{array}$} & \multicolumn{5}{|c|}{ Deflection for $50 \mathrm{ft}-\mathrm{lb}$ a moment } \\
\hline & & \multicolumn{3}{|c|}{ At 30 in on lever arm } & \multicolumn{2}{|c|}{$\begin{array}{l}\text { Equivalent } \\
\text { for 12-in arm }\end{array}$} \\
\hline & & $\begin{array}{l}\text { Meas- } \\
\text { ured b }\end{array}$ & $\begin{array}{c}\text { Zero } \\
\text { offset }\end{array}$ & $\begin{array}{c}\text { Cor- } \\
\text { rected } \\
\text { for zero }\end{array}$ & $\begin{array}{l}\text { Meas- } \\
\text { sured } b\end{array}$ & $\begin{array}{c}\text { Cor- } \\
\text { rected } \\
\text { for zero } \\
\text { offset }\end{array}$ \\
\hline $\mathrm{PB}-\mathrm{C}$ & $\begin{array}{l}\text { Out end - } \\
\text { Out front - } \\
\text { Out back - }\end{array}$ & \begin{tabular}{c|}
$i n$ \\
0.308 \\
.533 \\
.392
\end{tabular} & $\begin{array}{c}i n \\
0.105 \\
.168 \\
.097\end{array}$ & $\begin{array}{c}i n \\
0.413 \\
.701 \\
.489\end{array}$ & $\begin{array}{c}\text { in } \\
0.123 \\
.213 \\
.157\end{array}$ & $\begin{array}{l}\text { in } \\
0.165 \\
.280 \\
.196\end{array}$ \\
\hline PC-1. & $\begin{array}{l}\text { Out end. - } \\
\text { Out back - }\end{array}$ & .265 & $\begin{array}{l}.065 \\
.062\end{array}$ & $\begin{array}{l}.330 \\
.304\end{array}$ & $\begin{array}{l}.106 \\
.097\end{array}$ & .132 \\
\hline PD-1 & $\begin{array}{l}\text { Out end - - } \\
\text { Out front- }\end{array}$ & .103 & $\begin{array}{l}.025 \\
.059\end{array}$ & $\begin{array}{l}.128 \\
.297\end{array}$ & $\begin{array}{l}.041 \\
.095\end{array}$ & $\begin{array}{l}.051 \\
.119\end{array}$ \\
\hline SE-2. & $\begin{array}{l}\text { Out end. } \\
\text { Out back - }\end{array}$ & .548 & $\begin{array}{l}.115 \\
.173\end{array}$ & $\begin{array}{l}.663 \\
.798\end{array}$ & $\begin{array}{l}.219 \\
.250\end{array}$ & $\begin{array}{l}.265 \\
.319\end{array}$ \\
\hline $\mathrm{SC}-2$ & $\begin{array}{l}\text { Out end - } \\
\text { Out front } \\
\text { Out back. }\end{array}$ & $\begin{array}{l}.567 \\
.465 \\
.488\end{array}$ & $\begin{array}{l}.132 \\
.107 \\
.117\end{array}$ & $\begin{array}{l}.699 \\
.572 \\
.605\end{array}$ & $\begin{array}{l}.227 \\
.186 \\
.195\end{array}$ & $\begin{array}{r}.280 \\
.229 \\
.242\end{array}$ \\
\hline $\mathrm{SA}-2$ & $\begin{array}{l}\text { Out end- - } \\
\text { Out back - }\end{array}$ & .770 & $\begin{array}{l}.108 \\
.043\end{array}$ & $\begin{array}{l}.878 \\
.300\end{array}$ & $\begin{array}{l}.308 \\
.103\end{array}$ & $\begin{array}{l}.351 \\
.120\end{array}$ \\
\hline ClA-1... & $\begin{array}{l}\text { Out end } \\
\text { Out back }\end{array}$ & $\begin{array}{l}.085 \\
.094\end{array}$ & $\begin{array}{l}.024 \\
.028\end{array}$ & $\begin{array}{l}.109 \\
.122\end{array}$ & $\begin{array}{l}.034 \\
.038\end{array}$ & .044 \\
\hline CIC-4. & $\begin{array}{l}\text { Out end - } \\
\text { Out back. }\end{array}$ & .121 & $\begin{array}{l}.026 \\
.026\end{array}$ & $\begin{array}{l}.147 \\
.126\end{array}$ & .048 & $\begin{array}{l}.059 \\
.050\end{array}$ \\
\hline CIE & $\begin{array}{l}\text { Out end } \\
\text { Out back }\end{array}$ & .112 & $\begin{array}{l}.030 \\
.037\end{array}$ & $\begin{array}{l}.142 \\
.151\end{array}$ & $\begin{array}{l}.045 \\
.046\end{array}$ & .057 \\
\hline
\end{tabular}

- Includes $10 \mathrm{ft}-\mathrm{lb}$ from lever-arm moment.

b Measured increment of deflection caused by addition of $40 \mathrm{ft}-\mathrm{lb}$ moment. c Extrapolated from moment-deflection curve (see figure 2.6-5).

enough to bend with this movement or (b) strong enough to withstand the bending moment caused by the movement, without damaging the tub.

Thus there is a need for a test that imposes a moment equal to the probable maximum that can be transferred to the fixture by conventional drainfitting assemblies as a result of timber shrinkage or building settlement. The recommended test is based on a consideration of, and data on, these two factors.

\section{d. Comments on Performance Requirements}

\section{(1) Suggested Format for Performance Level}

The bathtub shall withstand the application of $\mathrm{ft}-\mathrm{lb}$ of moment or a deflection of ____ in, as described in paragraph $2.6 \mathrm{~b}(3)$, without exhibiting surface damage such as cracking, crazing, spalling, lifting of surface coating, etc. The surface damage shall be determined by the inspection procedure prescribed in section 2.8 .

\section{(2) Rationale for Suggested Format}

A limit of $50 \mathrm{ft}$-lb of moment is about the maximum that would be transferred by the presently used assemblies because of their inherent flexibility. A deflection limit of 1.25 in at 30 in (equivalent to 0.5 in at 12 in) would be a conservative one, since (a) the deflection caused by the weight of the lever arm is not measured by this method, and (b) in many buildings, such as reinforced-concrete or steel-framed buildings, or well-constructed buildings framed with dry lumber, the differential movements should be much less than the limit suggested for ths test. On the other hand, some factor of safety is needed to take into account differential movements that can develop in some high-rise systems from thermal expansion of waste and soil stacks.

It should be noted that all tubs tested resisted a 50 -ft-lb moment without damage and with measured deflections well below 1.25 in at 30 in.

The test results suggest that presently manufactured bathtubs are capable of withstanding without damage a moment about the drain outlet equal to or greater than the 50 -ft-lb likely to be transferred by the drain-fitting assemblies ordinarily used.

\subsection{Watertight-Joint Potential (Bathtub)} (S106)

No test method exists for determining the watertight-joint potential of bathtubs and no test method is recomemnded. It would seem reasonable that some requirement be made for the water bead along the wall. Federal Specification WW-P-541b(4), 1962 [3] and Commercial Standard CS 77-63 [4] both specify a minimum upturn of water bead of $5 / 16$ in. The minimum upturn found on the tubs investigated in this test program was $3 / 8 \mathrm{in}$.

The watertightness of the joint between the floor and the tub apron is dependent upon factors other than bathtub design. These factors are (a) installation and support techniques, (b) differential thermal movements between tub and floor, (c) adhesion, (d) flexibility, and (e) durability of the jointing material. An investigation into design features of bathtubs which would affect the watertight-joint potential was beyond the scope of the present program. However, the recommended tests for Concentrated Load, Sump Sidewall (sec. 2.5), for Concentrated Load (Static) (sec. 2.2), and for Hot-Water Resistance (sec. 2.18) each limit permissible deflections under loading. These limitations should assure indirectly some protection against excessive movement of portions of a bathtub in contact with the wall or with the finished floor when the tub is subjected to loading. These maximum-permissible deflections also provide some guidance on the amount of movement that should be accommodated by joint sealants.

\subsection{Surface Inspection (M201)}

\section{a. Purpose and Scope}

The purpose of the surface-inspection test is (a) to specify a standard procedure for inspection of a sanitary plumbing fixture for defects and blemishes, and (b) to define the type and number of imperfections that are permissible in a newly 
manufactured fixture. Although the inspection procedure as specified can be used for all types of sanitary plumbing fixtures, the types and permissible number of defects and blemishes as stated herein apply to bathtubs only.

\section{b. Recommended Test Method}

\section{(1) Inspection Procedure}

Maintain the temperature of the inspection area and fixture to be inspected at $75 \pm 10^{\circ} \mathrm{F}$. Wash the fixture with soap and water and rinse with tap water. After drying, use a sponge to apply an ink solution consisting of 50 percent by volume water-soluble black ink in tap water, or use an ink that contrasts in color if the fixture is colored. Wipe excess ink from surface with a damp cloth and allow fixture to dry.

Inspect the surface of the ink-treated fixture visually at a normal reading distance for blemishes and defects. Use a light source of partially diffused daylight ol substantially equivalent artificial light, with a luminous intensity near the inspection surface of not less than 100 nor greater than $200-\mathrm{ft}$ candles. If surface blemishes or defects are observed to be segregated in a particular area of the fixture, prepare a small cardboard sheet or thinmetal sheet with a circular viewing window three inches in diameter. Use this inspection window to make counts of defects within the area of maximum concentration of defects.

\section{(2) Suggested Surface-Finish Requirements}

The surfaces of the fixtures intended to be visible after installation shall be smooth and free from local variations in color and texture that detract from the appearance of the fixture. Some waviness is typical of certain finishes, and this waviness shall not be a cause for rejection. Other imperfections in the finish that shall or shall not be permissible when fixture is examined as specified in paragraph $2.8 \mathrm{~b}(1)$ are listed in table $2.8-1$.

\section{(3) Definitions}

Blisters-Rounded elevations of the surface that can be penetrated by application of a localized pressure.

Cracks-Visible fractures in the finish, usually of a hairline type.

Chips_Small damaged areas in the finish, such as those characterized by loss of coating fragments from a localized impact.

Dents-Local depressions or raised portions in the surface caused by an impact, or a permanent deformation, in which no fracture occurs.

Dimples-Slight depressions in the surface that do not extend to the backing material.

Dunts-Hairline fractures extending through the thickness of the fixture.

Die marks-Visible scorings in the surface finish caused by improper forming operations.
TABLE 2.8-1. Suggested surface-imperfection requirements

\begin{tabular}{|c|c|c|c|}
\hline Defect or blemish & $\begin{array}{c}\text { Maximum } \\
\text { dimension } \\
\text { (inches) }\end{array}$ & $\begin{array}{c}\text { Max. No. } \\
\text { permitted } \\
\text { within any } \\
\text { 3-in-diam area }\end{array}$ & $\begin{array}{l}\text { Max. No. } \\
\text { permitted } \\
\text { per fixture }\end{array}$ \\
\hline 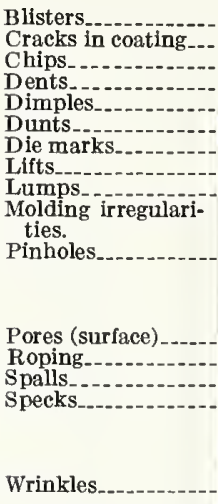 & $\begin{array}{r}1100-164 \\
164-1 / 32 \\
1 / 32-1 / 16 \\
>1 / 16\end{array}$ & 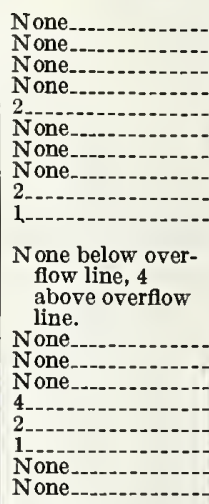 & $\begin{array}{l}\text { None. } \\
\text { None. } \\
\text { None. } \\
\text { None. } \\
8 . \\
\text { None. } \\
\text { None. } \\
\text { None. } \\
8 . \\
8 . \\
\text { None below over- } \\
\text { flow line, } 8 \\
\text { above overflow } \\
\text { line. } \\
\text { None. } \\
\text { None. } \\
\text { None. } \\
\text { Not counted. } \\
\text { 8 s. } \\
5 \text { b. } \\
\text { None. } \\
\text { None. }\end{array}$ \\
\hline
\end{tabular}

a A total of 24 is permitted when a wall surround is an integral part of fixture.

$\mathrm{b} A$ total of 12 is permitted when a wall surround is an integral part of fixture.

Lifts-Areas of coating that are separated from the backing material, usually over a fairly large area.

Lumps-Raised portions on a finish, such as those characterized by an accidental application of a blob of coating material during the manufacturing operation.

Molding irregularities-Any visible distortion of small size relating to mold imperfections.

Pinholes-Small holes in a coating that extend to the backing material.

Pores (surface)-Small voids at the surface of the tinish.

Roping-Shallow ridges and valleys in a finish with no decorative pattern.

Spalls-Small discontinuities in the surface caused by the loss of fragments after manufacture. These discontinuities may or may not extend to the backing material. In porcelain-enamel coatings, spalls of this type are often referred to as fish scales.

Specks-Particles of embedded foreign matter that produce areas of contrasting color on the surface, but not including specks or flecks purposely incorporated into a finish to produce a decorative pattern.

Wrinkles-Corrugations in the finish that can be seen or felt and which follow no fixed pattern.

\section{(4) Information to be Reported}

Include the following in the test report:

1. Identification of fixture;

2. A qualitative description of color uniformity;

3. A qualitative statement on uniformity of texture; 
4. A statement as to the presence or absence of each surface imperfection listed in table 2.8-1 together with the size and number of each, when present;

5. A statement as to whether the fixture passes or fails the surface-finish-requirements specified in paragraph $2.8 \mathrm{~b}(2)$.

\section{c. Test Results and Discussion}

\section{(1) Discussion of Test Development}

Surface-finish requirements as incorporated into Commercial Standards and into Federal Specifications were reviewed for each material that is being used for sanitary plumbing fixtures. All of these requirements were quite similar. This permitted their consolidation into a single surface inspection test. The consolidation was done in such a way that any currently produced bathtub fixture that now passes its own commercial standard for surface inspection will also pass the requirements set forth in section $2.8(\mathrm{~b})$.

No laboratory investigations were either possible or were they needed in the development of this particular test. However, numerous inspections of fixtures furnished for test were made using the specified test procedures. All the fixtures inspected passed the requirements of section $2.8(\mathrm{~b})$.

\section{d. Comments on Performance Requirements}

\section{(1) Suggested Format for a Performance Level}

Surfaces of the fixture intended to be visible after installation shall meet the requirements for finish quality listed in paragraph $2.8 \mathrm{~b}(2)$ and in table 2.8.1.

\section{(2) Rationale for Suggested Format}

Since new fixtures that pass the requirements for surface finish specified in the commercial standards are apparently acceptable to the general public, there would seem to be no legitimate reason for increasing the surface-finish requirements from their present levels. In effect, the suggested format as given above would insure that the present quality levels are maintained.

\subsection{Water Absorption (M202)}

A water absorption test for sanitary plumbing fixture materials might serve as a control test for some material. The amount of water absorbed might also bear some relation to performance of given materials when subjected to other tests.

No test is recommended for water absorption at this time, because (1) existing tests for water absorption do not closely simulate service exposure, and (2) certain other tests recommended in this report probably provide adequate protection against any important effects attributable to water absorption that may occur in a service environment.
A test method for water absorption of FRPE sanitary ware is specified in section 6.2 of the proposed revision of CS 221-59 [1]. This involves total immersion of specimens cut from an FRPE bathtub in water at $23{ }^{\circ} \mathrm{C}$ for $24 \mathrm{hr}$. according to the procedure of paragraphs 6 (a) of ASTM D570$63[5]$. Water absorption is required not to exceed 0.50 percent by weight.

Other test methods for water absorption of sanitary ware are described in standards $[3,6,7]$. These involve total exposure of broken specimens to boiling water, after which the absorption is required not to exceed specified percentages by weight.

These tests are not considered to be an adequate simulation of typical exposure of a bathtub to water under normal use conditions. Among the deficiencies of these tests as performance tests to evaluate the water-absorption effect on sanitary ware are the following:

1. Some of the tests involve the unrepresentative exposure of both surfaces and cut or broken edges of a specimen to water at unrealistically high temperature. Furthermore, different materials with suitable service records are known to absorb widely varying amounts of water in immersion tests of cut or broken specimens.

2. For the kinds of materials used for bathtubs, failure caused by water absorption is more likely to result from flaws or defects that are widely separated rather than from effects of uniform penetration of water. The exposure of small flat specimens cut from the fixture may not reveal tendencies to defects that sometimes occur at the fillets or curved areas between the bottom and sidewalls.

3. The existing test methods for water absorption are considered useful essentially as control tests for materials on which some service experience on performance has been accumulated; hence, without modifications, they probably would have limited value for new materials even as control tests.

Several of the tests recommended herein are believed to provide the needed protection against possible deleterious effects of water absorption through the finished surfaces of sanitary ware. These are given in section 2.18 (hot-water resistance), sec. 2.10 (abrasion resistance), section 2.12 (surface-impact resistance), and section 2.16 (scratch resistance). However, it is emphasized here that no correlation between test results and service performence has been attempted with respect to water absorption per se, nor were any measurements of water absorption made in developing the recommended tests.

\subsection{Abrasion Resistance (M203)}

\section{a. Purpose and Scope}

The purpose of this test is to evaluate resistance of sanitary plumbing fixtures to the type of abrasion that occurs in normal use. 


\section{b. Recommended Test Method}

\section{(1) Apparatus}

The apparatus for abrading specimens shall be the Gardner Heavy Duty Wear Tester, ${ }^{6}$ shown in figure 2.10-1. This apparatus as used herein abrades specimens by the reciprocating action of four hog-bristle brushes moving back and forth across 12 specimens (three per brush). The specimens are mounted at the same level on a horizontal bed. A water slurry of scouring powder is fed continuously through small holes in the brushes while the equipment is in operation. The brushes, each of which carries a load of $1,100 \mathrm{~g}$, traverse the specimens at a fixed frequency of 120 strokes (60 cycles) $/ \mathrm{min}$. The length of the stroke is $13 \mathrm{in}$. The velocity of travel is constant except during the reversal at the end of each stroke. The feed rate of the slurry through each brush is controlled at 3.0 to $3.5 \mathrm{ml} / \mathrm{min}$. The brushes are mounted in brush holders, provided with fittings for plastic tubing, $1 / 8$-in inside diameter. The slurry is contained in a battery jar, 8 in in diameter by 12 in high. Four aluminum tubes extend into the jar and plastic trbing, 1/8-in inside diameter, is connected to these tubes. The slurry is kept in suspension with a motor-driven stirring apparatus. The slurry is delivered to the four brushes through the plastic tubing by means of a metering pump.

The apparatus for measuring abrasive-wear depth shall consist of a dial thickness or depth gage, graduated in 0.001 -in increments with a sensor stem $(1 / 4$ in in diam and flat on the end). The gage shall be mounted on a clamp above a flat plate, so that the height above the plate can be adjusted for specimens of varying thickness.

6 Available from Gardner Laboratory, Inc., P.O. Box 5728 , Bethesda, Md. 20014. While this test method is described in terms of the Gardner Machine for concreteness, other machines terms of the Gardner Machine for concreteness, other machines
with equal or better performance in all essential respects should be acceptable.

\section{(2) Standard Abrasive}

A "standard" abrasive slurry, rather than the slurry of household scouring powder specified in the proposed revision of CS 221-59 [1], shall be used for the test described herein. This slurry shall be prepared from the following ingredients:

Ground quartz powder

Sodium carboxymethyl cellulose

Trisodium phosphate

Water

$2700 \mathrm{~g}$

$15 \mathrm{~g}$

$60 \mathrm{~g}$

$3000 \mathrm{ml}$

The ground quartz powder shall conform to the following sizing, ${ }^{7}$ in accordance with Standard Specifications for Sieves for Testing Purposes, ASTM E 11:

Through a U.S. No. 80 sieve

Through a No. 160 sieve

Through a No. 200 sieve

Through a No. 325 sieve

100 percent

98 percent

93 percent

74 percent

\section{(3) Specimens}

The specimens for testing shall consist of three flat pieces, $33 / 4$ in square, that have been cut from the sump of each fixture. The backs of the specimens shall be ground flat and parallel with the face surface. Also, the edges shall be ground smooth and square. The final size shall be $35 \%$ in square. Prior to testing, plastic specimens shall be glued with a water-resistant adhesive to a flat $35 / 8$ in square, No. 11 gage, stainless-steel backing plate.

\section{(4) Test Procedure}

Maintain the temperature of the testing laboratory and specimens at $75 \pm 5^{\circ} \mathrm{F}$. Test the speci-

7 Ground quartz powder with this sizing is used currently in several popular household scouring powders and is available as "No. 160 mesh pottery flint" from the Pennsylvania Glass Sand Corp., Gateway Building, Pittsburgh, Pennsylvania.

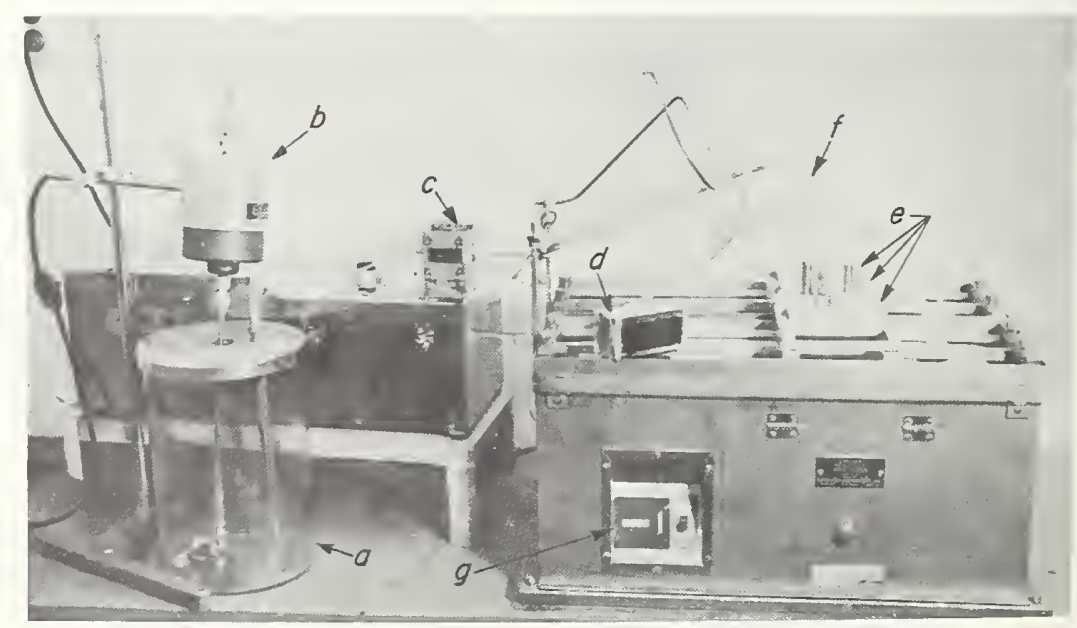

a, battery jar for slurry ; b, motor-driven stirrer ; c, slurry metering pump; d, brush removed from holder; $e$, brushos in holder; $f$, plastic tubing ; $g$, counter.

Figure 2.10-1. Gardner heavy-duty wear tester. 
mens using the Gardner Heavy Duty Wear Tester following the operating procedure outlined in section 6.5 of the proposed revision of CS 221-59, but using the abrasive slurry specified herein in paragraph $2.10 \mathrm{~b}(2)$ in place of the Ajax brand powder specified in the proposed revision. The essential features of the test procedure are described below:

Dissolve the sodium carboxymethyl cellulose in the water. Next add the trisodium phosphate and ground quartz powder and suspend by stirring. With the power-driven stirrer in operation, adjust the flow rate to 3.0 to $3.5 \mathrm{ml} / \mathrm{min}$. The flow rate can be determined for each setting by measuring the volume delivered in $10 \mathrm{~min}$ to a $100 \mathrm{ml}$ graduate.

Clamp 12 specimens in the two trays on the horizontal bed of the machine, six to each tray. This provides four rows of three specimens each, comprising one row for each of the four brushes. Use shims as necessary to adjust the specimens and end plates to the same height. If there are less than 12 specimens, use specimens of the same or similar material to fill in the blank spaces.

Assemble the scrubbing apparatus, consisting of brushes, holders, and guide plate, and connect the plastic tubing from the slurry jar to the brush holders. Start the pump and determine that the slurry is flowing freely without air bubbles in the tubing. Scrub at a rate of 60 cycles per minute for 10,000 cycles (20,000 strokes) except stop the machine at $2,500,5,000$, and 7,500 cycles to observe specimens, to wash excess slurry from the specimen trays, and to change the brush positions (see table 2.10-1). Also check brush blocks at each inspection period to be certain that the holes are free for the passage of slurry.

TABLE 2.10-1. Schedule for changing brushes

\begin{tabular}{c|r|r|r|r}
\hline \multirow{2}{*}{ Test Period in Cycles } & \multicolumn{4}{|c}{ Position of brush in machine* } \\
\cline { 2 - 6 } & $\begin{array}{c}\text { Brush } \\
\text { No. 1 }\end{array}$ & $\begin{array}{c}\text { Brush } \\
\text { No. 2 }\end{array}$ & $\begin{array}{c}\text { Brush } \\
\text { No. 3 }\end{array}$ & $\begin{array}{c}\text { Brush } \\
\text { No. 4 }\end{array}$ \\
\hline & & & & \\
\hline $0-2,500$ & 1 & 2 & 3 & 4 \\
$5,000-7,000$ & & 2 & 3 \\
$7,500-10,000$ & 3 & 4 & 1 & 2 \\
\hline
\end{tabular}

*From front to back of machine.

If the coating on any of the specimens should wear through to the backing material prior to completion of the test as evidenced by a change in color and texture, remove the specimen from the bed and replace it with another specimen of the same or similar material. This will prevent the possibility of a worn-out specimen from affecting results from the other specimens.

When the 10,000 cycles (20,000 strokes) have been completed, remove all specimens from the bed and measure the abrasive wear depth with the depth gage to the nearest $0.001 \mathrm{in}$. In making this measurement, place the specimen on the flat plate and adjust the clamp on which the gage is mounted so that the stem of the gage touches the specimen. Next, move the specimen to a position such that the stem of the gage contacts the approximate center of the wear pattern. Set the zero of the dial gage at the lowest depth that is observed in this area. Finally, move the specimen so that the stem of the gage contacts the unabraded surface. This reading is the abrasive-wear depth for the specimen. The abrasive-wear depth for the fixture is the arithmetic average for the three specimens.

\section{(5) Information to be Reported}

Include the following in the test report:

1. Specimen identification;

2. Cycles required to wear through the coating, in cases where the coating is worn through to the backing material, as shown by cliange in color and texture;

3. If no wear-through occurs on any of the specimens, report the abrasive-wear depth for each specimen and also the average for the three specimens.

\section{c. Test Resulto and Discussion}

\section{(1) Discussion of Existing Methods}

Three test methods for evaluating the abrasion resistance of sanitary plumbing fixtures were investigated. One of these is described in the ASTM test for abrasion resistance of porcelain enamels [8]. The method of abrading specimens consists of placing fixed weights of alloy steel balls, abrasive, and water in a cylindrical container with a rubber ring at the bottom to serve as a gasket. The balls and ablasive rest on the surface of the specimen. The container is clamped to the specimen and the assembly placed on the platform of an oscillating shaker " RoTap" machine with no tapper). The treatment time is calibrated through use of standard specimens of plate glass.

Two types of abrasion are measured. For surface abrasion, the abrasive is the fraction of Pennsylvania glass sand (quartz) passing a No. 70 sieve and retained on a No. 100 sieve. For subsurface abrasion, the abrasive is No. 80 electric corundum. Surface abrasion is measured by changes in $45^{\circ}$ specular gloss and subsurface abrasion is measured by changes in weight.

Although both surface- and subsurface-abrasion tests by this method have been shown to be reproducible, it has not been shown that this type of abrasive action simulates that which occurs in the normal use of sanitary plumbing fixtures. Abrasion of installed fixtures occurs largely from the use of scouring powder for cleaning. The action of oscillating steel balls moving over an abrasive on the surface of a specimen does not generate the same type of abrasive action as that of a person cleaning the fixture with a commercial scour- 
ing powder that has been applied to a brush, sponge, or cloth.

Another method which was investigated was the Schiefer Abrasion-Testing Machine, originally designed for testing textiles [9]. In modifying the machine for testing floor covering [10], a brass cup was added to hold the specimen and a nylon brush and alkaline soap solution were used to provide the abrasion. Both cup and brush were rotated at $250 \mathrm{r} \mathrm{pm}$ with axes of rotation one inch apart. In the present investigation, trials were made using this modification on specimens of porcelain-enameled steel, circularly cut to fit the brass cup. A slurry of Ajax brand scouring powder and water was used as the abradant. The same nylon brush used to test floor covering was employed with four pounds of force being applied to the brush. After 10,000 revolutions, the center region of the specimen was worn, rather than the outer portion, although the brush covered the entire specimen. Apparently only the "high spots" on the specimens were affected by the treatment. In an attempt to eliminate this difficulty, the bristles were removed from a nylon brush and replaced with sponge rubber. This pad was then used with Ajax slurry to abrade a second porcelain-enameled steel specimen. Again the specimen was worn near the center but not on the outer portion. In other tests, a cellulose sponge with Ajax slurry showed practically no effect on a specimen after 10,000 cycles. Also, Pellon non-woven cloth was cemented onto the nylon brush holder and another porcelainenameled-steel specimen abraded with Ajax for 10,000 cycles at a 4 -lb force. Although this treatment resulted in a more uniform abrasion, the surface being dull over most of the test area, the abrasion was still not sufficiently uniform, nor was it measurable with the depth gage.

It was apparent that a good deal of additional work is necessary to determine whether the Schiefer machine can be adapted to testing sanitary ware. Its use in testing of sanitary ware is time-consuming largely because of the difficulty in preparing the circular specimens required in present applications of the machine.
The one test method in current use for sanitary fixtures that apparently simulates actual cleaning practices for sanitary ware is that specified in section 6.5 of the proposed revision of CS 221-59 [1]. The abrasion requirement in this proposed standard for FRPE fixtures is that the coating shall not wear through to the backing material after 10,000 wear cycles in the Gardner Heavy Duty Wear Tester, modified as described in the proposed revision. This test, with minor modifications, is the one recoinmended as a performance test for abrasion resistance based on the present study. Results of tests using this method are given in section $2.10 \mathrm{~d}(2)$ of this report.

Other tests that have been used for abrasionresistance testing of sheet or plate materials were reviewed but no tests were made $[11,12,13,14]$. It was obvious that none of these tests closely simulated the action of cleaning a fixture with scouring powder.

\section{(2) Test Data}

Table 2.10-2 compares the results obtained when sanitary ware materials were tested in accordance with (a) section 6.5 of the proposed revision of CS 221-59 and (b) the method specified in section $2.10 \mathrm{~b}$ herein. The agreement in the results between the two test procedures is good. This might be expected, since the only differences between the two tests is in the abrasive slurry. The data indicate that the "standard abrasive slurry" specified in section $2.10 \mathrm{~b}(2)$ gives approximately the same abrasive action as does the Ajax scouring powder specified in the proposed revision of CS 221-59.

Coating-thickness contours across the surfaces of an FRPE and a porcelain-enameled-steel specimen after 10,000 wear cycles (20,000 strokes) with "standard abrasive" are shown in figure 2.10-2. Results with a porcelain-enameled cast-iron specimen, although not shown, were similar to those for porcelain-enameled steel. The loss in thickness for porcelain-enameled surfaces after the 10,000 cycle treatment was approximately $0.0002 \mathrm{in}$, although accurate measurements could not be made owing to the uneveness of the surfaces.

TABLE 2.10-2. Results of abrasion tests with Gardner heavy duty wear tester

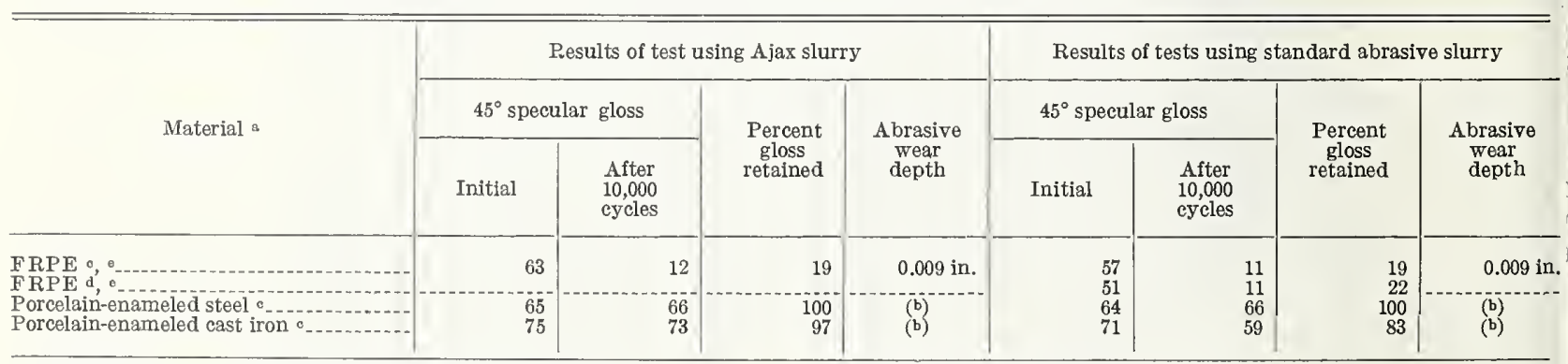

a Three specimens were used for each material in each test.

b The abrasive-wear depth on the porcelain-enameled specimens was too small for measurement by the method used. Some loss was indicated, however, since an increase in roughness occurred from the test treatment.
- Flat specimens supplied by manufacturer.

d Specimens cut from bathtub.

Wear-through to fiber-glass backing occurred on one specimen of the three. 


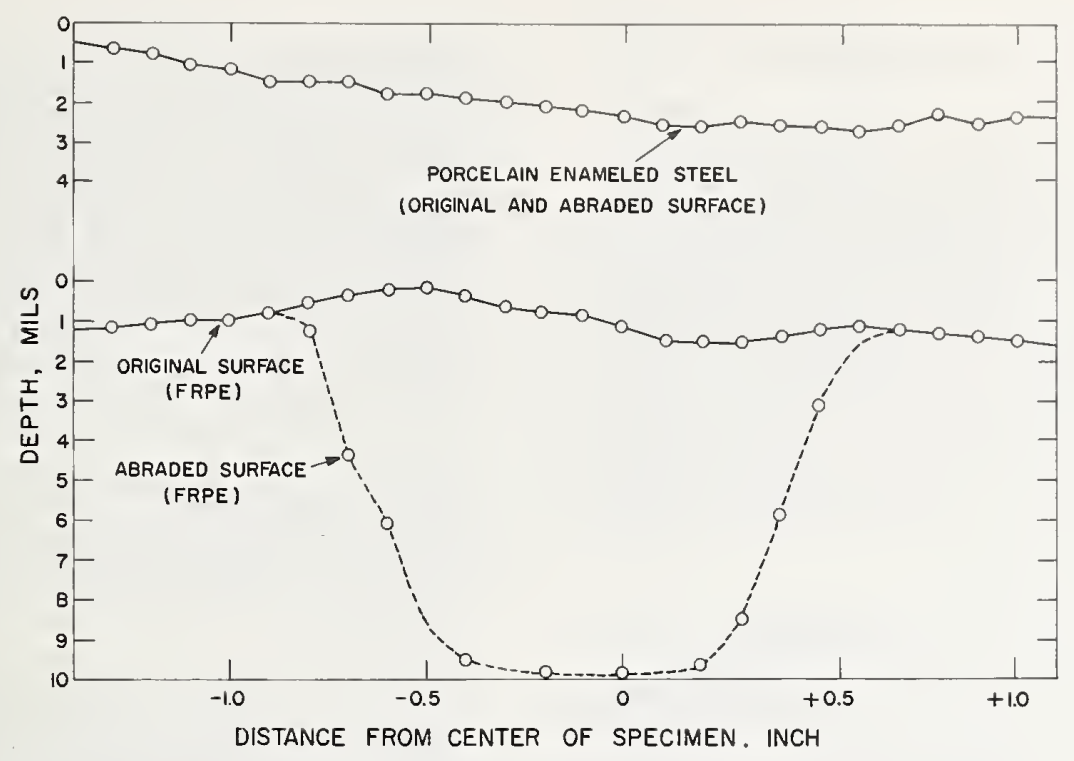

FIgURE 2.10-2. Profiles of original and abraded surfaces of porcelainenameled steel and FRPE specimens.

\section{(3) Rationale for Test Selection}

The reason for recommending the abrasion test specified in section $2.10 \mathrm{~b}$ are as follows:

1. The recommended test method simulates the abrasive wear that occurs in service through the common practice of cleaning sanitary fixtures with abrasive scouring powders. Another potentially applicable method (the Schiefer test) requires further development work for application to sanitary fixture materials.

2. The basic equipment necessary to make the test is available commercially and the necessary modifications can be made in any well-equipped laboratory. A similar test using this equipment is already in use for FRPE fixtures; thus laboratories are familiar with the equipment and its use.

3. The differences in abrasion resistance between the various materials currently used for sanitary ware as evaluated by the recommended procedure appear to be of the same order of magnitude as indicated both by qualitative handrubbing tests and field observations.

\section{d. Comments on Performance Requirements}

\section{(1) Suggested Format for a Performance Level}

Wear-through to the backing material as evidenced by a change in color and texture shall not occur on any of the three specimens. Also, in those cases where no wear-through occurs, the average wear depth for the three specimens shall not exceed in.

\section{(2) Rationale for Suggested Format}

It was not possible in the present study to establish a relation between the number of cycles in the wear tester and the abrasive wear in service. To suitably investigate a relation of this type would require an expensive and time-consuming survey of both porcelain-enameled and FRPE fixtures. Since both time and budget were limited, such a survey could not be made during the contract year. In attempting to set a realistic wear depth requirement the following factors need to be considered:

1. It seems to be the consensus of the FRPE sanitary ware industry that gel-coat thickness should be greater than $0.010 \mathrm{in}$, both from the manufacturing and end-use standpoints. Presumably this is a sound consensus based on industry experience accumulated over the past 5 years. It should be pointed out that a polyester gel-coat applied at a thickness of greater than 0.010 in would not wear through to the backing material in 10,000 cycles.

2. The introduction of new materials having an abrasion resistance appreciably lower than the current gel-coats would be prevented if the average wear depth was set at $0.010 \mathrm{in}$. This might be desirable since until such time as it can be demonstrated that household scouring powders will not be used on plastic fixtures, a high performance level for abrasion resistance would seem to be almost mandatory.

3. Wear-through to the base material in less than 10,000 cycles should not be permitted, since exposure of the base material would be highly undesirable from the standpoint of sanitation and overall appearance.

4. Selection of 10,000 cycles for the test duration is based on the requirements specified in the proposed revision of CS 221-59. A shorter testing period would not seem advisable until such time as the relation between wear rates in the test and wear rate in service can be investigated adequately. 


\subsection{Cleanability and Soilability (M203A)}

\section{a. Purpose and Scope}

The purpose of this test is to evaluate both the aesthetic soilability and cleanability of sanitary plumbing fixtures. Soilability is defined as the degree to which a surface accumulates and retains the kinds of soiling materials associated with sanitary plumbing fixtures. Cleanability refers to the ease of removal of these same soiling agents. Retention and removal of bacteria are not included in the scope. The discussion of this test is related specifically to bathtubs and shower receptors althongh it has some applicability to lavatories, sinks, and water closets.

\section{b. Selection of Test Method}

A specific test method is not recommended. An acceptable test procedure for soilability should be comprised of two major elements: (1) a reproducible soiling agent that suitably simulates actual soiling materials in the bathtub with respect to chemical composition, color, adherence properties, hardening and drying properties, etc., and (2) a suitable method for evaluating the accumulated soiling material in terms of some physical property such as weight, volume, reflectance, etc.

An acceptable test procedure for cleanability should be comprised of three major elements: (1) a soiling agent that suitably simulates actual soiling materials in a bathtub (see above), (2) a scrubbing procedure that suitably simulates techniques, and materials used under actual service conditions, and (3) a suitable method for evaluating the aesthetic cleanliness of the surface in terms of some physical property such as reflectance or retention of some tracer material, the presence of which can be detected in quantitative fashion.

A number of existing methods, laboratory investigation of some of these methods, and development work on new standard soiling agents and measurement techniques are described. Additional laboratory work is summarized that is needed to develop a suitable standard soiling agent, scrubbing procedures, and procedures for evaluation of accumulation of soil and cleanliness of the surfaces of sanitary plumbing fixtures.

\section{c. Discussion of Existing Test Methods}

\section{(1) Soilability}

Iaboratory investigation indicated that the soiling agents developed for publisined test procedures did not suitably simulate the soiling materials in a bathtub. While there is no scientific evidence to support it, the common idea is that the ring in the bathtub is the most difficult cleaning problem. No publications were discovered that described attempts to study or duplicate "bathtub ring."
Most of the research work on soilability has been done with textiles. Certainly, human soil is one of the ingredients of the soiling materials deposited on bathtub plumbing fixtures and is probably an important constituent of bathtub ring. Undoubtedly shirts and pillowcases are soiled chiefly from persons wearing or using these items. Dorothea Marra and Lloyd I. Osipow [15], on the basis of analyses of the material from such soiled fabrics, proposed a soil with the following composition:

Carbon (Darco S-51)

Percent

by weight

Coconut oil

Coconut oil fatty acids

Mineral oil, heavy

25.2

32.4

16.2

16.3

Benton 34.

10.0

Actually, a standard soiling agent for test purposes in relation to sanitary fixtures should include other representative materials, as discussed in section 2.11e.

\section{(2). Cleanability}

A number of different test methods have been used to evaluate the cleanability of surfaces. These are described briefly together with a discussion of their relevance to performance tests for sanitary plumbing fixtures.

(i) Cleanability Test for Fiber-Glass-Reinforced Polyester Bathtubs [1]

The soiling agent used in this test is a "standard dirt" formulated of specified percentages of carbon black, magnetic iron oxide, calcium stearate, motor oil, a wetting agent, and water.

In section 4.4.1 of the proposed revision of CS 221-59 [1], a test method involving the use of the "standard dirt" for detection of voids in the surface is described. Section 6.5 describes the use of the test method as a criterion or measure of cleanability after a 10,000 cycle abrasion treatment of the surface. In testing for cleanability as in section 4.4.1, surfaces to be evaluated are first conditioned by hand scrubbing with wet sponge and scouring powder. About $5 \mathrm{~g}$ of "standard dirt" per $16 \mathrm{in}^{2}$ of surface is then rubbed into the surface with a dampened chamois, using heavy thumb pressure. The dirt is allowed to dry for at least 1 hour and then washed with a clean, dampened chamois and liquid detergent before visual inspection of the surface for dirt retention.

In evaluating abraded surfaces, as prescribed in section $6.5,10 \mathrm{~g}$ of the "standard dirt" are applied to the abraded specimens and rubbed into the surfaces with a dampened chamois, using heavy thumb pressure. After the dirt has dried for at least one hour, the specimens are washed with a liquid household detergent cleanser for about 50 cycles or until no more dirt appears to be removed. Evaluation of the dirt remaining after this clean- 
ing treatment is accomplished by comparing the white-light reflectance before the dirt is applied with that after the dirt is removed by the specified cleaning treatment. Since this test is already in use for sanitary ware materials, data were obtained in the present investigation following the procedures in the proposed revision of CS 221-59 and also using a modified procedure. The results are given in section $2.11 d$.

The "standard dirt" in the proposed revision of CS 221-59 is not recommended, principally because of its ease of removal. The findings on this characteristic will be discussed further in section $2.11 \mathrm{~d}$ herein. As discussed in section 2.11e, it would be desirable to use a more representative, standard soiling agent in both the soilability and the cleanability tests.

\section{(ii) Pencil Test}

In the field measurements described in Appendix A, marks made with a $3 \mathrm{~B}$ drawing pencil were used as a "standard soiling agent" on fixtures of various materials. Cleanability was categorized by ease of removal of these marks using a dry cloth, a damp cloth, a damp cloth with soap, or a damp cloth with household cleaner. While this simple test provides a four-step rating or classification of cleanability, the pencil marks cannot be said to simulate agents in a bathtub in service.

\section{(iii) Washability Tests for Paints}

1. A washability test for painted surfaces is prescribed in a Federal Specification [16]. A soiling medium of law umber, petrolatum, and mineral spirits is applied to the panel with a doctor blade. The coating is dried for $1 / 2$ hr at $105-110^{\circ} \mathrm{C}$ and then cooled. The panel is then tested in a windshield-wiper type of washability apparatus with wet sponge and abrasive soap for 35 cycles (70 strokes). The "apparent daylight reflectance" and $60^{\circ}$ specular gloss are determined before and after this treatment.

In considering the suitability of this test for sanitary plumbing fixtures, it should be noted that the soiling medium specified is unlike that encountered in sanitary plumbing fixtures. The use of a liquid detergent for cleaning, rather than an abrasive soap, should be explored since the abrasive soap might cause a change in the surface during the test.

2. The effectiveness of cleaning agents for painted surfaces was investigated by Wesley E. Shelberg, James L. Mackin, and Ross K. Fuller [17].

The specimens were soiled with "synthetic dirt," formulated to resemble urban and shipboard dirts. The formulation for urban dirt was based on previous chemical and physical analyses of street sweepings from six large eastern U.S. cities, that passed a No. 200 sieve. The following formulation was used to represent urban dirt :
Humus

38.0

Portland cement

16. 3

Silica Powder.

16. 3

Diesel oil

0.9

Used automobile lubricating oil

1.3

Carbon

1. 6

Iron oxide, ${ }^{8}$ magnetic, $\mathrm{Fe}_{3} \mathrm{O}_{4}$

0.3

Sodium chloride

5.4

Clay, "average grade"

16. 3

Stearic acid

1.8

Oleic acid

1.8

8 The iron oxide was probably in powdered form.

This formulation for a soiling agent probably merits investigation since it includes some of the materials likely to be found in soils on sanitary plumbing fixtures. However, some of the elements of human soiling materials, such as body oils and skin particles, are not present.

\section{(iv) Tests for Bacterial Cleanability [18]}

Glass, china, stainless steel, and aluminum plates were seeded with bacteria tagged with radioactive phosphorus, $\mathrm{P}^{32}$. The dishes were washed under various conditions in a commercial dishwasher and radioactive counts performed on the dishes. The above test is not considered applicable to sanitary plumbing fixtures since it is concerned with bacterial cleanability whereas the present study is concerned with evaluating aesthetic cleanability.

\section{(v) Washability of Dinnerware}

1. The National Sanitation Foundation at the School of Public Health, Univer'sity of Michigan, has developed a Use and Wear Machine for simulating use and wear on materials and finishes for chinaware, as mentioned in Western Plumbing Official for May-June 1964. One method for measuring the effectiveness of cleaning procedures is the "salt-shaker" test, described by E. H. Armbruster and G. M. Ridenour [19]. A mixture of 85 percent talc and 15 percent Safranine- $\mathrm{O}$ dye is dusted on the surface and rinsed with water. Residual red dye is an indication of remaining fatty oil or grease, protein, and starch.

This is a simple method but not quantitative and applies more to food soil than to the soils likely to be deposited on sanitary plumbing fixtures in bathrooms.

2. Louis E. Wells, Jr. [20] described a method for evaluating liquid detergents using soiled dinner plates and a weighted brush, operated by hand. This might be a good method for preliminary testing but a machine-operated brush would give a more uniform and reproducible cleaning action. 
(vi) Cleantiness of Floors

The cleanliness of floors has been measured by Robert J. Weatherby [21]. A predetermined area of the surface is wiped in a controlled manner with a standard area of a standard fabric and the amount of dirt picked up measured by light transmission, using a portable densitometer. In order to test the procedure in the laboratory, a standard soil was applied to glass plates and test wipes made on these plates. The formulation of the standard soil is as follows:
Lamp black
$0.5 \mathrm{~g}$
Bentonite clay
$10.0 \mathrm{~g}$
Nonionic wetting agent, ethy-
lene oxide-octyl phenol con-
densate
Ethyl alcohol
2. 0 drops
2. $0 \mathrm{ml}$
Water
$100.0 \mathrm{ml}$

This method might be used to evaluate the amount of dirt remaining on sanitary plumbing fixtures and thus to evaluate soilability and cleanability but the amount of residual dirt is probably much less than that found on floors. The soiling medium probably does not resemble bathroom soil.

\section{d. Laboratory Studies of Soilability and Cleanability}

Laboratory studies of cleanability of bathtubs were made in the present investigation on specimens abraded by the Gardner Heavy Duty Wear Tester using two different abrasive slurries. One slurry was the mixture of 50 percent commercial Ajax cleanser and 50 percent water by weight specified in the proposed revision of CS 221-59. The other slurry was prepared at the National Bureau of Standards using nonproprietary materials as described in section 2.10 on Abrasion Resistance herein. The soiling medium used on the abraded specimens was the "standard dirt" of the following composition, specified in the proposed revision of CS 221-59:

Percent by weight

Carbon black, pigment grade.

Iron oxide, magnetic, $\mathrm{Fe}_{3} \mathrm{O}_{4}$, powered--

Calcium stearate.

Motor oil, 30W viscosity

Nonionic wetting agent, ethylene oxide-octyl phenol condensate...--

Water

The liquid detergent used on the specimens abraded with Ajax slurry was the commercial detergent, "Mr. Clean," as specified in the proposed revision of CS 221-59. The liquid detergent used on the specimens abraded with the nonproprietary NBS slurry was a liquid detergent of the following composition, prepared at the National Bureau of Standards:
Tetrapotassium pyrophosphate

Biodegradable nonionic nonyl phenolethylene oxide detergent

Ethylene glycol monobutyl ether, also known by the trade name "Butyl Cellosolve"

Sodium xylenesulfonate

Distilled water

75.5

The results of the cleanability tests are summarized in table 2.11-1. The results show that the modified test procedure, using nonproprietary abrasive shurry and liquid detergent, yielded greater loss in reflectance (see note b, table 2.11-1) for the FRPE specimens than did the procedure described in the proposed revision of CS 221-59. This was probably due principally to differences in the detergents, since the data on abrasion resistance in section 2.10 herein show that the abrasion produced by the two slurries was about equal for the FRPE specimens.

\section{TABLE 2.11-1. Cleanability of abraded sanitary ware} specimens:

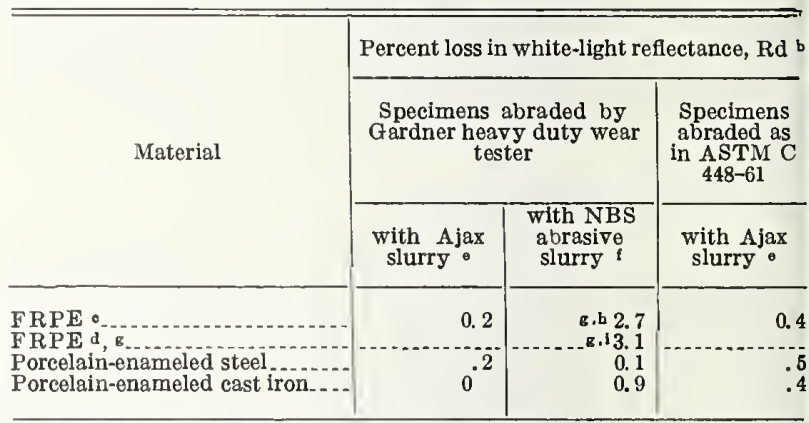

a Each value is the average of values for three specimens.

b After soiling with "Standard Dirt" and cleaning with liquid detergent. Measurements by Gardner Color-Difference Meter according to theprocedure of ASTM D 1365-60T [38].

- Flat specimens supplied by the manufacturer.

d Specimens cut from bathtub.

- Mr. Clean was used for the cleanabilty test.

i Mr. Clean was used for the cleanabilty test.
i nBS nonproprietary detergent used for cleanability test.

g One of the specimens wore through the gel-coat.

$b$ After cleaning with abrasive slurry, Rd increased 4.4 percent.

i After cleaning with abrasive slurry, Rd decreased 4.2 percent.

The losses in white-light reflectance, shown in table 2.11-1 for the porcelain-enameled specimens, were largely independent of the abrasive slurries and detergents used. The measurements were made with the Gardner Color-Difference Meter as specified in the proposed revision of CS 221-59, according to the procedure of ASTM D 1365-60T [38].

Some of the abraded specimens were coated with "standard dirt," the excess wiped off with paper wiping tissue and the specimens examined with a linear-traverso microscope. An FRPE specimen abraded by the Gardner Wear Tester showed numerous long scratches in the direction of wear pattern, with no pits. Porcelain-enameled cast-iron and steel specimens, abraded in like manner, showed very few pits on the cast-iron and about 
76 pits per linear inch on the steel specimen. Specimens abraded as by ASTM C 448-61 [8] method showed many pits. The entire surface of the FRPE specimen was pitted with little or no space between pits. The porcelain-enameled cast-iron specimen had 357 pits per linear inch, while the steel specimen had 378 per linear inch. From these observations and the foregoing data in table 2.11-1, it appears that deep scratches may affect cleanability much more than do pits.

Limited laboratory studies were made on soiling media. The studies made on cleanability showed that it was not necessary to use scouring powder to remove the "standard dirt" specified in the proposed revision of CS 221-59, unless the surface was badly worn. This was true even when the standard dirt was allowed to dry for 24 hours before removal.

Common experience with bathtubs indicates that "bathtub ring" adheres rather tenaciously to enameled surfaces if allowed to dry overnight. Many brands of toilet soap will also stick tightly to an enameled surface if allowed to dry in contact with the surface. The field survey of installations of FRPE fixtures revealed that most housewives used scouring powder for cleaning their bathtubs. Comparison of these observations with the laboratory experience indicated that the standard dirt specified in the proposed revision of CS 221-59 was more easily removed than actual bathtub soil.

In an attempt to develop a soiling medium more like that encountered in bathtubs, "synthetic bathtub ring" was produced on a number of flat specimens of sanitary ware in the stainless-steel tank used for the Water-Resistance Test, section 6.1 of the proposed revision of CS 221-59.

A soiling medium was first formulated from the following ingredients:

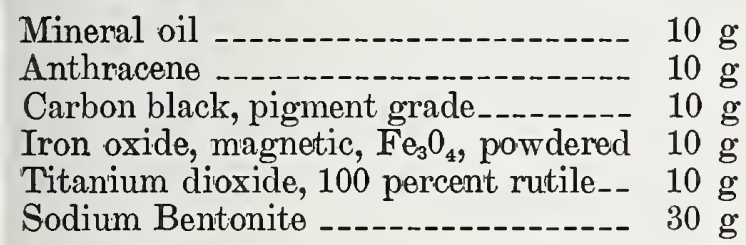

The stainless-steel tank was filled with distilled water and solutions of calcium and magnesium chlorides and sodium bicarbonate added to produce hardness equivalent to $300 \mathrm{ppm}$ as $\mathrm{CaCO}_{3}$. The water was then heated to $120-130^{\circ} \mathrm{F}$ and 1 percent neutral soap powder contain ng no additives and 0.1 percent soiling medium was added. The mixture was stirred and allowed to stand in contact with the specimens for about $30 \mathrm{~min}$. The tank was drained and the specimens allowed to dry overnight. Another experiment was tried, using a superfatted soap in place of the soap powder. However, in both cases, the "synthetic bathtub ring" was easily removed by dry wiping, as shown visually and by examination under ultraviolet light, which fluoresces the anthracene. This did not appear to be a promising approach, because of the ease with which the soil could be removed.

\section{e. Recommendations for Future Development}

\section{(1) Soiling Agents}

An essential starting point for the development of test procedures for both soilability and cleanability is a reproducible soiling agent that suitably simulates actual soiling materials in sanitary plumbing fixtures. Actually, typical soiling agents may differ for bathtubs, lavaboratories, sinks, water closets, etc.

Based on the laboratory experience obtained during this investigation, it is considered necessary to explore actual bathtub soiling materials involving hard water, bath soap, and human subjects. Analysis should be made of bathtub soil to determine the nature and proportions of various constituents as a basis for synthesizing a representative standard soiling medium. Consultation with the manufacturers of toilet soap and detergents is desirable as a means for identifying the principal ingredients in soaps and to reduce the amount of research and analysis required. It is considered possible to develop a standard soiling agent that will suitably simulate the chemical composition, color, adhesion properties, hardening and drying properties, etc., of actual soiling agents, and which can serve as a basis for performance tests on soilability and cleanability.

\section{(2) Evaluation of Accumulation}

It is probable that, with some initial exper:mentation in whole bathtubs, the soiling process can be adequately studied on flat samples cut from bathtubs or shower stalls, using a small-scale apparatus. In this event, the accumulation of soil could probably be determined by weight, with or without removal from the surface.

\section{(3) Soil Removal by Scrubbing}

It is probable that the essential measure of cleanability is the amount of energy or work required to remove the soiling agent and produce an appearance of aesthetic cleanliness. This involves the cleaning device (brush, sponge, cloth, etc.), the cleaning agent (detergent or scouring powder), the pressure used in scrubbing, the force required to move the scrubbing element across the surface of the specimen, and the number of strokes over the surface. Existing methods do not attempt to evaluate cleanability in these terms. These parameters of the scrubbing process all vary widely in actual practice.

It would be highly desirable to standardize the elements of the scrubbing process if meaningful comparisons are to be made for different materials. If the soiling process can be effectively produced on flat samples in a small-scale apparatus, it would 
be possible to use the Gardner Heavy Duty Wear Tester, equipped with suitable brushes or sponges, under a standard pressure, and a standard nonproprietary detergent or scouring powder, to determine the amount of scrubbing effort required to clean a surface or to compare the cleanability of various surfaces. It might be desirable to use a liquid detergent as the cleaning agent rather than a scouring powder, to avoid possible problems of particle imbedment in the scrubbing element, and to magnify any differences that might exist in the number of strokes or work required to attain a given level of cleanliness.

\section{(4) Evaluation of Aesthetic Cleanness}

White-light reflectance is presently used (sec. 2.11d) to indicate the amount of soiling medium remaining on a surface after cleaning. The soiling medium used in the test contains black pigments which reduce the reflectance of a white or lightcolored surface, which has a high white-light reflectance before soiling. In attempting to correlate this method for evaluating cleanability with aesthetic cleanness, it must be established that natural dirt also reduces white-light reflectance of the surface and that the change in reflectance is related to the amount of dirt.

The test described in section $2.11 \mathrm{~d}$ gives an indication of the amount of soiling medium retained in the scratches on the surface resulting from abrasion. Hence it is an indication of abrasion as well as cleanability and soilability and was designed as an indicator test for abrasion. It seems likely that, with further work to correlate visual response, type and quantity of soil, and reflectance, white-light reflectance could be used as a measure of aesthetic cleanness of white sanitary ware. The apparatus is commercially available, it is sufficiently sensitive to simulate visual resolution, and a fairly good correlation between white-light reflectance and visual response has already been established.

The white-light reflectance of a dark-colored surface is low and there may not be sufficient contrast between the surface and the soiling medium or natural dirt to indicate the amount of soiling. Hence the method outlined in section $2.11 \mathrm{~d}$ may not be valid and white-light reflectance may not be a good indication of cleanness or abrasion of colored sanitary ware. Some additional research work would be needed to develop suitable modifications of the procedure for colored plumbing fixtures. This might take the form of a different coloring agent in the standard soiling medium. Correlation between reflectance measurements on colored surfaces with various degrees of soiling and visual responses would also be needed.

Soilability and cleanability tests should be carried out on both new specimens and abraded specimens.

\subsection{Surface-Impact Resistance (Bathtub) (M204)}

\section{a. Purpose and Scope}

The purpose of this test is to determine whether or not the finished surface of a bathtub will withstand certain impact loads on critical areas without suffering mechanical damage. The impact load imposed by the recommended test is a blow on a rounded edge of the rim by an aluminum tube mounted on the end of a pendulum.

\section{b. Recommended Test Method}

\section{(1) Apparatus}

The apparatus shall be as shown and described in figure 2.12-1. Essentially it is a pendulum-type impact device made so that the tup (striking part) strikes the inside convex corner of the front rim of the bathtub at an angle of $45^{\circ}$ from the horizontal.

\section{(2) Preparation of Test Specimen}

Place the bathtub on the floor and level it. Use framing and/or shims when required to prevent rocking or shifting of the specimen when tested. In addition, distribute sufficient weights in the bottom of the bathtub to provide approximately $250 \mathrm{lb}$ of total weight including the weight of the bathtub.

Inspect the test area prior to the test using the procedure outlined in section 2.8. Test only those areas without defects. Make certain that each test point is at least 2 in from any defective or damaged area.

\section{(3) Test Procedure}

Maintain the temperature of the testing laboratory and bathtub at $75 \pm 5^{\circ} \mathrm{F}$. Position the test apparatus so that the center of the tup will strike the test surface at an angle of $45^{\circ}$ with the horizontal. This procedure is illustrated schematically in figure 2.12-1. Select the area for test along the inside convex corner of the front rim. Test a total of 10 points.

Drop the pendulum against the test surface in 1-in increments of height-of-drop until cracking, chipping, or other damage in the surface is observed, or until a 30 -in height-of-drop is achieved. Inspect for damage to the surface using the procedure outlined in section 2.8. Rotate the tup slightly after each point is tested so that a new area of the tup strikes the test point. Record the height-ofdrop of the pendulum when the damage occurs, and describe the damage.

\section{(4) Information to be Reported}

Include the following in the test report:

1. Specimen identification;

2. Location of the 10 test points indicating the distance of each from the drain end of the tub; 


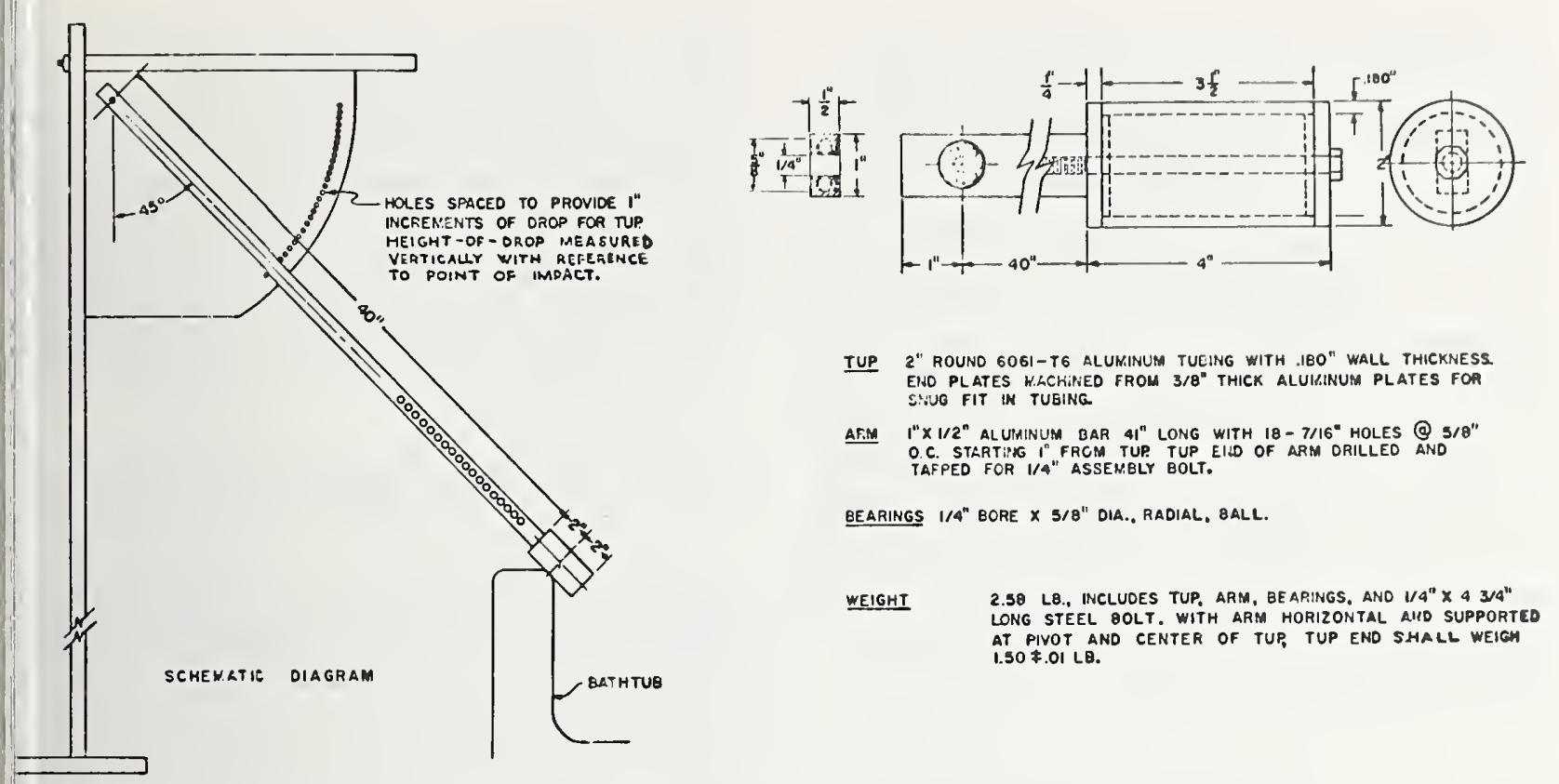

FIGURE 2.12-1. Surface impact-resistance test apparatus.

3. The height-of-drop for cracking, chipping, or other damage at each point;

4. Description of the damage.

\section{c. Test Results and Discussion}

\section{(1) Test Development}

Several test methods were tried prior to the development and selection of the recommended method. The first method tried (table 2.12-1) involved the use of a $1 / 2$-lb steel ball 11/2 in in diameter as the striking object. This method was essentially as described in the proposed revision of CS 221-59 [1] except that a plastic cylinder fitted with bubble-type plumb devices was used as a guide tube. The steel ball was allowed to fall free from various heights on both flat and curved surfaces of the specimens. The results of these tests indicated that

TABLE 2.12-1. Results of drop-impact tests on bathtubs using 1/2-lb steel ball, 11/2 in-diam

\begin{tabular}{|c|c|c|c|c|}
\hline $\begin{array}{l}\text { Location of } \\
\text { test areas }\end{array}$ & $\begin{array}{l}\text { Specimen } \\
\text { No. }\end{array}$ & $\begin{array}{l}\text { Height } \\
\text { of drop, } \\
\text { in }\end{array}$ & $\begin{array}{l}\text { No. of } \\
\text { damaged } \\
\text { areas }\end{array}$ & $\begin{array}{l}\text { No. of } \\
\text { tests }\end{array}$ \\
\hline $\begin{array}{l}\text { Bottom or ledge } \\
\text { (horizontal flat). }\end{array}$ & $\begin{array}{l}\text { SA-3 } \\
\text { SC }-3 \\
\text { CIC-3 } \\
\text { PB-2 }\end{array}$ & $\begin{array}{l}36 \\
36 \\
36 \\
36\end{array}$ & $\begin{array}{r}\mathrm{a} \\
0 \\
0 \\
\mathrm{~b} 1\end{array}$ & $\begin{array}{l}3 \\
3 \\
4 \\
3\end{array}$ \\
\hline $\begin{array}{l}\text { Inside } \operatorname{rim} \text { (convex } \\
\text { radius). }\end{array}$ & $\begin{array}{l}\text { SA-3 } \\
\text { SC-3 } \\
\text { CIC-3... } \\
\text { PB-2 }\end{array}$ & $\begin{array}{r}12 \\
6 \\
6 \\
24\end{array}$ & $\begin{array}{l}.0 \\
06 \\
\text { d } \\
\text { e } 3 \\
11\end{array}$ & $\begin{array}{l}8 \\
3 \\
3 \\
3\end{array}$ \\
\hline
\end{tabular}

- small chip.

b Small gouge.

- Chips ranging from $1 / 10$ to $1 / 2$ in maximum dimension.

d Chip, 7/8-in maximum dimension.

- Faint mar.

I Fine scratches. the convex surfaces of the tubs were most susceptible to damage. It was also noted that the precise point of impact was critical. The steel ball test was abandoned because of difficulty in controlling the point of impact on the convex surfaces, and also because the high rigidity of the steel ball was not characteristic of objects likely to be dropped on bathtubs after installation. A second series of tests was tried with a pendulum apparatus similar to the recommended apparatus except that the tup used was a glass bottle. Variations in weights and dimension's of bottles of the same nominal size plus the danger from glass breakage led to the use of an aluminum cylinder as the striking object.

\section{(2) Test Data}

The results of tests on a number of porcelainenameled-steel tubs are presented in table 2.12-2. The reported results are confined to porcelainenameled-steel tubs only although porcelain-enameled cast-iron and FRPE tubs were also tested. The results of tests on cast-iron units are not included in table 2.12-2 as no failures occurred at the maximum height-of-drop. The same was true for the FRPE tubs with one exception. Specimen PB-2 at a point of double curvature failed at an average height-of-drop of 181/4 in for eight test points. Nine test points located at areas of single curvature withstood the maximum height-of-drop without damage.

The results tabulated for other test areas in table 2.12-2 are included to show that a definite test area must be specified since differences in impact resistances among different areas of the same specimen are significant. 
TABLE 2.12-2. Surface impact-resistance test results a

\begin{tabular}{|c|c|c|c|c|}
\hline Location of test area & $\begin{array}{l}\text { Specimen } \\
\text { No. }\end{array}$ & $\begin{array}{l}\text { Avg. ht. of } \\
\text { drop to } \\
\text { failure }\end{array}$ & $\begin{array}{l}\text { Number } \\
\text { of drops }\end{array}$ & $\begin{array}{l}\text { Standard } \\
\text { deviation }\end{array}$ \\
\hline Inside front rim... & $\begin{array}{l}\text { SE-4... } \\
\text { SA-4 } \\
\text { SC-2 b. } \\
\text { SC-2 } \\
\text { SC-4... }\end{array}$ & $\begin{array}{r}\text { Inches } \\
13.8 \\
8.2 \\
7.6 \\
7.3 \\
7.0\end{array}$ & $\begin{array}{r}13 \\
9 \\
8 \\
9 \\
3\end{array}$ & $\begin{array}{l}3.37 \\
1.64 \\
1.51 \\
1.00 \\
1.00\end{array}$ \\
\hline Outside front rim - & $\begin{array}{l}\text { SE-4 } \\
\text { SA-4 } \\
\text { SA-2 } \\
\text { SC-2.-. } \\
\text { SC-4 }\end{array}$ & $\begin{array}{r}10.3 \\
7.8 \\
7.7 \\
6.6 \\
5.9\end{array}$ & $\begin{array}{r}9 \\
13 \\
11 \\
9 \\
13\end{array}$ & $\begin{array}{l}1.73 \\
1.16 \\
1.27 \\
.88 \\
1.06\end{array}$ \\
\hline Inside back rim .. & $\begin{array}{l}\text { SE-4.-- } \\
\text { SE-4 } \\
\text { SC-4 - } \\
\text { SC-2 b. } \\
\text { SC-2... } \\
\text { SA-4..- }\end{array}$ & $\begin{array}{r}17.7 \\
16.2 \\
12.0 \\
10.9 \\
10.7 \\
7.6\end{array}$ & $\begin{array}{l}9 \\
9 \\
7 \\
8 \\
9 \\
8\end{array}$ & $\begin{array}{l}7.97 \\
5.30 \\
2.52 \\
1.46 \\
1.42 \\
1.19\end{array}$ \\
\hline Inside head-end... & SA-4.... & 8.3 & 3 & 1.53 \\
\hline
\end{tabular}

A Apparatus used as shown in figure 2.12-1.

b 2 d Set.

- 2-in x 4-in timber under ledge.

\section{(3) Rationale for Test Selection}

The primary reason for the selection of this method of test was that the height-of-drop and the point of impact can be easily controlled and reproduced. The selection of aluminum as the material for the tup was prompted by the similarity of its modulus of elasticity to that of glass.

The inside radius of the front rim was chosen as the test area because this area is vulnerable to impact blows in normal service, and is conveniently located for testing with the apparatus developed for this test.

\section{d. Comments on Performance Requirements}

\section{(1) Suggested Format for a Performance Level}

The average of the heights-of-drop at first cracking, chipping or other damage for the 10 test points shall be not less than $\_$in. The minimum value for any one point shall be ___ in.

\section{(2) Rationale for Suggested Frormat}

That chipping occurs on some steel tubs is indicated by the results of the telephone survey (Appendix B). In setting height-of-drop limits, however, it should be kept in mind that about $3 / 4$ of the chips occurred during, or prior to, installation. More care during handling and installation probably would have reduced the observed damage by a sizable amount.

\subsection{Dimensional Stability (M205)}

This characteristic was defined by the ad hoc committee as the ability of a plumbing fixture to withstand the conditions of environmental exposure in service, and the conditions of normal handling and storage prior to installation without excessive distortion. There is no existing test method applicable to the determination of this property for sanitary plumbing fixtures and no test method is recommended. Extensive experimentation would be required to devise accelerated tests to evaluate permanent distortion in service in relation to time of use. Some data on permanent distortion after exposure to concentrated load separately and in combination with a water load are presented herein. Some data on permanent deflection during the hot-water resistance test are also presented.

\subsection{Bond Maintenance (Mechanical) (M206)}

Commercial Standard CS 221-59 specifies that FRPE specimens exposed to the ASTM B 117 salt spray test for $4000 \mathrm{hr}$ [22] shall not exhibit any "apparent" blistering, delamination, or other surface defects. No work was done on a test for this property in the present investigation. The tests recommended in sections $2.2,2.4,2.18$, and 2.20 covering concentrated static load, concentrated dynamic load, hot-water resistance, and radiantheater resistance, respectively, are believed to expose the fixture to some of the more severe service conditions that are likely to produce delamination or loss of bond. These tests should indicate the ability of the fixture material to maintain the bond between the structural back-up and the surface finish under service conditions.

\subsection{Surface Slip Resistance (Bathtub or Shower Receptor) (M207)}

\section{a. Purpose and Scope}

The purpose of this test is to evaluate the surface slip resistance of bathtubs and shower receptors. This property obviously is related to safety in the use of these fixtures.

\section{b. Selection of a Test Method}

No test method can be recommended at this time, because none of the existing test methods appear to be suitable, and it was not possible to develop a suitable method within the resources available in the present investigation. Three major elements would be pertinent to a suitable method:

(1) The sliding element of the test apparatus should effectively simulate the surface properties and resilience of some part of the human anatomy likely to be involved in slipping in a bathtub or a shower receptor. These properties would have to be determined through further study.

(2) The method of initiating slippage, i.e., dynamically or statically induced, would have to be selected from further information on falls in service (or other simulated service conditions) so 
as to effectively simulate the mechanisms of slippage in bathtubs and shower receptors.

(3) The nature of the fluid film to be used on the test surface should be selected from further study so as to simulate service conditions.

Finally, a relation between slip-resistance values determined in tests and actual slippage by human subjects (suitably protected against injury) in a service or simulated-service environment, using the same materials, would be highly desirable.

\section{c. Discussion of Existing Test Methods}

Two reports $[23,24]$ relating to test methods and apparatus for determining slipperiness of walkways were studied.

In horizontal-track methods, the sliding coefficient of friction at constant velocity is the ratio of the force required to drag the specimen to the weight of the sliding body, neglecting intermolecular forces between the surfaces. In inclined-track methods, the coefficient of friction is determined by the tangent of the angle of incline of the plane surface to the horizontal. The angle is adjusted until constant velocity is attained. The Sigler Slip Tester, a pendulum-impact machine, developed at the National Bureau of Standards for testing slipperiness of walkway surfaces, was based on the premise that, in the process of walking, slipping is most likely to occur when the rear edge of the heel contacts the walkway surface. 'The value obtained from use of the machine, the energy loss in a measured distance of movement across the surface, is called the "anti-slip" coefficient.

The simplest method, a horizontal-track method for floor surfaces, used by the Research Department of the Hospital Bureau, Inc., employs a 15lb spring scale and an $8-\times 10$-in canvas bag containing $10 \mathrm{lbs}$ of lead shot. The bag is placed on two layers of clean cheesecloth with the scale attached. If less than a $3-1 b$ drag will pull the bag across the floor, the surface is considered too slippery. If a drag of $5 \mathrm{lbs}$ or more is required, the floor is considered safe. However, it was reported that the results depend on operation and technique. Possibly a modification would be suitable for testing the slipperiness of bathtubs and shower receptors.

Another horizontal-track method is the Egan Slip Tester, manufactured by the Thwing-Albert Instrument Co., Philadelphia, $\mathrm{Pa}$. Friction is measured between two specimens, one secured to a moving platform and the other attached to a weighted sled connected to a spring dynamometer or electric load cell. This would not be suitable for measuring the slipperiness of sanitary ware, because only one surface of the sanitary ware is involved in slipping in a bathtub or shower receptor, while two surfaces are involved in the Egan Slip Tester.

Friction of floors has been studied by means of a household floor scrubbing and polishing unit, the power supply of which is connected to an ammeter. Increased current indicates greater friction and vice-versa. However, the brush is not similar in surface properties to the human foot or other part of the anatomy which might slip in a bathtub or shower receptor.

Another type of horizontal-track method, measuring static friction instead of kinetic friction, is represented by the Hunter Machine, the James Slip Tester, and the Dura Slip-Resistance Tester, all similar in principle. The Hunter Machine consists of a slotted weight, placed between two vertical guide bars of the frame, and a thrust arm pivoted at one end near the center of gravity of the weight and at the other end through the center of a shoe. The sliding specimen, a footwear material, is attached to the underside of the shoe and rests on the track, a flooring material. Initially the shoe is placed with the thrust arm close enough to the vertical so that the specimen will not slip on the track. By means of a screw and lug, the shoe can be drawn forward by small increments, increasing the horizontal component of the shoe until the specimen slips on the track and the weight drops. The position of the lug at the instant of slippage is an indication of the frictional force. This method seems deficient because the relationship between frictional properties of footwear materials and the sole of the human foot is unknown, and the method of initiating slippage seems unlike that involved in falls in bathtubs and shower receptors.

The Sigler Slip Tester is essentially a compound pendulum which sweeps a shoe material over the walkway surface to be tested. A mechanical shoe, forming the lower end of the pendulum, is so arl'anged that a test piece of rubber, leather, or other heel material, $11 / 2$ in square, can be attached to the underside of the shoe at an angle of 10,20 , or 30 degrees to a horizontal plane. A helical spring is used to press the edge of the heel against the walkway surface. The pendulum, released from a predetermined fixed height, is allowed to sweep over the floor specimen or surface to be tested. A pointer attached to the framework at the pendulum's center of rotation records the heights to which the pendulum swings beyond the floor specimen after contact. From the data, an anti-slip coefficient between the two materials is determined. Deficiencies of this method are similar to, but possibly less serious than, those of the Hunter method.

The British Portable Skid-Resistance Tester [25] is an improved modification of the Sigler Slip Tester, designed for measurements on walkways and roadways. It is also the basis of a proposed ASTM method for measuring surface frictional properties. The slider assembly consists of an aluminum backing plate to which is bonded a $1 / 4 \times 1-\times 3$-in rubber strip. The rubber compound is synthetic rubber as specified in ASTM E249$64 \mathrm{~T}$ [26] and must not be more than 2 years old. 


\section{c. Test Results and Discussion}

Three bathtubs were evaluated for surface slip resistance, using the British Portable Skid-Resistance Tester, one of the available existing test machines. The procedure adopted for these trial tests was as follows:

Clean the fixture with synthetic detergent and water and thoroughly dry interior surfaces, taking care to remove mold-release wax from new FRPE surfaces. Level and adjust the test machine for 5 -in contact area ( $\pm 1 / 4$ in). Take four readings. Record the first reading in parentheses and disregard. Move to another location, readjust the machine, and take readings as before. Average the second, third, and fourth readings at the two locations for measuring dry slip resistance. Stopper the drain of the fixture and add enough water to make a pool in the lower portion. Perform measurements as before but slosh water onto the test area immediately before making each observation. Average the corresponding six readings for measuring wet slip resistance.

Measurements as shown in table 2.15-1 were made on one each of porcelain-enameled steel, porcelain-enameled cast-iron, and FRPE bathtubs, using the British Portable Skid-Resistance Tester. There was a noticeable difference between wet and dry slip resistance, the wet surfaces being much more slippery. There was no significant difference in wet slip resistance between any of the bathtubs tested. There were some differences in dry slip resistance, porcelain-enameled cast-iron and steel tubs being somewhat less slippery than FRPE tubs when dry. However, further study should be made, taking special care to remove any mold-release wax from FRPE tubs.

TABLE 2.15-1. Measurement of slip resistance of bathtubs with the British portable skid-resistance tester

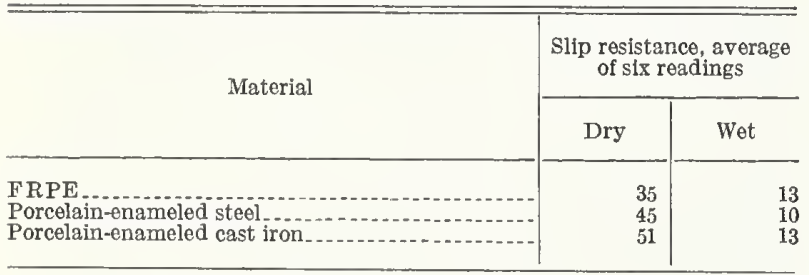

\section{e. Recommendations for Future Development}

Further work on a suitable test method should include attention to nature of the sliding element, the method of initiating slippage, and correlation between service experience and test results, as referred to in paragraph $2.15 \mathrm{~b}$.

Other parameters that should be evaluated, if possible, are

(1) Resilience of fixture material, and of force between sliding element and fixture surface. If any substantial local deformation occurs in the material beneath the feet of a bather, the resulting "depression" might reduce the tendency to slip due to a shift in body position. This effect, if it is appreciable, might be affected by unit force between the surfaces in contact, area of contact, and resilience or flexibility of the fixture material.

(2) Amount, temperature, and composition of liquid over test surface. It is conceivable that slip resistance may be different for hot and cold wetted surfaces, and may be different when soap is used than when only clean water is used. Opinions have been volunteered by some persons that wet slip resistance may be least when only a film of water remains in a bathtub.

Performance limits should be based on a relation between test results and data from a service or simulated service environment, so that the limits set can be looked upon as reasonable in the interests of safety in use.

The above suggestions are made principally because opinions have been volunteered (see Appendix A) that some materials feel less slippery when wet than others, and because these variables were not studied in the present investigation.

\subsection{Scratch Resistance (M208)}

\section{a. Purpose and Scope}

The purpose of this test is to provide a method for evaluating the resistance of sanitary plumbing fixture materials to the type of scratches that detract from the aesthetic appearance of the fixtures. Scratches that cannot be seen with the unaided eye, either before or after accumulating soil, are not considered to be objectionable.

\section{b. Definitions}

\section{(1) Scratch}

For the purpose of this test, a scratch is defined as a permanent, elongated groove or a linear series of intermittent discontinuities in a surface caused by the mechanical movement of an object in contact with the surface. A scratch is characterized by great length with respect to both width and depth and is further characterized by displacement of material, without restriction on the method or manner of displacement. The displacement can be caused by any of the following:

(a) Plastic deformation (the plastic flow and piling up of material on either side of the groove).

(b) Cutting or tearing (the breaking of molecular bonds).

(c) Micro-melting (liquid flow resulting from frictional heat generated by a large force on a small localized area).

(d) Crushing and/or plowing (the dislodging of material from the surface, such that it either sloughs off spontaneously or accumulates as loosely adhering particles that can be easily brushed off). 


\section{(2) Visual Scratch Damage}

Visual scratch damage is defined as the marring or disfigurement of a surface by scratching to such an extent that either the scratch itself or foreign material retained in the scratch is readily visible to persons with $20-20$ vision.

\section{c. Recommended Test Method}

\section{(1) Apparatus and Materials}

The basic instrument used for this test is the Porcelain Enamel Institute Gouge Test Apparatus [27], modified for scratching. The essential features of the apparatus are shown schematically in figure 2.16-1. The reversible motor drives a screw shaft which slides the carriage across the top of the elevating table at a fixed velocity of 4 in per min. A specimen placed on the carriage is contacted from above by a scratching tool mounted on the underside of the counterweighted lever beam. The beam rests on a knife edge at its fulcrum and the working end of the beam has a suspended weight pan for varying the load on the scratching tool. The scratching tool is a rightcircular conical diamond with a vertex angle of $90^{\circ}$ and a 3 -mil radius point. ${ }^{9}$ The diamond tool is inclined $3^{\circ}$ off the vertical axis in the direction opposite to the movement of the carriage. The load on the diamond tool is calculated from the load on the beam and the lengths of the lever arms.

Any other instrument capable of making a straight scratch under a constant, controllable load may be used. However, the diamond scratching tool shall be as specified above.

The apparatus required for evaluation of scratches is a special viewing box which provides uniform viewing distance and angle, and uniform specimen illumination. A schematic diagram of the box is shown in figure 2.16-2.

One of the following soiling agents shall be used :

(a) The "standard dirt" specified in the proposed revision of CS 221-59. The formulation of this material is: 20 parts iron black (iron oxide,

Dlamond points of this geometry are avallable from the Tabor Instrument Corp., North Tonawanda, N.Y., Catalog No. 139-55.

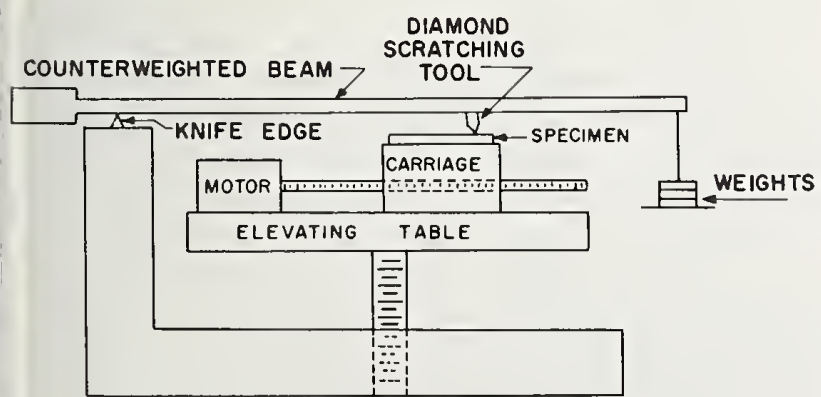

FIgURE 2.16-1. Scratch test apparatus.

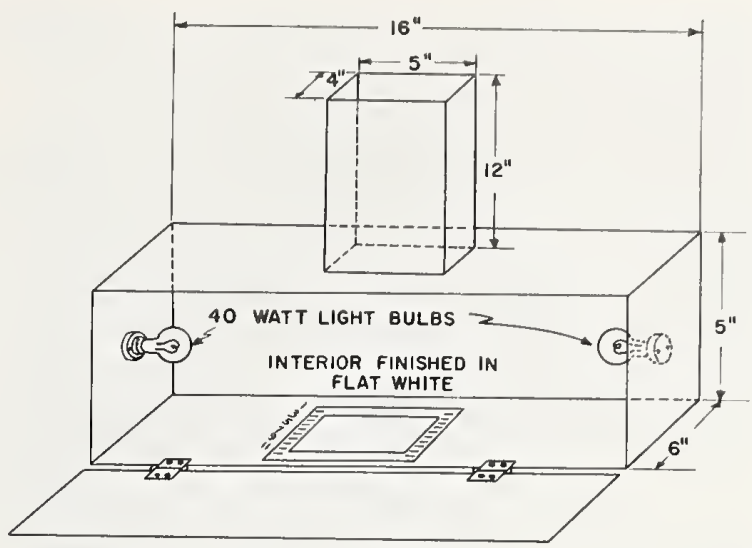

Figure 2.16-2. Specimen viewing box.

black, powdered), 20 parts carbon black (pigment grade), 10 parts calcium stearate, 5 parts $30 \mathrm{~W}$ motor oil, 1 part wetting agent (Triton $\mathrm{X}-100$, Rohm and Haas, or equivalent), and 44 parts tap water.

(b) A white paste made by mixing $5 \mathrm{~g}$ of titanium dioxide (pigment grade) with $10 \mathrm{~cm}^{3}$ mineral oil (clear and extra heavy).

\section{(2) Specimens}

Specimens shall consist of flat, 4 in $\times 4$ in pieces of the material cut from the fixture except that separately prepared specimens may be used if they are certified to be identical to the material used in the fixture.

\section{(3) Procedure}

\section{(a) Application of Scratches}

Maintain the temperature of the testing laboratory between 68 and $78{ }^{\circ} \mathrm{F}$, and the relative humidity between 45 and 65 percent. Precondition specimens in the laboratory atmosphere for at least two hours before test.

When using the instrument shown in figure 2.16-1, first balance the beam in the horizontal position by adjusting weights in the pan. Next, place a trial specimen on the carriage and raise the elevating table until the specimen makes contact with the point of the diamond scratching tool and then place additional weights in the pan so as to give a small load on the diamond. The load, in grams, on the diamond is calculated from the weight in the pan and the lever ratio. When the carriage is started, allow the diamond to traverse about 2.5 in across the face of the specimen. After making the scratch, lower the elevating table and return the carriage to the original position.

Repeat the above procedure with increasing loads on the diamond until the approximate load is found that causes a visible scratch. This load shall be called the "estimated critical load." Next, select a series of loads such that five are greatel" 
than the estimated critical load, by increments of 5 percent, and five are less than the estimated critical load, by decrements of 5 percent.

After the estimated critical load has been determined, prepare a fresh specimen for testing by marking eleven reference points, spaced $5 / 16$ in apart, along an edge of the specimen. Place this specimen on the carriage and position it so that the diamond scratching tool starts its movement at the first reference point. With one of the preselected loads in the pan, make a scratch (or pass) across the specimen. Repeat this procedure for each of the other pre-selected loads; however, the order of applying the loads shall be randomized so as to preclude a regular pattern which might tend to bias an observer, who later rates the specimen.

\section{(b) Application of Soiling Agent to Scratches}

In order to allow for elastic recovery and for any other delayed effect of scratching, do llot apply soiling agent until at least $18 \mathrm{hr}$ have elapsed after scratching.

When testing white- or light-colored fixtures apply a generous quantity of the black soiling agent to the specimen and rub it on by hand with a soft cotton cloth. Rub in random directions at first, but finally in a direction approximately normal to the scratches. Continue the rubbing until it appears that no additional dirt is being retained in scratches. The excess dirt is then wiped off the specimen surface with wadded paper towels. All wiping is done in a direction normal to the scratches. Several towels are used until no more dint shows on a towel. One to 2 minutes of vigorous rubbing with wadded towels is quite sufficient.

In the case of black fixtures, use the white soiling agent. The procedure is the same except that the excess soil shall be wiped off until no more is visible on the unscratched surface.

When fixtures of other colors are to be evaluated, select the soiling agent that shows the greater contrast with the fixture color.

\section{(c) Visual Examination of Specimens}

The scratched and soiled specimen is placed in the bottom of the viewing box and positioned under a holding frame so that the 11 reference marks on the specimen coincide with 11 numbered reference positions on the frame. An observer (other than the operator) looks down through the viewing port and searches for evidence of scratches. He records the number corresponding to each reference position on which he finds a seratch.

The operator determines from his records the loads on the diamond at which observable scratches occurred. The visual scratch damage rating assigned to the fixture is taken as the smallest load on the diamond, in grams, that caused a visible scratch on the specimen.

In the case of a fixture with a surface pattern that is directionally oriented, the rating assigned to the fixture is taken as the average rating obtained from two specimens, one scratched in the pattern direction and one scratched in a direction forming the maximum possible angle with the pattern direction.

\section{(4) Information to be Reported}

Include the following in the test report:

1. The color of the fixture.

2. Identification of the soiling agent that was used to detect scratches.

3 . The visual scratch damage rating of the fixture.

\section{d. Test Results and Discussion}

\section{(1) Discussion of Existing Methods}

Scratch tests have been in existence for many years. Perhaps the oldest is the Mohs Scale for determining the relative hardness of minerals. Like the Mohs test, many of the later scratch tests are also intended to measure hardness and are often designated "scratch-hardness" tests. Generally, scratch resistance is correlated with hardness, but not always. All of the known scratch-resistance or scratch-hardness tests depend on the material being scratched by a hard object under controlled conditions. The hard object (herein designated "scratching tool") may be pointed, such as a diamond-tipped or hardened-steel phonograph needle, or it may be sharp-edged, such as a knife edge or a diamond-cube edge. In some cases the specimen is rated by adjusting the load on the scratching tool until the first visible scratch appears. In other cases the scratch is made under a constant load and the rating is determined by measuring the width or depth of the scratch.

Each of the known scratch tests was evaluated, but none was found to be entirely suitable for rating the performance capabilities of all classes of sanitary plumbing fixtures. A common objection to most of these tests is that they were designed for a limited class of materials and are not readily adaptable to a group of materials with widely different scratch resistances.

\section{(2) Test Development}

The first attempt at developing a scratch test that would be suitable for all fixture materials was based on determining the smallest load that would produce a scratch on the specimen surface. The starting point of the scratch was determined with the aid of a microscope. Although this particular test appeared to rate materials in the proper order of scratch hardness, a valid objection to the test as it applies to sanitary plumbing fixtures was that a scratch which cannot readily be seen is not aesthetically objectionable. 
A reappraisal of the original purpose of a scratch test led to the conclusion that a better definition of the property that was desired to be measured might be stated thus: "The resistance of a fixture to the type of scratching in which either the scratch itself ol soil retained in the scratch becomes unsightly." Consequently, the above-mentioned threshold scratch test was rejected and the "Visual Scratch Damage Test" described in section $2.16 \mathrm{c}$ was developed.

\section{(a) Test Data}

Data obtained during development of the Visual Scratch Damage Test are given in table 2.16-1. All of the porcelain-enamel, vitreous-china, and gelcoat specimens tested were white.

\section{(b) Discussion of Test Data}

Variation in visual acuity among individuals naturally leads to some scatter in ratings. However, the data in table 2.16-1 show that the variations are not serious when materials of widely differing properties are rated. Furthermore, it is believed that scatter in results can be reduced significantly when more experience is gained in conducting the test. Table 2.16-1 includes some preliminary re-

TABLE 2.16-1. Visual scratch damage ratings

\begin{tabular}{|c|c|c|c|}
\hline \multirow{2}{*}{ Material } & \multicolumn{3}{|c|}{$\begin{array}{l}\text { Minimum load on diamond tool to } \\
\text { cause visible scratch (after soil- } \\
\text { ing), gm }\end{array}$} \\
\hline & $\begin{array}{l}\text { Average } \\
\text { of } 10 \\
\text { observers }\end{array}$ & $\begin{array}{l}\text { Standard } \\
\text { deviation }\end{array}$ & $\begin{array}{l}\text { Minimum } \\
\text { and } \\
\text { maximum } \\
\text { values }\end{array}$ \\
\hline $\begin{array}{l}\text { Porcelain enamel on steel: } \\
\text { Mfr. A }\end{array}$ & 980 & 152 & $855-1230$ \\
\hline $\begin{array}{l}\text { Mfr. B: } \\
\text { Spec. 1. } \\
\text { Spec. } 2 .\end{array}$ & $\begin{array}{l}790 \\
800\end{array}$ & $\begin{array}{r}24 \\
102\end{array}$ & $\begin{array}{l}740-798 \\
618-930\end{array}$ \\
\hline $\begin{array}{l}\text { Porcelain enamel on cast iron: } \\
\text { Mfr. A }\end{array}$ & 780 & 32 & $760-836$ \\
\hline $\begin{array}{l}\text { Mfr. B: } \\
\text { Spec. } 1 . \\
\text { Spec. } 2 .\end{array}$ & $\begin{array}{l}750 \\
620\end{array}$ & $\begin{array}{l}62 \\
44\end{array}$ & $\begin{array}{l}665-855 \\
551-703\end{array}$ \\
\hline $\begin{array}{l}\text { Vitreous china: } \\
\text { Mfr. A }\end{array}$ & 700 & $\therefore 0$ & 700 \\
\hline $\begin{array}{l}\text { Mfr. B: } \\
\text { Spec. } 1 \\
\text { Spec. } 2 .\end{array}$ & $\begin{array}{l}590 \\
570\end{array}$ & $\begin{array}{l}40 \\
29\end{array}$ & $\begin{array}{l}570-665 \\
523-626\end{array}$ \\
\hline $\begin{array}{l}\text { Gel coat on FRPE: } \\
\text { Mfr. A: }\end{array}$ & & & \\
\hline $\begin{array}{l}\text { Spec. } 1 \\
\text { Spec. } 2 .\end{array}$ & $\begin{array}{l}41 \\
47\end{array}$ & $\begin{array}{l}\text { 3. } 3 \\
2.0\end{array}$ & $\begin{array}{l}37-48 \\
38-48\end{array}$ \\
\hline $\begin{array}{l}\text { Mfr. B: } \\
\text { Experimental 1 }\end{array}$ & 57 & 20 & \\
\hline Experimental & $\begin{array}{l}65 \\
74\end{array}$ & $\begin{array}{l}4.0 \\
5.9\end{array}$ & $\begin{array}{l}57 \\
57-67 \\
57-76\end{array}$ \\
\hline $\begin{array}{l}\text { Plate glass: } \\
\text { Black background } \\
\text { White backgroInd }\end{array}$ & 810 & $\begin{array}{r}0.9 \\
80 \\
20\end{array}$ & $\begin{array}{c}51-60 \\
810 \\
808-855\end{array}$ \\
\hline $\begin{array}{l}\text { Stainless steel, type } 304 \text { (280-mesh } \\
\text { abrasive finish): } \\
\text { Scratched parallel to grain } \\
\text { Scratched perpendicular to grain. }\end{array}$ & $\begin{array}{r}285 \\
19\end{array}$ & $\begin{array}{l}\text { s } 0 \\
\text { a } 0\end{array}$ & $\begin{array}{r}285 \\
19\end{array}$ \\
\hline
\end{tabular}

a Each observer made an independent determination of the minimum load that produced visual evidence of a scratch. The loads employed ranged in steps of 5 percent of the estimated critical load. Thus, potential variations between results reported by different observers within the range bounded by one step above to one step below the reported scratching load could not be detected by the procedure used, and in such instances the computed standard deviation was zero. sults; i.e., data accumulated before the test precedure had been firmly set.

The scratches on plastic and vitreous materials have different appearances. The scratch on a plastic specimen is usually a continuous, nearly uniform groove. On the other hand, a light scratch on porcelain enamel or vitıeous china nay be observable in this test only as a series of discontinuities caused by the scratching tool breaking through sub-surface bubbles. This led to variations among observers, particularly in borderline cases where there were only two or three damaged areas observable along the line traversed by the diamond point.

\section{(3) Rationale for Test Selection}

There is no other known test that rates materials according to their resistances to being visibly scratched and to retaining visible soil in the scratches. It is believed that the recommended test simulates a condition that occurs frequently in service, i.e., a fixture is scratched by a sharp or pointed object such as a grain of sand, a tool, edge of a soap dish, etc. Subsequently, the scratch accumulates foreign matter and becomes unsightly.

\section{e. Comments on Performance Requirements}

\section{(1) Suggested Format for a Performance Level}

The visual scratch damage rating of the exposed surface of the fixture shall be not less than grams.

\section{(2) Rationale for Suggested Format}

Inasmuch as all currently manufactured sanitary plumbing fixtures have apparently received public acceptance with respect to their scratch resistance, it might be reasonable to set the performance level at a value slightly below the minimum value found for materials used in contemporary fixtures. Such a performance level would disqualify any future fixture material with a scratch resistance substantially lower than the minimum value found for the presently used materials. In addition, the mere presence of a scratch-resistance requirement should tend to encourage improvement in this property of fixtures.

The data on scratch resistance obtained in this investigation show a wide range in the values for the different materials. This set of results illustrates the essential difficulty that arises when widely different levels of performance are exhibited by different materials for a given characteristic, and indicates that it may not always be logical to set a single performance level for all materials.

\subsection{Drainability (Bathtub) (M209)}

\section{a. Purpose and Scope}

The purpose of this test is to evaluate the ability of a bathtub to drain quickly and completely. 


\section{b. Recommended Test Method}

\section{(1) Apparatus}

The essential apparatus for this test is shown in figure 2.17-1, consisting of supporting structures, slope gage, graduated glass cylinder, and receiving vessel. Requirements are as follows :

\section{(a) Fixture support}

The supporting structure shall be stable under the load imposed by a bathtub, and shall be equipped with facilities for careful adjustment of level such as leveling screws or thin shims.

\section{(b) Outlet fitting}

The fitting shall be a standard drain-outlet fitting of diameter appropriate to the drain opening in the bathtub.

\section{(c) Stope gage and base}

The slope gage shall be an instrument having a calibrated accuracy to within $\pm 0^{\circ} 5^{\prime}$ and finest scale graduations of $0^{\circ} 10^{\prime}$ or less. Base of gage shall be at least one third of length of bathtub, or the instrument shall be placed on a stiff metal straight edge of this length.

\section{(d) Vessels}

The 1,000-ml graduated glass cylinder shall have finest scale graduations of $10 \mathrm{ml}$ or less, a height-to-diameter ratio of at least 5.0, and a calibrated accuray to within $\pm 5 \mathrm{ml}$ at any depth. The receiving vessel shall be cylindrical, shall have a volume not exceeding twice the tangent-depth

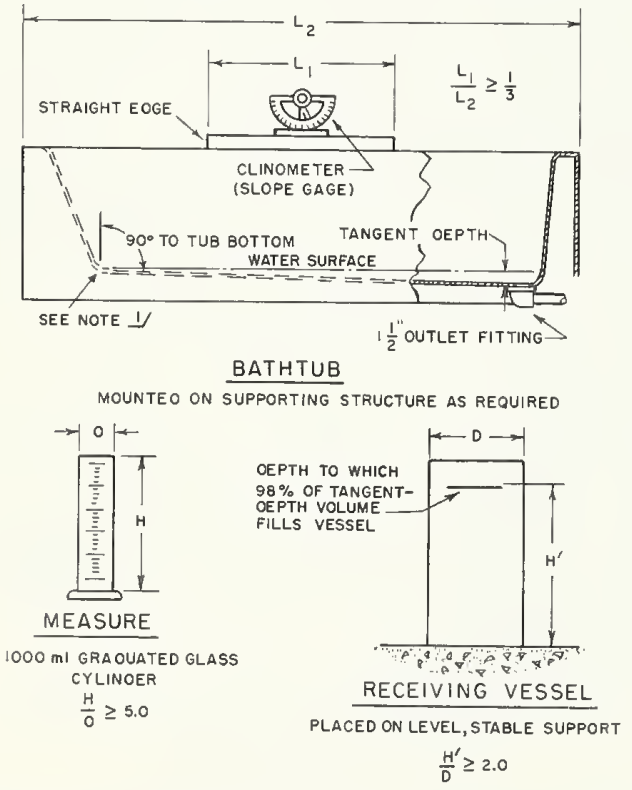

${ }^{1}$ Water surface coincides with point of tangency between fillet and bottom of tub.

Figure 2.17-1. Apparatus for drainability test. volume for the bathtub, ${ }^{10}$ and shall have a heightto-diameter ratio of at least 2 , based on the depth to which 98 percent of the tangent-depth volume fills the vessel. The receiving vessel shall either be transparent or shall be fitted with a transparent sight tube of at least $1 / 2$ in diam to facilitate precise determination of water surface elevation.

\section{(e) Timing device}

The timing device shall have the finest indicating scale graduations not exceeding $1.0 \mathrm{sec}$ and a calibrated accuracy to within \pm 1.0 percent when measuring a 60 -sec period.

\section{(2) Procedure}

Maintain the temperature of the testing laboratory, bathtub, and water used for testing at $70 \pm$ $10^{\circ} \mathrm{F}$. Place the bathtub to be tested on the supporting structure and install the drain outlet fitting without overflow fittings but with drain plug so that no leakage occurs when the plug is in place and water is introduced into the bathtub. Adjust the top rim of the bathtub so that it is level from front-to-back at the drain end of the fixture, and so that the longitudinal dimension of the front rim slopes away from the drain to the extent of $0^{\circ} 30^{\prime}\left( \pm 0^{\circ} 5^{\prime}\right)$ as determined by averaging three measurements taken at the left, center, and right positions along the length of the front rim. After establishing the specified rim slope, adjust the nominally horizontal outlet tube of the drain fitting to a slope of at least $0^{\circ} 30^{\prime}$ in the direction of discharge.

Thoroughly clean the entire inside surfaces of the bathtub, graduated cylinder, and receiving vessel with water and soap or synthetic detergent. rinse, scrub out with alcohol, and air dry. Insert drain plug and, using graduated cylinder, fill fixture with clean tap water to tangent depth as determined and marked with the aid of a straight edge at least 24 in long. Carefully record volume of water required, and calculate 98 percent of tangent-depth volume. Remove drain plug and allow bathtub to drain completely, discarding the water discharged.

Using the graduated cylinder, determine and mark the receiving-vessel depth corresponding to 98 percent of tangent-depth volume for the bathtub being tested. In making this determination, place the receiving vessel on a stable, level surface beneath the bathtub drain outlet. Mark both lateral and angular positions so the position can be duplicated in successive measurements.

In order to wet inside surface of bathtub preparatory to making measurements, replace drain plug and fill bathtub with water to tangent-depth line as previously marked. Remove drain plug and

10 See figure 2.17-1 for illustration of tangent-depth volume. Tangent-depth volume is defined as the volume of water required to fill the bathtub to a depth such that the water surface coincides with the point of tangeney between the inside bottom surface of the bathtub and the curved area at the end opposite the drain, as determined on the longitudinal centerline of the bathtub by means of a straight edge placed on the bottom. 
allow tub to drain until continual dripping ceases, at which time replace the drain plug.

Refill bathtub with tangent-depth volume of water, empty receiving vessel and replace in marked position, remove drain plug, and measure time duration of discharge required to bring water level in receiving vessel up to the mark corresponding to 98 percent of the tangent-depth volume.

Replace ḋrain plug immediately after cessation of continual dripping, and collect water clinging to inside surface of bathtub bottom with a flexible, non-absorbent squeegee. By use of the graduated cylinder, determine volume of water collected.

Repeat the three last-mentioned steps, obtaining measurements in triplicate for drainage time and retained water. Compute average values from the measurements in triplicate.

In using the graduated cylinder, wet inside surface immediately before using, shake out and discard excess water. If repeated uses of cylinder are necessary to determine marking level on receiving vessel or to fill bathtub to tangent depth, shake inside surface water into receiving vessel or bathtub, as appropriate, after each such use. Immediately before each use of the receiving vessel, first wet inside surface and then, holding upside down, shake vigorously, so as to dislodge excess water or foreign matter clinging to inside surface of vessel.

\section{(3) Information to be Reported}

Include the following in the test report:

1. Tangent-depth volume;

2. Time for discharge of 98 percent of tangent-depth volume;

3. Volume of water retained after cessation of dripping.

\section{c. Test Results and Discussion}

\section{(1) Discussion of Existing Methods}

A review of standards for plumbing fixtures did not yield any reference to a test for drainability.

\section{(2) Test Development}

In developing a test, measurements were first made to determine the nature of the discharge curve near the end of the period of drainage for a bathtub (the last $3 \mathrm{gal}$ ). In addition, the effect of bottom slope on the amount of water retained after cessation of dripping was investigated. These data are shown in figures 2.17-2 and 2.17-3. From these data it was concluded that a bottom of near zero slope, a slope away from the drain, or a wavy or warped bottom could be detected by measuring the water retained after cessation of dripping.

In further development work, five bathtubs were tested using the plocedure prescribed under section $2.17 \mathrm{~b}(2)$, and the data are shown in table 2.17-1. In these tests, specimen SC-1 retained somewhat less water after dripping than shown in figure 2.17-2: this was apparently because it was not thoroughly cleaned before the test represented in the figure. The data of table 2.17-1 show reasonably good repeatability and agreement between results by different observers.

TABLE 2.17-1. Results of drainability tests

\begin{tabular}{|c|c|c|c|}
\hline $\begin{array}{l}\text { Specimen material and } \\
\text { identification }\end{array}$ & $\begin{array}{l}\text { Tangent- } \\
\text { depth } \\
\text { volume }\end{array}$ & $\begin{array}{c}\text { Time to } \\
\text { discharge } \\
90 \text { percent } \\
\text { tdva }\end{array}$ & $\begin{array}{l}\text { Volume } \\
\text { retained } \\
\text { on bottom } \\
\text { surface }\end{array}$ \\
\hline Enameled steel (SC-1) .... & ${ }_{3 l}^{m l}, 300$ & $\begin{array}{l}s e c \\
\quad \text { b } 43.7 \\
\quad \circ 42.9 \\
\text { b } 41.8 \\
\circ 45.4\end{array}$ & $\begin{array}{ccc}m l & \\
& \text { ь } 35 \\
& \circ 28 \\
& \text { b } 30 \\
& \circ & 30\end{array}$ \\
\hline Enameled cast iron (CIA-1) $\ldots$ & 8,600 & $\begin{array}{l}20.2 \\
19.2 \\
19.7\end{array}$ & \\
\hline FRPE $(P C-4) d$ & 10,710 & $\begin{array}{l}14.3 \\
15.5 \\
15.4\end{array}$ & \\
\hline FRPE $(\mathrm{PB}-3)^{\mathrm{d}} \ldots$ & 12,000 & $\begin{array}{l}19.9 \\
19.3 \\
22.0\end{array}$ & $\begin{array}{r}109 \\
107 \\
94\end{array}$ \\
\hline FRPE (PB-2) & 12,000 & $\begin{array}{l}23.9 \\
25.0 \\
25.1\end{array}$ & $\begin{array}{l}67 \\
84 \\
72\end{array}$ \\
\hline
\end{tabular}

a Tangent-depth volume, as indicated in figure 2.17-1. b Observer A.

- Observer B.

d Test made after completion of 100 -hr boil test.

SPECIMEN SC-1 BOTTOM SLOPE $10-40^{\prime}$ $\mathrm{H}_{2} \mathrm{O}$ TEMPERATURE $75^{\circ} \mathrm{F}$

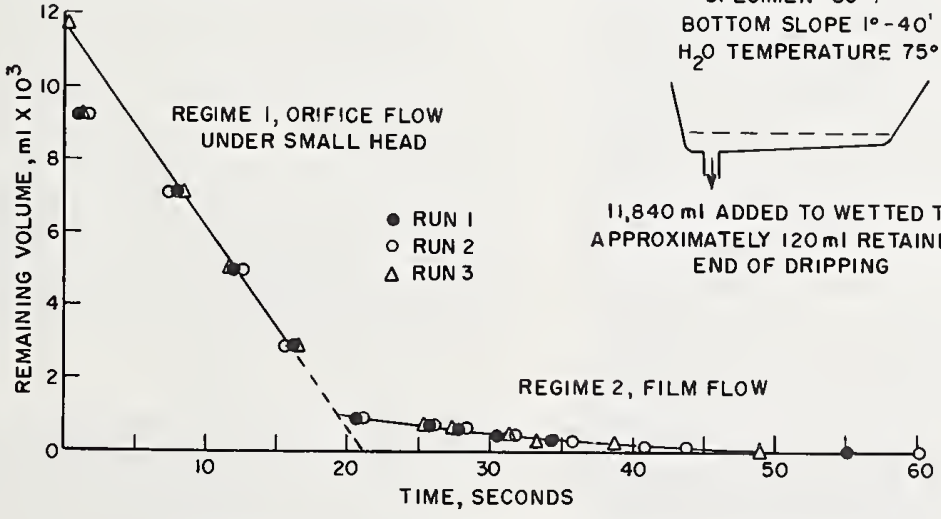

FIGURE 2.17-2. Discharge pattern for bathtub. 


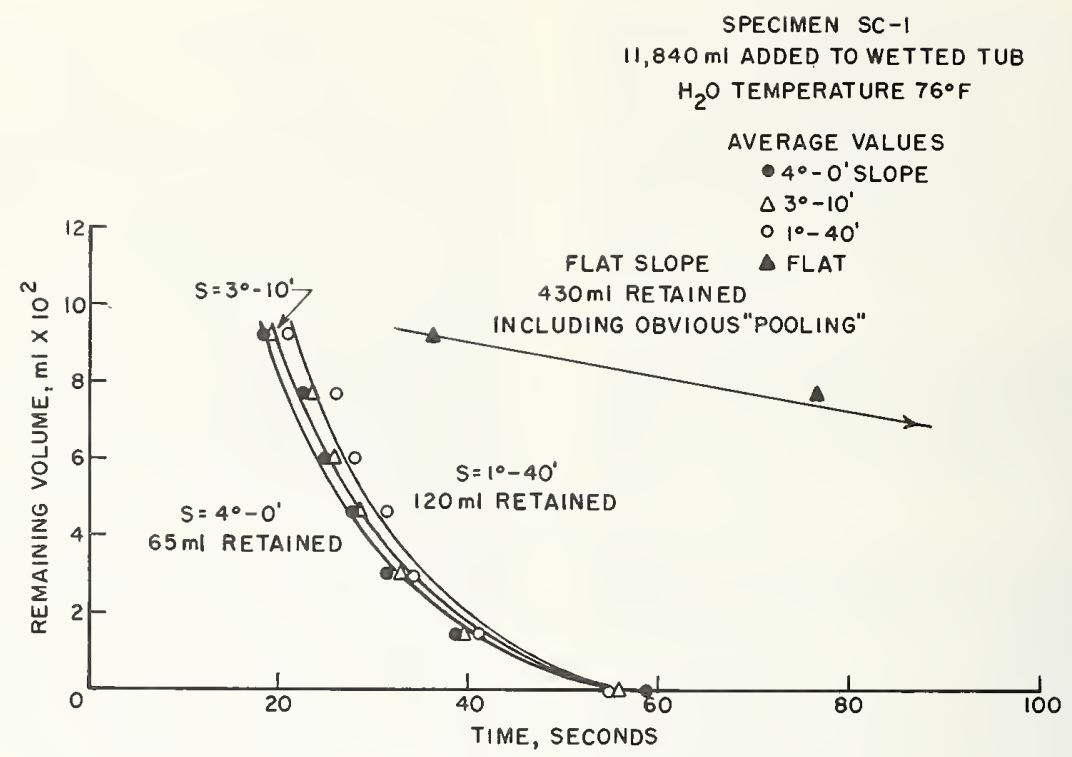

Figure 2.17-3. Bottom slope effect in bathtub drainage test, regime 2.

The test on specimen $\mathrm{PB}-3$ yielded a value of retained surface water slightly in excess of $100 \mathrm{ml}$. This was not surprising in view of the appearance of the test specimen which had previously been subjected to a 100 -hr boil test. Apparently some permanent warping of the bottom had occurred, and the surface was roughened with many blisters. These conditions probably contributed to the retention of excessive water.

\section{(3) Rationale for Test Selection}

Since important properties to be evaluated by this test are duration of drainage near the end of the discharge period and retention of water on the bottom after cessation of continuous dripping, it was considered sufficient to base the tests on the quantity of water required to barely cover the bottom surface, referred to as the tangent-depth volume. By measuring the quantity of water retained after dripping, the "pooling" that might result from improper design or manufacturing errors can be detected. As a practical indication of the duration of time for the discharge of the tangentdepth volume, the time for discharge of 98 percent of the tangent-depth volume was used. While this percentage value was somewhat arbitrary, it was about the maximum value at which good repeatability could be obtained in the measurement of the time values and yet gave a meaningful comparative indication of duration of discharge for the amount of water required to cover the bottom of a bathtub. 'The requilement that the tests be made with a rim slope of $0^{\circ} 30^{\prime}$ opposite to the drain end of a bathtub is based on field measurements of rim slope of installed fixtures. In these measurements the maximum deviation of rim slope from the horizontal approximated $0^{\circ} 30^{\prime}$, although most fixtures were set very nearly horlizontal. A rim slope opposite to the drain end of the fixture was selected for test purposes since this condition imposes a more critical requirement than a slope toward the drain.

\section{d. Comments on Performance Requirements}

\section{(1) Suggested Format for a Performance Level}

The maximum allowable time for discharge of 98 percent of tangent-depth volume shall be sec (average of three measurements), as determined in accordance with the procedure in section $2.17 \mathrm{~b}(2)$. In addition, the maximum allowable quantity of water retained on the fixture surface below the tangent-depth plane shall not exceed _ ml (average of three measurements), as determined in accordance with the procedure in section $2.17 b(b)$.

\section{(2) Rationale for Suggested Format}

All bathtubs which were tested for drainability discharged 98 percent of the tangent-depth volume in less than one minute, and when new retained less than $100 \mathrm{ml}$ of water on the surface below the tangent-depth plane. A limitation on drainage time is of interest to the user since many persons prefer to scrub and rinse a bathtub immediately after bathing. Likewise, excessive retention of water on the surface due to surface irregularities and puddling makes cleansing and rinsing more difficult and time consuming, and may be aesthetically objectionable.

\subsection{Hot-Water Resistance (Bathtub) (T302)}

\section{a. Purpose and Scope}

The purpose of this test is to evaluate the ability of a bathtub to withstand exposure of the interior 
surface to hot water without blistering, cracking, checking, or loss of bond between surface coating and base material. Although development work on the test has been carried out only on bathtubs, with further derelopment work the test coinld probably be adapted to other fixtures.

\section{b. Recommended Test Method}

\section{(1) Apparatus}

The apparatus required comprises a heat source, an immersion heating element, a water-circulating pump, a temperature control, and a dial gage graduated to $0.001 \mathrm{in}$ for measuring displacements. One such system is shown in figures 2.18-1 and 2.18-2. The system shall be capable of inaintaining a water temperature of $120^{\circ} \mathrm{F}\left( \pm 5^{\circ} \mathbf{F}\right)$ at any point in the tub.

\section{(2) Supporting Structure}

A supporting structure as specified in section 2.2 shall be provided that is stable under the weight of
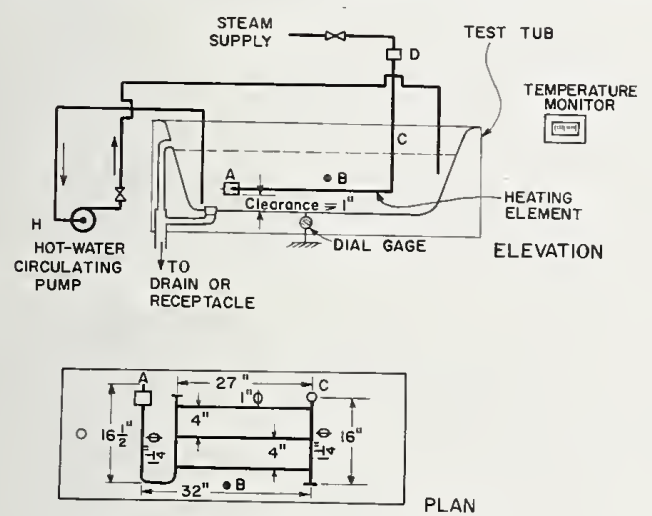

PLACEMENT AND DIMENSIONS OF HEAT ELEMENT IN TEST TUB MATERIAL: Type L Copper Woter Tube

A, steam trap safe for use at line pressure-opens to discharge condensate into test tub; $B$, thermostat and recorder sensor location approximately mid-depth and mid-length, 2 to 4 in from wall; C, riser, $3 / 4-i n$ copper or brass pipe; $D$, solenoid-operated steam valve, nominal capable of circulating $10 \mathrm{gpm}$ through suction and discharge lines.

F'IGURE 2.18-1. Apparatus for hot-water resistance test.

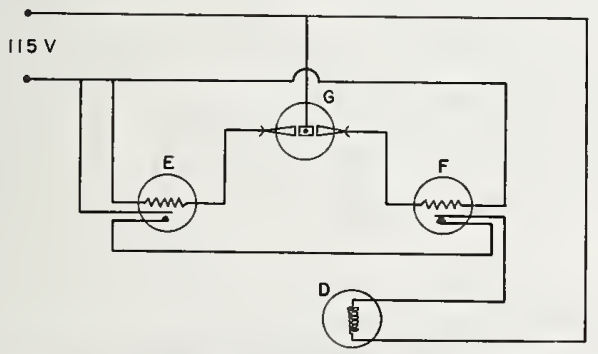

$D$, solenoid-operated steam valve, nominal $3 / 4$ in diam; $E$, 45-sec time-delay relay, contacts N.O.; F, 2-sec time-delay relay, contacts N.C.; G, bi-metallic thermoregulator, 3-wire

FIGURE 2.18-2. Temperature-control wiring diagram. a bathtub filled to the overflow outlet with water, and that will allow clearance under the bottom of the bathtub for deflection measurements with a dial gage. The bathtub shall be secured to the supporting structure as specified in section 2.2. In addition, a drain-fitting assembly shall be installed complete with overflow fitting and stopper. A flat surface shall be provided on the under-surface of the central point at the sump determined as specified in section 2.2, paragrapl b(3), so that center deflections of the sump can be measured normal to bottom.

\section{(3) Test Procedure}

Clean the inside surfaces of the bathtub with water and mild soap or synthetic detergent, rinse with water, dry, and then inspect for surface defects using the procedure described in section 2.8. Fill the fixture to the overflow outlet with water at cold-water supply temperature, drain and within 10 min after emptying determine the dial-gage reading representing the elevation of the center of the underside of the sump. This reading constitutes the zero reference for subsequent deflections. Next, fill the bathtub to the overflow outlet with clean tap water, set temperature control to $120^{\circ} \mathrm{F}$, turn on heat source and start temperature recorder and hot-water circulating pump. After water temperature stabilizes, adjust thermostat so that temperature of the water at recorder sensor (point B in fig. 2.18-1) as measured with a calibrated thermometer is maintained at $120^{\circ} \mathrm{F}$ within range of $\pm 2{ }^{\circ} \mathrm{F}$. Temperature measured with the thermometer approximately 1 in from the fixture surface at eight points (two points near the bottom at approximately the third points of the longitudinal centerline, also two points each near front and rear walls and one point near each end wall at approximately halfway depth) shall not vary from $120^{\circ} \mathrm{F}$ by more than $\pm 5^{\circ} \mathbf{F}$.

NoTE: Nonuniform temperature distribution may be corrected by adjusting circulating-pump discharge rate or position of free ends of suction and/or discharge lines.

Stop the test at intervals of $100 \mathrm{hr}$, drain the tub, and inspect the fixture for damage in accordance with the procedure described in section 2.8. Also, $30 \mathrm{~min}$ after draining, determine the center deflection of the sump. After the final 100-hr interval of exposure terminate the test, inspect the fixture for the final time, and make the final dial-gage reading. Note: The test may be terminated after any test interval if the inspection shows that the fixture has failed the requirements specified in paragraph $2.18 \mathrm{c}$.

\section{(3) Information to be Reported.}

Include the following in the test report:

1. Specimen identification, including overall dimensions

2. Description of test frame and method of fastening tub to frame

3. Results of visual inspections at beginning of test and at each successive inspection interval 
4. Deflection of center of sump $30 \mathrm{~min}$ after draining, at each 100-hr interval

\section{c. Test Results and Discussion}

\section{(1) Discussion of Existing Methods}

Hot-water exposure tests have been prescribed for several sanitary plumbing fixture materials. Among these are the 100-hr boil test for small specimens of FRPE materials described in the proposed revision of CS221-59 [1], and the total immersion test of a complete fixture in boiling water described for vitreous-glazed earthware in CS11143 [7]. Hot-water exposure of small specimens by total immersion is involved in the tests of thermal shock and water absorption for vitreous china described in CS20-63 [6] and FS WW-P-541b-54 [3]. However, none of these tests subjects the fixture to the type of exposure encountered in service; i.e., partially filling the fixture with hot water.

\section{(8) Test Development}

Three FRPE bathtubs were tested first as described in section $2.18 \mathrm{~b}$, with the test temperature maintained at $200-212{ }^{\circ} \mathrm{F}$. The tests were terminated after an aggregate of $100 \mathrm{hr}$ of exposure. The data are shown in table 2.18-1. Blistering occurred in all three tests at exposure times of $25 \mathrm{hr}$ or less. Cracking was observed in two of the three tests at 50 and $75 \mathrm{hr}$. Subsequently boil tests for $100 \mathrm{hr}$ as prescribed in the proposed revision of CS221-59 were made using specimens, 4 in sq, prepared by cutting from the undamaged areas of the tested fixtures; i.e., from above the water line. The results of these tests are shown in table 2.18-2. Blistering, but not cracking, was observed with these specimens. The relatively early blistering observed on specimens PB-3(1) and PB-3 (2) indicates that the thermal insulation provided by backing materials may reduce the resistance of gel-coats to blistering. This increased thermal insulation could easily result in a higher temperature in the coating as well as at the coating-substrate interface.

Deflections of the bathtub sumps due to prolonged exposure to water at or near the boiling point are summarized in table 2.18-1. In all three tests appreciable deflection recovery occurred upcn empting the bathtub, and recovery continued for some time afterwards. However, some residual deflection existed after periods of up to $72 \mathrm{hr}$. In one test, the lower rear wall of the sump assumed a noticeable permanent rearward set. This particular area was not supported by a reinforcement backing.

In preliminary development work, a porcelainenameled-steel bathtub was tested at a temperature approaching the boiling point for $53 \mathrm{hr}$, including $50 \mathrm{hr}$ of exposure essentially as described in section $2.18 \mathrm{~b}$, and the balance from the hot-water phase of 25 cycles of the thermal-shock test described in section 2.21. No noticeable effects were observed aside from a very slight dulling of the finish.

Two additional tests using whole FRPE bathtubs were made, one exposed to $160^{\circ} \mathrm{F}\left( \pm 5^{\circ} \mathrm{F}\right)$ water and one to $120^{\circ} \mathrm{F}\left( \pm 5^{\circ} \mathrm{F}\right)$. The results of the $160^{\circ}$ test are shown in table 2.18-1. As in the tests at the higher temperature, deflection recovery in the $160^{\circ}$ test continued for at least $90 \mathrm{hr}$ after emptying the tub. Blistering, however, did not appear until the 74 -hr inspection.

In the $120^{\circ}$ test (specimen $\mathrm{PC}-2$ ), inspections were made at the beginning, and at $74,146,241$, $355,500,600,796$, and $1000 \mathrm{hr}$ of exposure to $120^{\circ} \mathrm{F}$ $\left( \pm 5{ }^{\circ} \mathrm{F}\right)$ water. Blisters were not observed until the 500-hr inspection. At that time, the defects comprised less than half a dozen slightly raised areas of circular (up to $1 / 8$ in diam) or needle shape (up to $3 / 4$ in long). As in the earlier tests at higher temperatures, the blisters were less prominent after the bathtub had cooled. The 600$\mathrm{hr}$ inspection showed little if any further change in the surface condition. However at $796 \mathrm{hr}$, fiber and blister prominence had increased, and a number of new raised areas were observed. Still further deterionation was noted at $1000 \mathrm{hr}$. As before, some degree of recession was noted after cooling. Residual sump deflections taken immediately after draining the tub at the various inspection intervals ranged up to approximately $0.11 \mathrm{in}$, with some characteristic deflection recovery after remaining empty for a period of hours at room temperature.

In short-time load tests on FRPE bathtubs with 15 () lb of water at approximately $115^{\circ} \mathrm{F}$ on which was superimposed a $150-1 b$ concentrated load at the center of the sump bottom, maximum deflections of the sumps did not exceed approximately $0.05 \mathrm{in}$. These data are presented in section 2.13 .

While these trials showed that the particular FRPE bathtubs furnished for test were incapable of withstanding exposure to hot water for long periods at temperatures of $160^{\circ} \mathrm{F}$, or higher, without exhibiting surface defects, bathtubs in service are probably only rarely exposed to such temperatures and then probably for very short intervals of time.

Two series of $100-\mathrm{hr}$ boiling water tests were performed on 4 -in $\times 4$-in flat specimens provided by manufacturers or specially prepared in the laboratory. Equipment was used conforming to that specified under paragraph 6.1.1 of the proposed revision of CS 221-59 [1]. The results of the first series of tests are summarized as follows:

\begin{tabular}{|c|c|}
\hline $\begin{array}{l}\text { Material } \\
\text { Porcelain-enameled cast-iron, } \\
\text { SD105. }\end{array}$ & $\begin{array}{l}\text { Appearance After Boiling } \\
\text { Dull and etched. }\end{array}$ \\
\hline $\begin{array}{l}\text { Porcelain - enameled - steel, } \\
\text { CID. }^{\mathrm{a}}\end{array}$ & $\begin{array}{l}\text { Slightly dulled; slight } \\
\text { yellowing. }\end{array}$ \\
\hline $\begin{array}{l}\text { FRPE: } \\
\text { Sanitary ware gel coat }\end{array}$ & $\begin{array}{l}\text { Same as before treat- } \\
\text { ment. }\end{array}$ \\
\hline
\end{tabular}




\section{Material}

Experimental sanitary ware gel-coat.

Conrentional boat gelcoat. $^{\text {b }}$

Sanitary ware gel-coat.
Appearance After Boiling Same as before treatment.

Badly checked and peeling.

Numerous blisters; discolored to a dirty yellow.

Specimen from bathtub manufacturer.

b Laboratory specimen, specially prepared by gel-coat producer.
In the above tests, the specimens were not preconditioned except by cleaning with 1 percent trisodium phosphate solution.

In the second series of tests on 4-in $\times 4$-in flat specimens, the specimens were preconditioned with Bon Ami for 20 full strokes in a lapping machine. Gloss measurements were made before and after the boiling tests with careful cleaning

TABLE 2.18-1. Results of hot-water exposure tests of FRPE bathtubs at $205^{\circ} \mathrm{F}$ and $160^{\circ} \mathrm{F}$

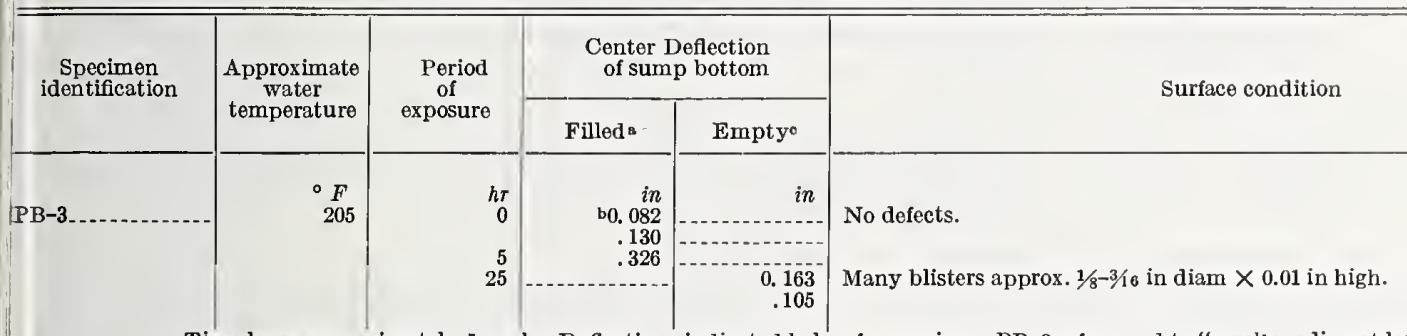

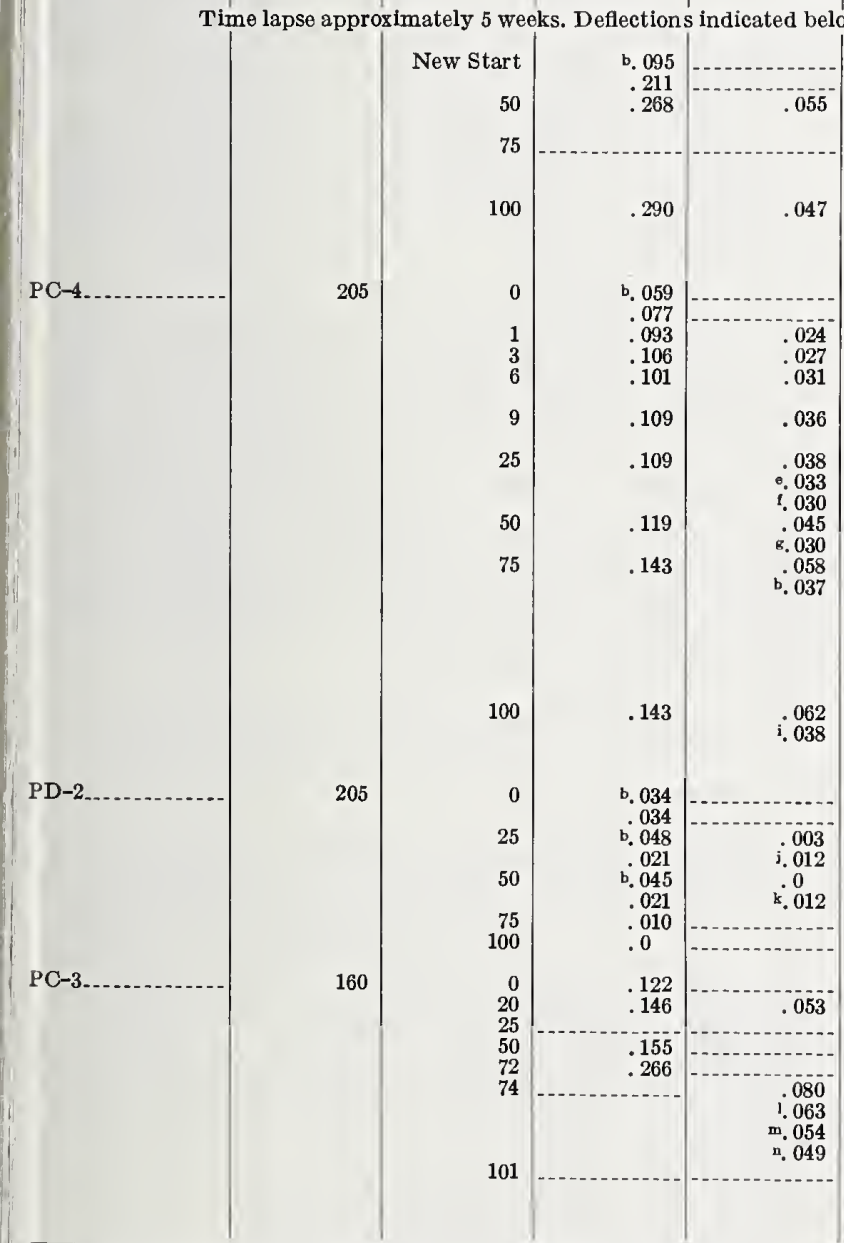

A number of blisters $1 / 4$ in diam, especially in area of front radius. Longitudinal cracks in rear radius on both sides of overflow opening.

Greater number of blisters, ranging up to $1 / 4$ in diam. Largest blisters in corners. Blisters tended to recede upon cooling. Fiber impressions evident. Additional cracks especially at ends, some in branching pattern.

More blisters than at 75 hr, some up to $7 / 10$ in across. Recede somewhat on cooling. Bottom warped outward near edge of reinforcement at back of sump. Cracking worse than at $75 \mathrm{hr}$, length of eracks ranging up to approx. $12 \mathrm{in}$ No defects.

Two small blisters near center of bottom.

A number of additional bisters.

A $\mathrm{B} \mathrm{C}^{\circ}$ (Hot Tub)

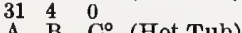

$\begin{array}{llll}40 & 4 & 0 & (\text { Hot Tub) }\end{array}$

A $\quad$ B $\mathrm{C}^{\circ}$ (Hot Tub)

$\begin{array}{llll}45 & 6 & 0\end{array}$

A B $C^{\circ}$ (Cold Tub) Many large blisters just below water line. Size diminished on cooling.

A B $\mathrm{C}^{\circ}$ (Cold Tub) Two hours after draining, blister counts of 20 to 80 $\begin{array}{llllll}24 & 2 & 0 & \text { were obtained from randomly spaced 6-in circular }\end{array}$ areas on sidewalls, ranging up to $3 / 10$ in dism (up to $1 / 6$ in on bottom). Needle shaped raised ar to $1 / 8$ in on bot tom). Needre-shaped raised areas Two small areas on lower sidewall contained numerous short, parallel cracks.

\section{A $\quad \mathrm{B} \quad \mathrm{C}^{\circ}$ \\ $9=-($ Cold Tub)}

No defects.

Surface below water line covered with numerous tiny blisters, except in front corners.

Blisters increased in number ( $1 / 16$ in to $1 / 8$ in) All areas below water line blistered, many blisters joined with adjacent blisters.

Blisters flattened out considerably, many having burst open.

No defects.

No defects.

No defects.

Approx. 20 blisters on finished surface of tub bottom, ranging from $1 / 8$ in to $1 / 4$ in diam. Blister prominence decreased upon cooling.

Blisters noticeably less prominent. Three new blisters approx. 1/4 in diam on concave surface of an inside corner slightly below water line. Outlines of numerous filaments of fiberglass.

NoTES:

Water at temperature in column 2 except where otherwise noted.

b Water at cold water supply temperature.

- Measured immediately after emptying except where otherwise noted.

d Measured after tub had been empty for $25 \mathrm{~min}$.

- Measured after tub had been empty for $1 / 2 \mathrm{hr}$.

${ }^{i}$ Measured after tub had been empty for $11 / 2 \mathrm{hr}$.

$\mathrm{g}$ Measured after tub had been empty for $24 \mathrm{hr}$.

b Measured after tub had been empty for $3 \mathrm{hr}$.

i Measured after tub had been empty for $1 \mathrm{hr}$. j Measured after tub hadbeen empty for $42 \mathrm{hr}$.

$\mathrm{k}$ Measured after tub had been empty for $72 \mathrm{hr}$

1 Measured after tub had been empty for $2 \mathrm{hr}$.

$\mathrm{m}$ Measured after tub had been empty for $25 \mathrm{hr}$.

$n$ Measured after tub had been empty for $90 \mathrm{hr}$.

- Designations A, B, and C identify 6-in circular areas on longitudinal centerline of finished surface of bottom of bathtub. $A$ was at mid-point, $C$ adjacent to drain, and $B$ at opposite end of tub. Numbers indicate blister counts in the respective areas. 
TABLE 2.18-2. Results of 100-hr boil test of 4-in $\times$ 4-in FRPE specimens cut from above waterline of whole bathtubs previously subjected to 100-hr boil test

\begin{tabular}{|c|c|c|c|c|}
\hline \multirow{2}{*}{ Specimen identification } & \multicolumn{4}{|c|}{ Surface condition at indicated time } \\
\hline & $25 \mathrm{hr}$ & $50 \mathrm{hr}$ & $75 \mathrm{hr}$ & $100 \mathrm{hr}$ \\
\hline PB-3(1), plywood backed... & Many small blisters.. & Blisters slightly enlarged. & Some bursted blisters . - & Many bursted blisters, \\
\hline PB-3(2), plywood backed... & Many small blisters. & Blisters slightly enlarged & Some bursted blisters . ........ & Many bursted blisters, \\
\hline PB-3(3), no backing. & Few blisters & Same as at $25 \mathrm{hr}$. & Same as at $50 \mathrm{hr}$. & Many blisters pinpoint size \\
\hline PB-4(1), no backing--- & No noticeable change. & No noticeable change. & $\begin{array}{l}\text { Three blisters } 1 / 8 \text { in }-3 / 16 \text { in } \\
\text { diam, fiber impressions }\end{array}$ & $\begin{array}{l}\text { Several additional small } \\
\text { blisters. }\end{array}$ \\
\hline PC-4(2), no backing... & No noticeable change. & No noticeable change.- & Fiber impressions beginning & Approx. 12 blisters ranging \\
\hline PC $-4(3)$, no backing & No noticeable change & No noticeable change..-. & $\begin{array}{l}\text { Fiber impressions beginning } \\
\text { to develop. }\end{array}$ & $\begin{array}{l}\text { Approx. } 12 \text { blisters not as } \\
\text { pronounced as spec. } \\
\text { PC-4(2), receded upon } \\
\text { cooling. }\end{array}$ \\
\hline $\begin{array}{l}\text { PD-2 ( } 6 \text { specimens, no } \\
\text { backing). }\end{array}$ & $\begin{array}{l}\text { No noticeable change at } \\
24 \mathrm{hr} \text {. }\end{array}$ & $\begin{array}{l}\text { Gel coat on all specimens } \\
\text { covered with tiny blisters, } \\
\text { similar to pebble-finish } \\
\text { paint surface }(48 \mathrm{hr} \text {.) }\end{array}$ & $\begin{array}{l}\text { Blisters on all specimens } \\
\text { larger than } 48 \mathrm{hr} \text {. }\end{array}$ & $\begin{array}{l}\text { Blisters burst on all } \\
\text { specimens, leaving surface } \\
\text { similar to peeling paint. }\end{array}$ \\
\hline
\end{tabular}

and drying preceding the gloss measurements in each case. The results were as follows:

\begin{tabular}{|c|c|c|c|}
\hline & & ${ }_{45^{\circ}} \underset{\text { Gp }}{\mathrm{Slo}}$ & $\begin{array}{l}\text { ecular } \\
\text { sis }\end{array}$ \\
\hline Material & Appearance After Boiling & $\begin{array}{l}\text { Before } \\
\text { Boiling }\end{array}$ & $\begin{array}{l}\text { After } \\
\text { Boiling }\end{array}$ \\
\hline Vitreous-china ${ }^{a} \ldots .$. & Slightly dulled $\ldots . .$. & 56.1 & 21. 6 \\
\hline $\begin{array}{l}\text { Porcelain-enameled } \\
\text { cast-iron: }\end{array}$ & & & \\
\hline CID $84^{a}$ & $\begin{array}{l}\text { Dull and etched } \\
\text { surface. }\end{array}$ & 70.9 & 2. 3 \\
\hline$X 1 b_{\ldots} \ldots \ldots$ & $\begin{array}{l}\text { Dull, etched, some } \\
\text { yellowing. }\end{array}$ & 70.4 & 20.8 \\
\hline $\begin{array}{l}\text { Porcelain-enameled- } \\
\text { steel, SD } 110 .^{a}\end{array}$ & $\begin{array}{l}\text { Dull and etched } \\
\text { surface. }\end{array}$ & 63.6 & 19. 4 \\
\hline $\begin{array}{l}\text { FRPE, sanitary } \\
\text { ware gel-coat: }\end{array}$ & & & \\
\hline A105 & $\begin{array}{l}\text { Same as before } \\
\text { boiling. }\end{array}$ & 14. 9 & 22. 1 \\
\hline PA 83 a $\ldots \ldots \ldots$ & $\begin{array}{l}\text { Numerous blisters } \\
\text { over entire } \\
\text { surface. }\end{array}$ & 8.8 & 5. 6 \\
\hline
\end{tabular}

Tests at low temperatures require long testing times. However, there was at least an indication from the data that low-temperature performance might be predicted from high-temperature data. The possible existence of an exponential relationship between water temperature and time-tofailure was indicated from the results of tests on three bathtubs of the same make, one specimen at each of the three temperatures. If this correlation could be satisfactorily established, a test temperature greater than $120^{\circ}$ could be selected so that test duration could be reduced. However, there are not sufficient data at this time to recommend the higher test temperature.

\section{(3) Rationale for Test Selection}

An exposure test of the entire bathtub (inside surface below over-flow-outlet level) is recommended for two reasons:
1. 'The detection of susceptibility to deterioration on exposure to hot water is more certain with the use of a whole fixture than if only a few small specimens cut from the fixture were tested.

2. Any possible effects of unequal stress distributions and other characteristics that might be associated with curved surfaces in whole fixtures probably cannot be detected in hot-water tests of small flat specimens.

It is recognized that the recommended test involves a prolonged exposure, whereas in service the exposure is typically intermittent. Thus, the recommended test does not incorporate thermal shock, nor does it allow for possible effects caused by alternate wetting and drying. Some consideration was given to the desirability of combining both termal-shock and hot-water resistance into a single test. A discussion of this possibility appears in section 2.21. However, this will require further development work.

\section{d. Comments on Performance Requirements}

\section{(1) Suggested Format for Performance Level}

The bathtub shall withstand exposure of the interior surface to water at a test temperature of $120^{\circ} \mathrm{F}$ for __. hr without blistering, cracking, loss of bond between surface coating and base material, or other damage as detected by the surface-inspection test of section 2.8. In addition, residual deflection after ___ hr of exposure when measured $30 \mathrm{~min}$ after empitying bathtub shall not exceed in.

\section{(2) Rationale for Suggested Format}

The requirement of the appearance of no defects in a bathtub surface after a given exposure to water at $120^{\circ} \mathrm{F}$ is believed to be a reasonable requirement. A bathtub is meant for bathing and if blisters and cracks or other defects that seriously affect its usability appear after only short 
periods of service, the fixture is not performing the function for which it was intended. It was assumed that a total of $400 \mathrm{hr}$ of exposure might occcur in eight years of service. However, since most baths are probably taken at water temperatures appreciably less than $120^{\circ} \mathrm{F}$, and since timeto-failure appears from the test results to be lengthened by lowering the temperature, $400 \mathrm{hr}$ of exposure at $120{ }^{\circ} \mathbf{F}$ could represent a normal service hot-water exposure of much longer than eight years. Hence, $400 \mathrm{hr}$ without the appearance of defects might be considered as a fairly reasonable test requirement.

It should be pointed out that the blisters that first appeared in the tests were not of a type that would have made the tubs immediately unusable in service, although their presence would have been undesirable. The observed tendency of these blisters to recede on cooling, however, does not suggest that their appearance is of no significance. When a blister occurs the original bond of the coating to the substrate is destroyed, and for this reason the coating may be subject to spalling at these blister points during later service. In fact, it is even possible that the small spalls observed on some of the older tubs in the field inspection of FRPE fixtures could have originated from this cause.

A possible limit on center deflection of the sump 30 min after draining the hot water from the bathtub would be $1 / 8$ in. This value is based on the following considerations:

1. A center deflection of $1 / 8$ in that uniformly diminishes with distance from the center should not present a drainability problem in bathitubs with bottom slopes comparable to those of current production. The deflection limit recommended may include an inherent safety factor, since the intermittent loading occurring during use would tend to cause less sump deflection in some materials than continuous hot-water loading for the same period of exposure, and also because many polymeric materials (such as FRPE) will continue to recover for much longer periods than the $30 \mathrm{~min}$ specified in paragraph $2.18 \mathrm{c}$.

2. Field information on bathtubs did not show a significant incidence of drainability problems; hence, it may be inferred that sump-bottom deflection from hot-water exposure has not been a problem with the current materials. The FRPE bathtubs tested pass the suggestion deflection requirement. Because of their particular properties, porcelain-enameled metal bathtubs are not subject to permanent deflection from exposure to hot water. However, the same sort of a deflection limit is proposed as both necessary and desirable so as to prevent possible future use of materials that may have permanent deflections sufficiently high to affect adversely their drainability.

\subsection{Gigarette-Burn Resistance (T303)}

\section{a. Purpose and Scope}

The purpose of this test is to evaluate the ease of removal of chars or stains caused by lighted cigarettes that are left in contact with a flat surface of a, sanitary fixture.

\section{b. Recommended Test Method}

\section{(1) Test Procedure}

Maintain the temperature of the testing laboratory at $75 \pm 5^{\circ} \mathrm{F}$. Store the fixture in the laboratory at least 4 hours prior to testing to permit it to reach temperature equilibrium.

Select any three contemporary but popular brands of cigarettes and designate them Brands $\mathrm{A}, \mathrm{B}$, and $\mathrm{C}$, respectively. Remove three cigarettes from a freshly opened package of Brand A, light each one, and immediately after lighting, place each burning cigarette on any flat horizontal surface of the fixture, with the burning end in contact with the surface and not less than $1 / 4$ in from a fixture edge. If the fixture has no suitable flat, horizontal areas, the fixture may be tilted so that a flat area will be horizontal, or alternatively, flat specimens may be cut from the fixture.

Separate the burning ends of the cigarettes during test by a distance of at least 6 inches. After 2 $\min ( \pm 2 \mathrm{sec}$ ), remove each cigarette from the fixture and allow the tested area to cool to room temperature. Repeat the same operations and procedures with three cigarettes of Brand B, placing each one on an area of the fixture adjacent to the earlier test areas. Finally, repeat the same operations and procedures with cigarettes of Brand C.

After all test areas have cooled to room temperature, assign a burn rating to each test area on the basis of the rating method shown in table 2.19-1.

To evaluate burn ratings of $80^{\circ}$ and lower, use a $1 / 4$-in wide strip of 220 -mesh abrasive paper $(6 / 0)$ fastened to a rigid backing strip to abrade away the coating at the test areas until a depth is reached where no more than a faint trace of discoloration remains. Measure thickness of coating removed with a depth gage that can be read to 0.2 mils $(0.0002$ in). Record these readings and, in addition, on any three of the test spots, continue to abrade the coating until the substrate becomes visible. Measure these depths and designate the average as the coating thickness. Compute for each spot the percent of the coating thickness that must be removed to a point where only a faint trace of the discoloration remains.

After burn-resistance ratings have been assigned to each test area in accordance with the rating method, add all of the nine burn-resistance ratings and divide the sum by nine to obtain the burnresistance rating of the fixture. 


\begin{tabular}{|c|c|}
\hline $\begin{array}{l}\text { Cigarette- } \\
\text { burn rating }\end{array}$ & Criteria \\
\hline $\begin{array}{r}100 \\
90 \\
80 \\
70 \\
60 \\
50 \\
40 \\
30 \\
20 \\
10 \\
0\end{array}$ & $\begin{array}{l}\text { Stain removable by dryrubbing with a soit cotton cloth. } \\
\text { Stain removable by wet rubbing with a soft cotton cloth. } \\
\text { Stain removable by any scouring treatment that does not measurably decrease the coating thickness. } \\
\text { Stain eliminated by removal of not more than } 10 \text { percent of coating thickness. } \\
\text { Stain eliminated by removal of not more than } 20 \text { percent of coating thickness. } \\
\text { Stain eliminated by removal of not more than } 30 \text { percent of coating thickness. } \\
\text { Stain eliminated by removal of not more than } 40 \text { percent of coating thickness. } \\
\text { Stain eliminated by removal of not more than } 50 \text { percent of coating thickness. } \\
\text { Stain eliminated by removal of not more than } 60 \text { percent of coating thickness. } \\
\text { Stain climinated by removal of not more than } 70 \text { percent of coating thickness. } \\
\text { Stain not eliminated by removal of } 70 \text { percent of thickness. }\end{array}$ \\
\hline
\end{tabular}

s For molded fixtures with no coating, burn ratings of 70 and lower are based on measured char depths only. If, for these fixtures, the stain is eliminated by removal of not more than 2 mils of material from the surface, the burn re sistance is 70 ; by not more than 4 mils, 60 ; by not more than 6 mils, 50 ; by not

\section{(2) Information to be Reported}

Inchnde the following in the test report:

1. The three brands of cigarettes that were selected for testing;

2. Total thickness of coating;

3. Depth of coating removed at each test spot and average of the three depth measurements for each of three cigarette brands. Do not identify test data with cigarette brand names.

4. The assigned cigarette-burn-resistance rating for the fixture.

\section{c. Test Results and Discussion}

\section{(1) Discussion of Existing Methods}

A search of the literature disclosed only one test method for cigarette-burn resistance. This appeared as one part of ASTM D 1300-53T [11].

This particnlar test uses a calibrated automobile cigarette lighter with a controlled wattage input placed $0.313 \pm 0.003$ in from the surface of the specimen. Heating of the surface is by radiation. Failure is defined as evidence of blistering, permanent discoloration, or charring after $110 \mathrm{sec}$ of exposure for the standard grade of material and $10 \mathrm{~min}$ for the cigarette-proof grade.

\section{(\&) Test Development}

Consideration of the aforementioned ASTM test procedure indicated that (a) it might be unnecessarily complex and involved as a test for sanitary ware, and (b) the small cigarette-lighter source might not simulate an actual burning cigarette since the heating of the test surface is almost entirely by radiation, whereas, when a lighted cigarette is placed on a surface, some of the heating is by conduction. As a result of these considerations the development of a new cigarette-burn test was initiated which led to the recommended test method described in paragraph $2.19(\mathrm{~b})$.

\section{(a) Effect of time of contact}

Figure 2.19-1 shows the results of a series of tests made on one FRPE specimen with a gelcoat thickness of 22 mils. It can be seen that char more than 8 mils, 40 ; by not more than 10 mils, 30 ; by not more than 12 mils 20 ; and by not more than 14 mils, 10 . If the stain is not eliminated by removal of 14 mils from the surface, the burn rating is zero.

depth goes up rapidly with the time of contact. Partly on the basis of these results, but mostly from considerations of the average time of contact that might be expected in service, a contact time of 2 min was proposed for the standard condition.

\section{(b) Effect of cigarette brand}

Four cigarette brands were tested on the same specimen. The results are summarized in table $2.19-2$.

The differences in the char-depth averages for the various brands are not statistically significant at the 0.05 -probability level except for Brand D, which gave significantly lower char-depth than Brand $\mathrm{A}$ and Brand $\mathrm{C}$. The burn-test rating of the specimen for all four brands, however, was 60 .

\section{(c) Burn ratings of porcelain enamels and vitreous china}

Burn ratings of both porcelain on steel and cast iron, and of the glaze on vitreous china were 100 when measured according to the system outlined in the table. This rating might drop for abraded surface since condensed tars would undoubtedly be more difficult to remove from the roughened finishes.

\section{(d) Effect of gel-coat thickness}

Although not studied systematically, there was some evidence that char-depth increases with gelcoat thickness. A char-depth of 4.6 mils was measured with Brand A cigarettes for a 22 -mil thick gel-coat as against a char-depth of 1.9 mils for what was presumably the same gel-coat with a thickness of 10.2 mils. The burn-resistance ratings of the two specimens would, according to table $2.19-1$, be 50 and 60 , respectively.

\section{(e) Comparison of char-depths determined by two operators}

Two different operators evaluated the burn resistance of a 4 - by 4 -in FRPE specimen with a 10-mil thick gel-coat. Brand A cigarettes were used. The results follow : 


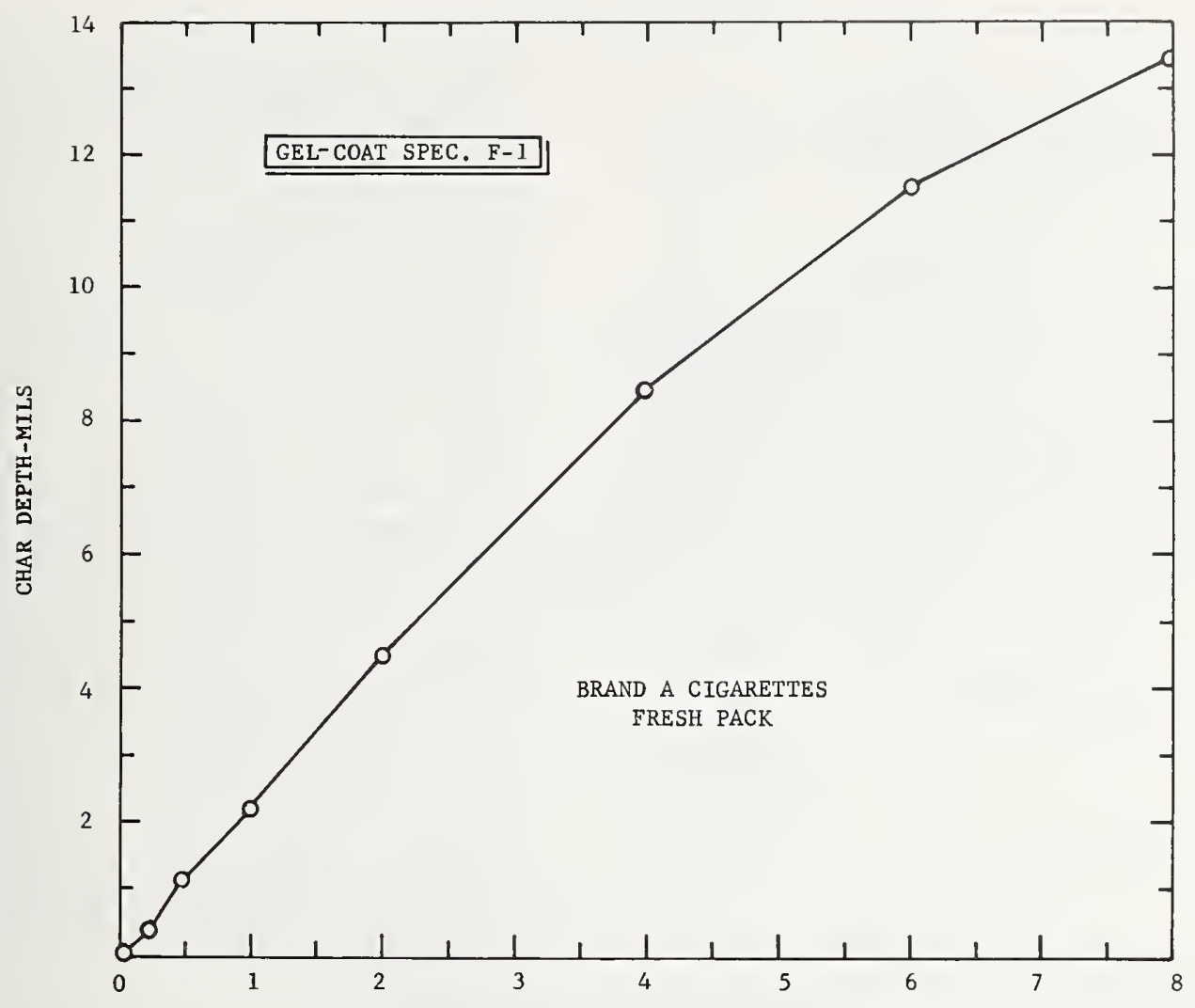

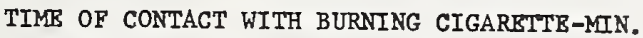

FIgURE 2.19-1. Char depths for a 22-mil polyester gel coat on a 0.10-in FRPE backing.

Char Depth in Mils

\begin{tabular}{c|c|c}
\hline Spot No. & $\begin{array}{c}\text { Operator } \\
\text { No. } 1\end{array}$ & $\begin{array}{c}\text { Operator } \\
\text { No. 2 }\end{array}$ \\
\cline { 2 - 3 } & 2.6 & 1.8 \\
& 2.2 & 2.0 \\
\hline & 1.5 & 2.0 \\
\hline & 1.8 & 2.2 \\
Avg & 1.8 & 1.4 \\
S.D. & 1.9 & 2.0 \\
\hline
\end{tabular}

There is not significant difference between the two averages at the 0.05 -probability level.

(f) Burn resistance ratings for specimens of Formica and Lucite

A small specimen of laminated thermoplastic sheet (Formica-mottled grey) was tested with Brand A cigarettes. The coating thickness was 10.7 mils while the backing sheet was 0.050 in thick. No metal foil was laminated into the structure. No charring was observed at any of the three test areas. The condensed tars present at each area were removable by dry rubbing; hence, the cigaretteburn-resistance rating for this particular Formica specimen was 100.

The average char depth on a $3 / 8$-in-thick specimen of clear Lucite was measured as 2.1 mils. Since no coating was present, the burn-resistance rating was determined as specified in the footnote of table 2.19-1. The burn-resistance rating was 60 for this particular specimen.

TABLE 2.19-2. Summary of cigarette burns tests on two FRPE specimens with polyester gel coats

\begin{tabular}{|c|c|c|c|c|c|c|c|}
\hline $\begin{array}{c}\text { Specimen } \\
\text { No. }\end{array}$ & $\begin{array}{c}\text { Coating } \\
\text { thick- } \\
\text { ness }\end{array}$ & $\begin{array}{l}\text { Ciga- } \\
\text { rette } \\
\text { brand }\end{array}$ & $\begin{array}{l}\text { Test } \\
\text { oper- } \\
\text { ator }\end{array}$ & $\begin{array}{l}\text { No. of } \\
\text { tests }\end{array}$ & $\begin{array}{l}\text { A verage } \\
\text { char } \\
\text { depth }\end{array}$ & $\begin{array}{l}\text { Stand- } \\
\text { ard } \\
\text { devia- } \\
\text { tion }\end{array}$ & $\begin{array}{l}\text { Ciga- } \\
\text { rette- } \\
\text { burn } \\
\text { rating }\end{array}$ \\
\hline $\begin{array}{l}\text { PA-1 b } \\
\text { PA-1 } \\
\text { PA-1 }\end{array}$ & $\begin{array}{c}\text { mils } \\
10.2 \\
10.2 \\
10.2\end{array}$ & $\begin{array}{l}\text { letter } \\
\text { A } \\
\text { A } \\
\text { B }\end{array}$ & $\begin{array}{l}1 \\
2 \\
1\end{array}$ & $\begin{array}{l}6 \\
6 \\
6\end{array}$ & $\begin{array}{c}\text { mils } \\
1.97 \\
1.90 \\
1.72\end{array}$ & $\begin{array}{r}0.35 \\
.25 \\
.22\end{array}$ & $\begin{array}{l}60 \\
60 \\
60\end{array}$ \\
\hline $\begin{array}{l}\text { PA-2 } \\
\text { PA-2 } \\
\text { PA-2 }\end{array}$ & $\begin{array}{l}10 \\
10 \\
10\end{array}$ & $\begin{array}{l}\mathrm{A} \\
\mathrm{C} \\
\mathrm{D}\end{array}$ & $\begin{array}{l}2 \\
2 \\
2\end{array}$ & $\begin{array}{l}6 \\
6 \\
6\end{array}$ & $\begin{array}{l}1.90 \\
1.90 \\
1.63\end{array}$ & $\begin{array}{l}.10 \\
.10 \\
.31\end{array}$ & $\begin{array}{l}60 \\
60 \\
60\end{array}$ \\
\hline
\end{tabular}

a See table 2.19-1 for procedure used to assign rating.

b Thickness of fiber-glass-resin backing, 0.14 in.

c Thickness of fiber-glass-resin backing, $0.11 \mathrm{in}$. 
(g) Burn-resistance ratings of FRPE fixtures

The burn-resistance ratings were obtained on two FRPE bathtubs. No difficulties were encountered in performing the tests. Both units gave a burn-resistance rating of 70 .

\section{(3) Rational for Test Selection}

Admittedly, the proposed test tends to be somewhat qualitative, especially with respect to the end point, which depends both on the judgment and visual acuity of the observer. However, since nine burned areas are evaluated, and since char depths obtained over a relatively wide range of percentage loss in thickness yield the same burn-resistance rating, high scatter in results among the observers would not be expected. One desirable feature of the test is that it exactly simulates the service exposure involved in this performance characteristic.

\section{d. Comments on Performance Requirements}

\section{(1) Suggested Format for a Performance Level}

The burn-resistance rating of the fixture shall be not less than —_ when measured as prescribed in paragraph $2.19(\mathrm{~b})$.

\section{(2) Rationale for Suggested Format}

Lighted cigarettes are occasionally placed on the flat ledges of bathtubs. The field survey made near the beginning of the project showed that burns from this practice were not uncommon on bath= tubs with organic finishes. At the same time, however, it was found that once a burn had occurred, a polyester gel-coat could be restored to almost its original appearance without the need for an expensive or complex repair operation or of the removal of an excessive amount of coating material. Other future organic finishes might not have this property. Therefore, it would seem desirable to require that the cigarette-burn resistance be approximately as great as the currently produced polyester gel-coat. A burn-resisting rating of not less than 50 would accomplish this purpose.

\subsection{Radiant-Heater Resistance (T303A)}

\section{a. Purpose and Scope}

The purpose of this test is to evaluate the resistance of a sanitary plumbing fixture to permanent damage caused by a radiant heater placed near the fixture.

\section{b. Recommended Test Method}

\section{(1) Apparatus}

Radiant Heater. The radiant heater to be used shall be a 650 -watt 120 -volt heater. The heating element shall be a wire-wound annulus of conical shape that operates in an air atmosphere. A 10-in bright metal parabolic mirror placed behind the heating element collimates the radiant flux. The front safety grill of the heater shall be removed prior to testing. Also, the heater shall be operated at the same voltage to \pm 2 volts for all tests described herein. In addition, the reflector shall be cleaned of accumulated dust and dirt prior to each use. The heater used in the present test was a Sears Roebuck Model 135. 71600.

Black-Panel Radiometer. A black-panel radiometer is required. This shall be constructed as specified in figure 2.20-1 (Part A). A null-type potentiometer (or a millivoltmeter) readable to $0.1 \mathrm{mV}$ is required to measure the response of the radiometer thermocouple.

Figure 2.20-1 specifies that a flat black paint shall be applied at a thickness of 0.002 in to the sensing area of the radiometer probe. This paint film may blister if the temperature of the probe is raised too rapidly during the first heat-up. Therefore, the paint film shall be cured prior to the test by moving the probe very slowly toward the radiant heater until a probe temperature of $250^{\circ} \mathrm{F}$ is indicated. The probe shall then be maintained at this temperature for $15 \mathrm{~min}$ to complete the curing, after which the painted surface shall be inspected for the presence of blisters. If blisters are present, the probe shall be repainted, and the paint film cured with a slower heating cycle. In no case shall the probe be used for the testing described herein unless the paint film is completely free of blisters.

The paint used as the probe coating shall be $3 \mathbf{M}$ Brand Black Velvet Coating (101-C10 Black), or equivalent. This is available in 6-oz spray cans from the Reflective Products Division, $3 \mathbf{M}$ Co., St. Paul, Minn. The required 0.002 in thickness is achieved with this paint by spraying as two coats but without permitting complete drying between the two applications. Film thickness can be determined by micrometer measurements before and after application.

\section{(2) Test Procedure}

A. Calibration of Radiant-Heater Response with Black-Panel Radiometer: Mount the heater and radiometer on a flat, horizontal surface using an arrangement such as that suggested in figure 2.20-1 (Part B). Then, with the temperature in the test room at $75 \pm 3^{\circ} \mathrm{F}$, place the probe at a distance of 27 in from the face of the heater. Position the probe with the painted surface facing the heater and also, with the center of the probe at the same height as the center of the reflector, and, in addition, center the probe with respect to the horizontal axis of the heater.

After positioning the heater, turn on the heating element and, after 5 min, measure the millivolt response from the probe thermocouple. Then, without turning off the heater, move the probe $1 / 2$ in in a lateral direction and after $2 \mathrm{~min}$, again measure the millivolt response. Repeat this operation moving the probe $1 / 2$ in in a lateral direction after each measurement until a position is reached 


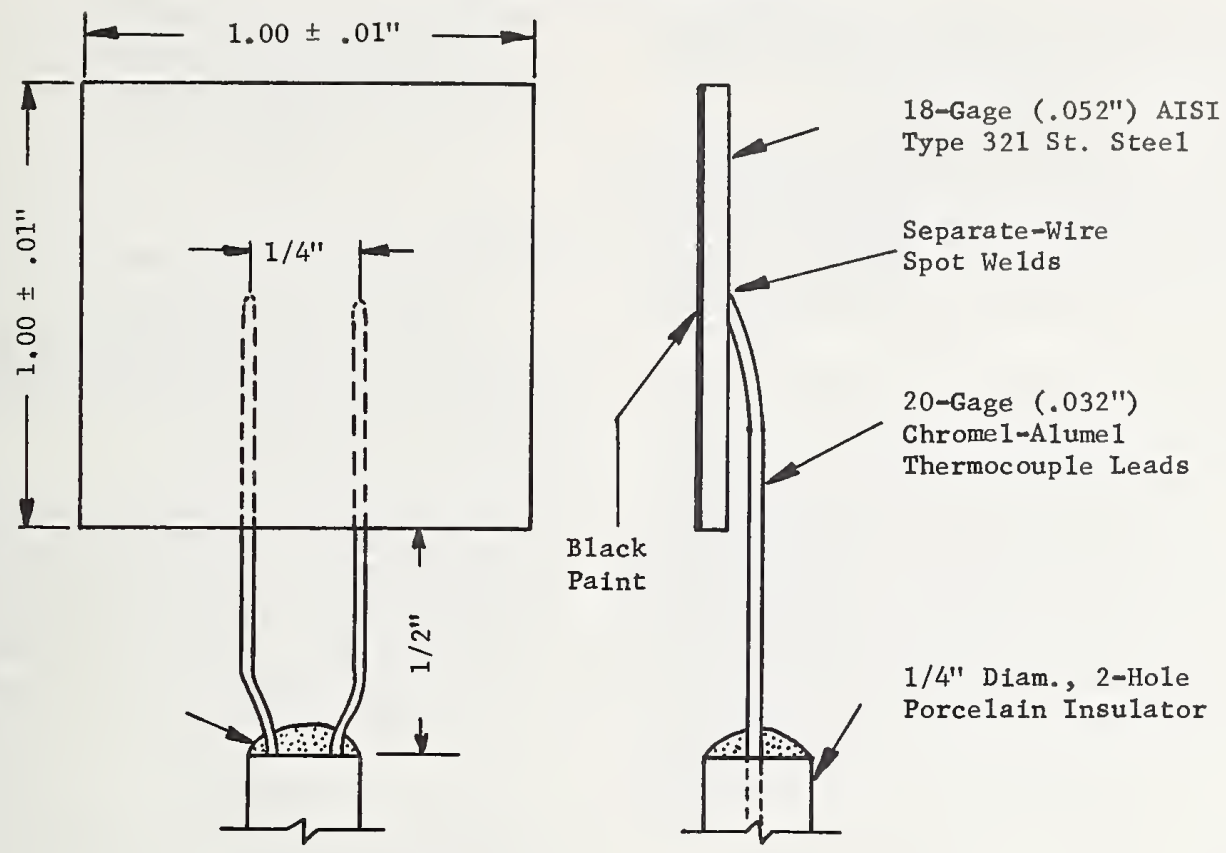

Note: Black paint to be sprayed to a thickness of 0.002". Abrade surface with $400 \mathrm{C}$ silicon carbide paper prior to spraying.

(B) SUGGESTED TEST ARRANGEMENT

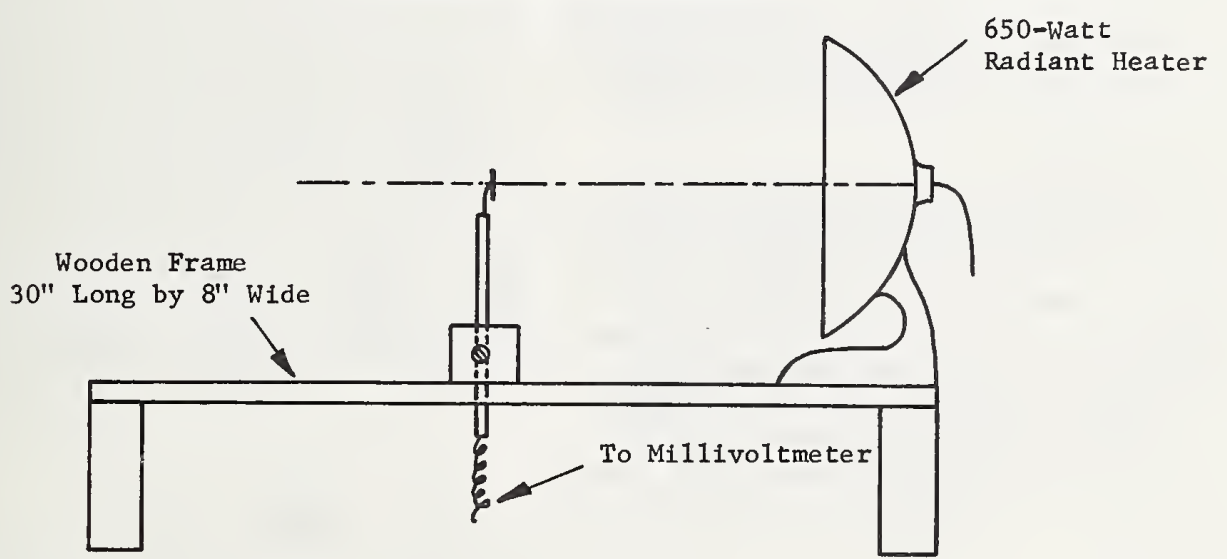

FIGURE 2.20-1. Black-panel radiometer probe and suggested arrangement for calibration of radiant heater.

that is approximately coincident with the outer rim of the reflector on the heater. Take the maximum reading obtained during this lateral scan as the millivolt response of the radiometer at the 27 -in distance.

Next, repeat the procedures outlined in the preceding paragraph with the probe placed $24,21,18$, $15,12,9$, and 6 in from the heater face, being certain in each case that the probe face is parallel to the front edge of the reflector on the heater.
After completing these measurements, convert the maximum millivolt readings obtained at each distance to temperature in ${ }^{\circ} \mathrm{F}$ using the standard conversion tables for Chromel-Alumel thermocouples given in ASTM Procedure: E230-63. In effect, these temperatures at each distance represent a maximum flux density calibration for the radiant heater.

Note: These maximum temperatures are referred to later as equivalent black-panel radiometer temperatures. 
B. Testing of Fixture: Place the fixture to be tested in its normal use position permitting it to rest freely on a horizontal heat-resistant surface. Use no closures at the fixture ends.

Next, select a vertical area near the center of the fixture that might be exposed in service to the flux from a portable radiant heater. For a bathtub with a front apron, select the test area near the center of the apron while for other fixtures, such as a shower stall, select any outer vertical surface as the test area.

Note: On fixtures other than bathtubs, only a part of the collimated flux may strike the test area.

Maintain the temperature of the testing laboratory at $75 \pm 5^{\circ} \mathrm{F}$. Store the fixture in the laboratory for at least four hours prior to testing to permit it to reach temperature equilibrium. As soon as this equilibrium has been established, position the reflector of the heater so that the front edge of the reflector is parallel to the test area and at a distance of 27 in from the fixture when measured from the outer rim of the reflector to the area to be tested. Also, adjust the height of the heater so that the collimated flux strikes approximately midway between the top and bottom of the test area.

After completing this positioning, turn on heater and expose the test area for $15 \pm 1 / 4 \mathrm{~min}$ to the radiant flux.

NoTE: Start timing when the heater is turned on rather than when it reaches its operating temperature. If no damage to the fixture is observed when examined within 2 min after turning off the heater, move the heater 3 in closer to the test area (24-in distance) and repeat all operations specified above.

NoTE: For the purposes of this test, damage consists of any cracking, blistering, and discoloration of the test surface as well as any distortion or buckling of the fixture.

Next, continue the testing by moving the heater three inches closer to the test area after each 15-min exposure period until a distance is reached where the 15 -min treatment causes some observable damage to the fixture. The radiant-heater resistance rating of the fixture is then taken as the equivalent black-panel radiometer temperature for this distance.

Note: If no damage occurs at the six-inch distance, the radiant heater resistance rating is reported as greater than the equivalent radiometer temperature at six inches. Likewise, if damage is observed at the 27-in distance, the resistance rating reported is less than the equivalent radiometer temperature at 27 in.

\section{(3) Information to be Reported}

Include the following in the test report :

1. Type of radiant heater, including manufacturer's name and number;

2. Type and thickness of paint used on blackpanel radiometer probe;

3. Type of instrument used for measuring millivolt response of probe thermocouple;
4. Distance between heater and fixture at which first damage was observed;

5. Type of damage, if any, that resulted from the radiant-heater treatment;

6. Radiant-heater-resistance rating of fixture.

\section{c. Test Results and Discussion}

\section{(1) Discussion of Existing Methods}

A search of the test literature failed to reveal any earlier tests for the resistance of a fixture material to damage from radiant heaters.

\section{(2) Test Development}

The first tests were made with 4 - $\times 4$-in specimens of FRPE mounted, face forward, in a small backing enclosure of $1 / 4$-in plywood. A small wire thermocouple was cemented into a hole drilled from the back of the specimen to the gel-coat interface. The hot junction was positioned so as to be touching the gel-coat. Indicated temperatures were recorded as the specimens were moved inward toward two types of radiant heaters. Results obtained with two FRPE specimens for this type of testing are shown in figure 2.20-2. The only permanent damage observed in these tests was a discoloration (yellowing) of the specimen after exposure at 6 inches to the $650-W$ heater.

Because of difficulties involved in standardizing the treatment described above, and also because thermal stresses encountered in a fixture would not be duplicated in a 4 - $\times 4$-in specimen, further work on this method was terminated. Instead, emphasis was placed on the exposure of actual fixtures to the radiant flux from a commercial heater. However, since no two heaters could be depended upon to give the same radiant flux per unit area at the same distance from the heater, it was necessary to devise a simple method of calibration. The method devised is described in section $2.20(\mathrm{~b})$. Although a more sophisticated calibra-

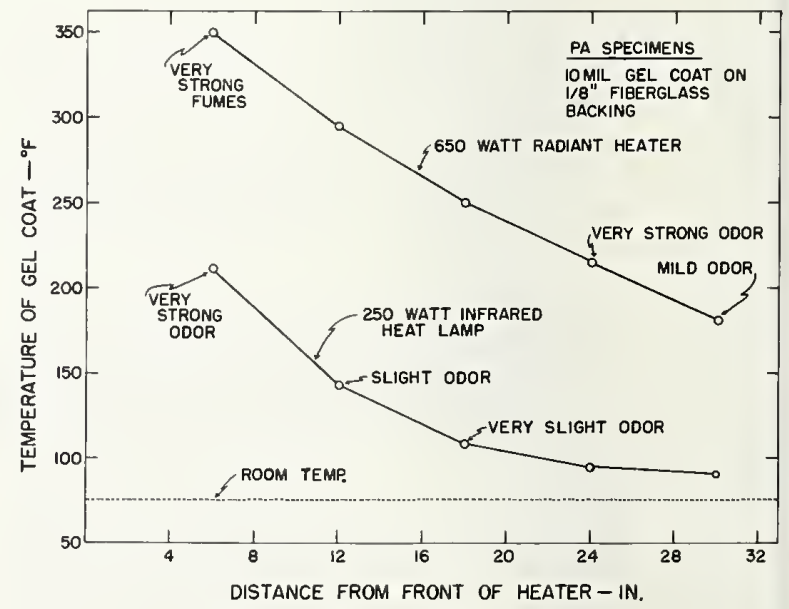

FIGURE 2.20-2. Results of preliminary radiant-heater tests with 4-in square specimens. 
tion approach might have been used that would involve, among other things, expensive calibrated radiometers with infrared windows, such an approach was not believed justified for the radiantheater tost. Results of measurements made with three different probes are given in table 2.20-1. It wili be noted that the three probes are in reasonably goo A agreement. The maximum difference between piobes was $13^{\circ} \mathbf{F}$. This occurred at the closest distance of approach to the heater.

Table 2.20-z lists the results of radiant-heater tests made on four FRPE bathtubs. Position No. 1 is the test area specified for bathtubs in section 2.20(b)2. Of the three tubs that could be tested in this area (PB-2, PB-4 and PD-1), two had radiant-heater-resistance ratings of greater than $215^{\circ} \mathrm{F}$ while one (PB-2) showed a blister at 18 in (203 ${ }^{\circ} \mathrm{F}$ rating). This blister almost completely receded on cooling. Nevertheless, the bond between coating and substrate had been ruptured by the treatment and this could easily lead to later deterioration.

\section{(3) Rationale for Test Selection}

Numerous alternative approaches might be used to evaluate the radiant-heater resistance of a fixture. One might be to place a specimen cut from

TABLE 2.20-1. Results with three black-panel radiometer probes prepared in accordance with section $2.20 b(1)$.

\begin{tabular}{|c|c|c|c|c|}
\hline \multirow{2}{*}{ Distance from Heater a } & \multicolumn{4}{|c|}{ Maximum Radiometer-Probe Temperature } \\
\hline & $\begin{array}{l}\text { Probe } \\
\text { No. } 1\end{array}$ & $\begin{array}{l}\text { Probe } \\
\text { No. } 2\end{array}$ & $\begin{array}{l}\text { Probe } \\
\text { No. } 3\end{array}$ & Average \\
\hline $\begin{array}{c}\text { in } \\
27 \\
218 \\
15 \\
12\end{array}$ & $\begin{array}{r}\circ F \\
156 \\
169 \\
195 \\
208 \\
221 \\
230 \\
243 \\
278\end{array}$ & $\begin{array}{l}\circ F \\
156 \\
173 \\
186 \\
203 \\
212 \\
225 \\
238 \\
265\end{array}$ & $\begin{array}{r}\circ F \\
160 \\
173 \\
186 \\
199 \\
214 \\
230 \\
247 \\
278\end{array}$ & $\begin{array}{ll}\circ F & \\
157 \\
172 \\
189 \\
203 \\
216 \\
228 \\
243 \\
274\end{array}$ \\
\hline
\end{tabular}

a Sears Model 135.71600,650-W heater. the fixture into an oven and determine the temperature at which deterioration was first observed. Such a method would not be simulative, however, since when a fixture is exposed to the flux from a radiant heater, heating is from one side only. Also, the temperature reached by a given material during radiant heating is strongly dependent on its infrared absorptance and emittance while in an oven all specimens will reach the same temperature irrespective of the thermal radiation properties of the surface layer.

The particular test recommended is believed to closely simulate the conditions that exist when a portable radiant heater is placed on the floor of a bathroom in such position that it faces a bathtub. Exposure for $15 \mathrm{~min}$ seems a reasonable time, although longer times might have been specified. Built-in panel heaters (either gas or electric) might operate almost continuously in a bathroom during cold weather. Heaters of this type, however, are normally positioned further from the fixture and hence the flux per unit area falling on the fixture would not reach the high values encountered with the portable heaters.

\section{d. Discussion of Performance Requirements}

\section{(1) Suggested Format for a Performance Level}

The radiant-heater resistance rating of the fixture shall be not less than ___ when measured by the methods and procedures specified in section 2.20(b). This rating is the equivalent black-panel radiometer temperature for the heater distance at which first damage to the fixture is observed.

\section{(2) Rationale for a Suggested Format}

In attempting to arrive at an equivalent blackpanel radiometer temperature for a performance level, one might consider a value of $215^{\circ} \mathrm{F}$. This represents the condition that exists when a typical portable heater with a power of $650 \mathrm{~W}$ is placed approximately 15 in from an exposed area of the fixture. This distance appears to be a reasonable

TABLE 2.20-2. Results of radiant-heater tests on FRPE bathtubs

\begin{tabular}{|c|c|c|c|c|}
\hline Tub No. & $\begin{array}{l}\text { Location } \\
\text { of test } \\
\text { area a }\end{array}$ & $\begin{array}{l}\text { Damage } \\
\text { distance } b\end{array}$ & Description of damage & $\begin{array}{l}\text { Rad.-heater } \\
\text { resistance } \\
\text { rating }\end{array}$ \\
\hline PB-2 - . & $\begin{array}{l}1 \\
2 \\
3\end{array}$ & $\begin{array}{ll}\text { in } & \\
& 18 \\
& 12 \\
& 12\end{array}$ & $\begin{array}{l}\text { One blister, } 21 / 2 \text { in. diameter } \\
\text { Slight discoloration } \\
\text { Slight discoloration. }\end{array}$ & $\begin{array}{ll}{ }^{\circ} F & \\
& 203 \\
228 \\
\\
228\end{array}$ \\
\hline PB-4 $\ldots$ & $\begin{array}{l}1 \\
2 \\
3\end{array}$ & $\begin{array}{l}12 \\
15 \\
18\end{array}$ & $\begin{array}{l}\text { Slight discoloration } \\
\text { Blister, } 21 / 4 \text { in. diameter } \\
\text { Blister, } 21 \% 2 \text { in. maximum dimension }\end{array}$ & $\begin{array}{l}228 \\
216 \\
203\end{array}$ \\
\hline $\mathrm{PC}-1 \mathrm{c}$. & $\begin{array}{l}2 \\
3\end{array}$ & $\begin{array}{l}6 \\
6\end{array}$ & $\begin{array}{l}\text { Slight discoloration } \\
\text { Slight discoloration }\end{array}$ & $\begin{array}{l}274 \\
274\end{array}$ \\
\hline PD-1 ... & $\begin{array}{l}1 \\
2 \\
3\end{array}$ & $\begin{array}{r}12 \\
6 \\
6\end{array}$ & 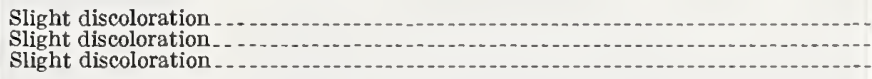 & $\begin{array}{l}228 \\
274 \\
274\end{array}$ \\
\hline
\end{tabular}

a No. 1-on apron midway between ends of tub. No. $2-$ on apron near drain end.

No. 3-on apron at end opposite drain. $\mathrm{b}$ Measured from front rim of reflector on heater to tub apron. - Test made on fixture that had been cut in half for other testing. 
one since, if the heater was placed closer than about 15 in to one of the current FRPE fixtures, a person in the bathroom would be forewarned of impending damage to the fixture by a rather strong odor of styrene.

Long-time effects from radiant heat at lower flux densities than that represented by a $650-\mathrm{W}$ heater at 15 in were not investigated because of time limitations. However, it seems unlikely that any damage from this type of treatment would be of especially serious nature.

The 15-min time period specified in section $2.20 \mathrm{~b}(2) \mathrm{B}$ is admittedly arbitrary. It was selected as being reasonably representative of the time that a portable heater might be left on in a bathroom.

\subsection{Resistance to Thermal Shock (T304)}

\section{a. Purpose and Scope}

The purpose of a thermal-shock performance test for a sanitary plumbing fixture is to evaluate the ability of the fixture to withstand (1) intermittent exposure of the finished surface to hot water, and (2) alternate exposure to hot and cold water, without exhibiting surface damage. Some degree of thermal-shock resistance is desirable in all sanitary plumbing fixtures. The need is probably least for water closets and urinals, since typical service exposure for these fixtures involves cold water at temperatures not far below normal room temperatures. The limited amount of work reported here was carried out only on a bathtub.

\section{b. Selection of a Test Method}

An apparatus was assembled for exposing a bathtub to repetitive cycles of thermal shock. This apparatus was tried out on one specimen of an enameled-steel tub. This apparatus would probably be suitable for use in thermal-shock tests with some further development and refinement, as described in paragraph 2.21e. No test method is recommended at this time, because (1) the existing published test methods reviewed impose conditions of exposure unrepresentative of service, (2) no correlation appears to have been established in the existing tests between number-of-cycles-tofailure and temperature, and (3) the limitations of the present investigation did not permit complete development of an adequate test.

A recommended test method should be relatively simple, and should effectively simulate the conditions imposed in service. Correlation between the effects produced in the test and the effects from service exposure would be needed.

\section{c. Performance Requirements}

Performance requirements cannot be stated precisely because more work is required on test development and more data are required on performance. However, it can be stated that a plumb- ing fixture should be capable of a reasonable period of service exposure, without exhibiting surface damage that can be detected by the inspection procedure described in section 2.8 .

\section{d. Test Results and Discussion}

\section{(1) Discussion of Existing Methods}

A few tests involving thermal shock have been developed by other groups for use with vitreouschina and vitreous-glazed earthenware plumbing fixtures. The degree of correlation between the results obtained from these test procedures and from actual service exposure is unknown.

Among the tests referred to in existing plumbing fixture standards are the following:

1. Autoclave Test for Crazing of Vitreous Glazed Earthenware, Par. 11, CS 111-43 [7].

Flat pieces broken from a fixture (approx. 16 $i^{2}$ area on one side) are subjected to 75 -psi steam pressure in an autoclave for one hour, after which the pressure is released and the specimens are allowed to cool to room temperature in the autoclave. The specimens are then examined for cracking or crazing after applying a dye solution to the finished surface. Cracking or crazing after being subjected to four cycles of this treatment indicates failure.

2. Thermal Shock Test for Vitreous Glazed Earthenware, Par. 12, CS 111-43 [7].

A complete fixture is filled with boiling water which is maintained at the boiling point until the material is heated throughout, followed by rapid emptying and immediate refilling with ice water at a temperature of $38^{\circ} \mathrm{F}$. The ice water is maintained at $38^{\circ} \mathrm{F}$ by addition of ice until the fixture material is thoroughly cooled, after which the fixture is quickly emptied and the cycle repeated. Visible injury of the specimens upon exposure to 25 cycles of this treatment indicates failure.

3. Crazing Test for Vitreous China, Par. 6.4 of CS 20-63 [6] and Par. 10.11.4 of FS WW-P$541 \mathrm{~b}(4), 1962$ [3].

Test specimen 4 to $5 \mathrm{in}^{2}$ is suspended in a solution of anhydrous calcium chloride and water (equal portions by weight) and boiled for $11 / 2 \mathrm{hr}$. Then the specimen is removed and immediately plunged into an ice-water bath and allowed to cool. Following this, the specimen is soaked for $12 \mathrm{hr}$ in a concentrated solution of methylene-blue dye, and finally examined for craze lines. Visible evidence of crazing after this treatment indicates failure.

\section{(2) Test Development}

Apparatus was constructed and tried out which subjected the inside surface of a bathtub to thermal shock with a differential in water temperature approximating $160^{\circ} \mathrm{F}$. Figure $2.21-1$ is a schematic representation of the apparatus. The bathtub was filled with hot or cold water to the overflow outlet in about three minutes, and emptied in about four 


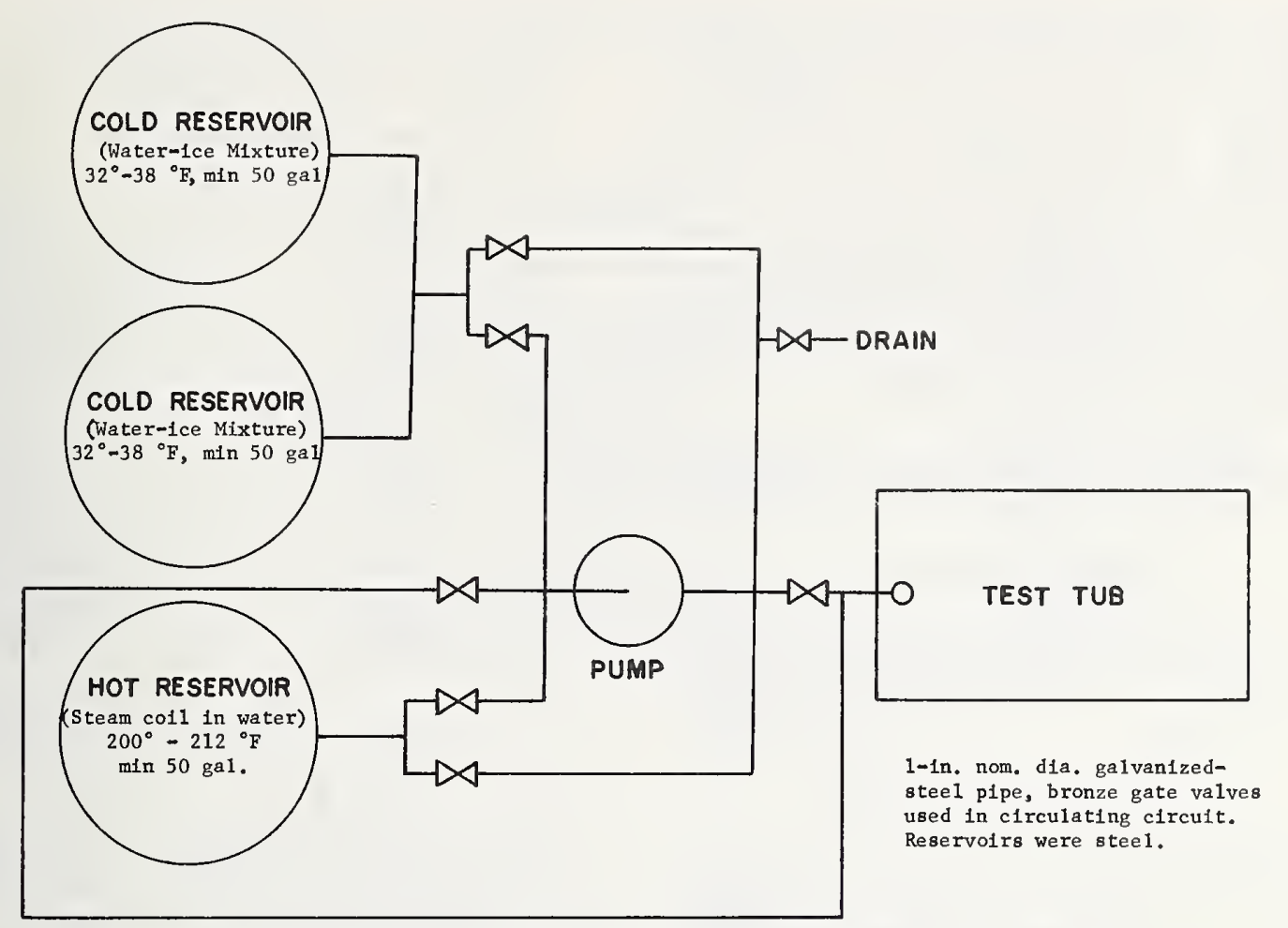

Heating element in hot-water reservoir capable of reheating water withdrawn from tub to boiling point in less than $20 \mathrm{~min}$. Two cold-water reservoirs were necessary to provide a supply of ice water every 20 min.

FIGURe 2.21-1. Schematic of thermal-shock test apparatus for complete bathtub.

minutes. A boiling-water reservoir with steam heating was provided, as well as an ice-water reservoir using ice cubes for coooling. A circulating pump and a pipe network with necessary valves provided the means for introducing and removing water from the fixture. A multi-channel temperature recorder provided a continuous record of the temperature of the water at the entrance to the tub, in the central area of the tub, and of the outside surface of the lower portion of the fixture at four points.

Based on trials with a porcelain-enameled steelbathtub, approximately $20 \mathrm{~min}$ per cycle was required to permit the outside surfaces of the sump to attain a maximum or minimum temperature, respectively, in the alternating hot and cold exposures. Cycle frequency was selected on the basis of these temperature measurements. Approximately $40 \mathrm{lb}$ of ice were required per cycle.

Table 2.21-1 summarizes some aspects of the operation of the apparatus shown in figure 2.21-1 in an 18-cycle trial test of a porcelain-enameledsteel tub. A six-channel temperature recorder was employed. Observations made on the porcelainenameled-steel bathtub after a 50-hr continuous boil test and 25 cycles of the thermal-shock test described here showed no surface effects other than a very slight dulling of the finish.

\section{(3) Comments on a Performance Level}

Since the test development was incomplete, no comments regarding a performance level are possible.

\section{b. Recommended Future Test Method}

It is recommended that further work be carried out with apparatus patterned after that shown in figure 2.21-1 with some modifications and refinements, such as automatic flow-control valves, mechanical chilling equipment, corrosion-resistant reservoirs and circulating equipment, and an improved temperature-control system. The criterion and method used for selecting cycle frequency should be considered further. It might be desirable to base this selection on the minimum and maximum temperatures attained within the fixture material rather than on outside surface temperatures.

TABLE 2.21-1. Characteristics of thermal-shock test* in trial run on porcelain-enameled-steel tub

\begin{tabular}{l|l}
\hline \hline Cycle time & $\begin{array}{l}\text { Approximately 20 min. } \\
\text { Approximately 10 min. }\end{array}$ \\
$\begin{array}{c}\text { Cold-to-hot peaks. } \\
\text { Hot-to-cold peaks } \\
\text { Incoming water temperature differ- } \\
\text { ential. }\end{array}$ & $\begin{array}{l}\text { Approximately 10 min. } \\
\text { Approximately } 175^{\circ} \mathrm{F} .\end{array}$ \\
$\begin{array}{c}\text { Water temperature differential in tub } \\
\text { located) }\end{array}$ & Approximately $158^{\circ} \mathrm{F}$. \\
Outside skin temperature differential & Approximately $150-155^{\circ} \mathrm{F}$, \\
depending on location.
\end{tabular}

*See figure 2.21-1.

Tests should be made on a statistically adequate number of specimens of several materials to establish the relation between number-of-cyclesto-failure and temperature differential and/or water temperature. Finally, it would be necessary to determine what constitutes a reasonable set of use conditions as they relate to frequency of 
use and temperature differential or water temperature, so that this set of conditions could bo considered in recommending test procedures. The performance level could then be set from test results on materials with known service performance.

Further development work should be planned with a view to the possible recommendation of an alternate hot-and-cold-water exposure test that could be used to combine the prolonged hot-water exposure test recommended in section 2.18 and the thermal-shock test discussed above.

\subsection{Resistance to Household Chemicals (C501)}

\section{a. Purpose and Scope}

The purpose of this test is to evaluate the resistance of bathroom plumbing fixtures to chemicals with which they are likely to come into contact during normal use.

\section{b. Recommended Test Method}

\section{(1) Equipment}

The test for resistance to household chemicals shall be made using test equipment prepared in accordance with figure 2.22-1.

\section{(2) Chemicals}

The resistance to attack by 20 different chemicals shall be evaluated. The chemicals that shall be used together with their required purity, concentration, and method of preparation are listed in table 2.22-1.

Note: Such items as soap, mineral oil, and pine oil are considered as chemicals for the purpose of this test.

\section{(3) Test Procedure}

Cut five flat 4 -in square specimens from the fixture to be tested and number these specimens from one through five. Clean each specimen with 1 percent by weight tri-sodium phosphate solution and cellulose sponge, rinse thoroughly with water, and dry.

Next, position specimen No. 1 into the testing assembly as illustrated in figure $2.22-1(\mathrm{~F})$. Tighten screws with a firm pressure to prevent leaking. Then, with the cell in a horizontal position, add $0.5 \mathrm{ml}$ of chemical No. 1 to cell No. 1, 0.5 $\mathrm{ml}$ of No. 2 to cell No. $2,0.5 \mathrm{ml}$ of No. 3 to cell No. $3,0.5 \mathrm{ml}$ of No. 4 to cell No. 4 . Use a hypodermic syringe to introduce the chemical into the cell through the needle holes in the Teflon cover sheet (fig. 2.22-1, part C). Insert Teflon plugs into each of the four holes in the top plate (fig. 2.22-1, part A).

After $2 \mathrm{hr} \pm 5 \mathrm{~min}$ at $75 \pm 5^{\circ} \mathrm{F}$, dismantle equipment, remove specimens, and rinse with water. Immediately after drying, inspect test
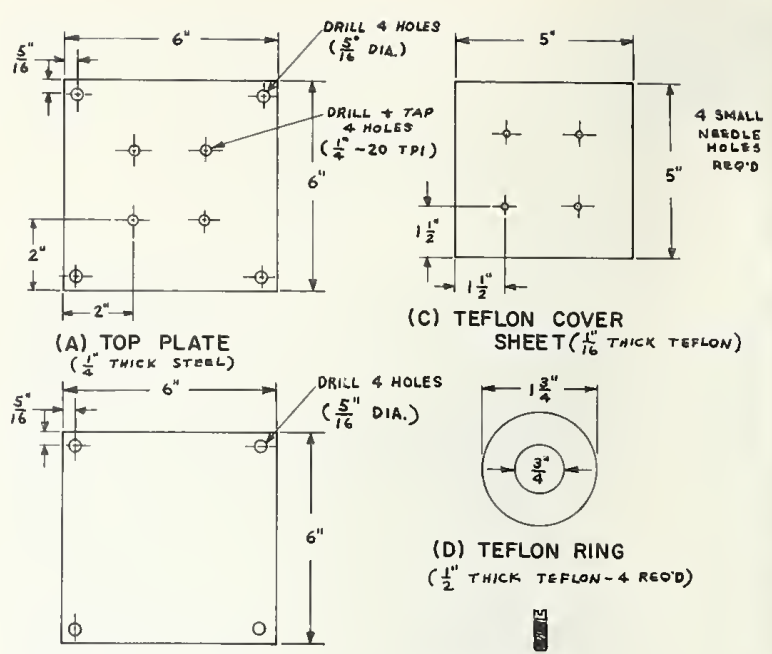

(c) TEFLON COVER SHEET ( $\frac{1 " 16}{16}$ THICX TEFLON)

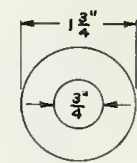

(D) TEFLON RING

( $\frac{1}{2}$ "THICK TEFLON - REOOD)

(B) BOTTOM PLATE

( $\frac{1^{\prime \prime}}{4}$ THICK STEEL)

(E) TEFLON PLUG

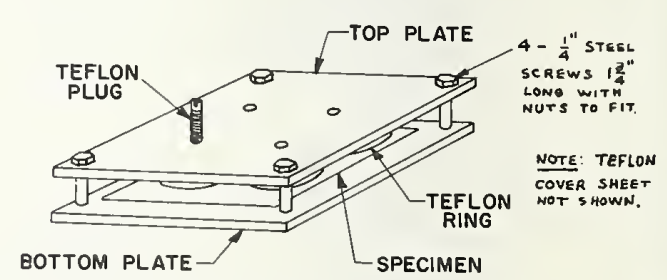

(F) ASSEMBLY

FIgURE 2.22-1. Apparatus for testing resistance to household chemicals.

areas for evidence of attack and assign a chemical-resistance rating to each itest area in accordance with the rating system specified in table 2.22-2.

Next, repeat the same test procedure with specimens No. 2, and chemicals No. 5, 6, 7, and 8. After assigning resistance ratings, follow the same procedure with specimens No. 3, 4, and 5 and thus obtain a resistance rating for all 20 chemicals listed in table 2.22-1. The household chemicals resistance rating for the fixture shali then be the arithmetic average of these 20 individual ratings.

\section{(4) Information to be Reported}

Include the following in the test report:

1. Effect observed for each test area.

2. Household chemicals resistance rating for each of the 20 chemicals.

3. The household chemicals resistance rating for the fixture.

\section{c. Test Results and Discussion}

\section{(1) Discussion of Existing Methods}

Few tests exist for evaluating the resistance of sanitary ware materials to common household chemicals. The commercial standards for porcelain-enameled bathtubs (CS 77-63, cast iron [4]; and CS 144-47, pressed steel [28]) include a requirement for resistance to citric acid, a chemical 
TABLE 2.22-1. Chemicals to be used in household chemicals test and reasons for their selection

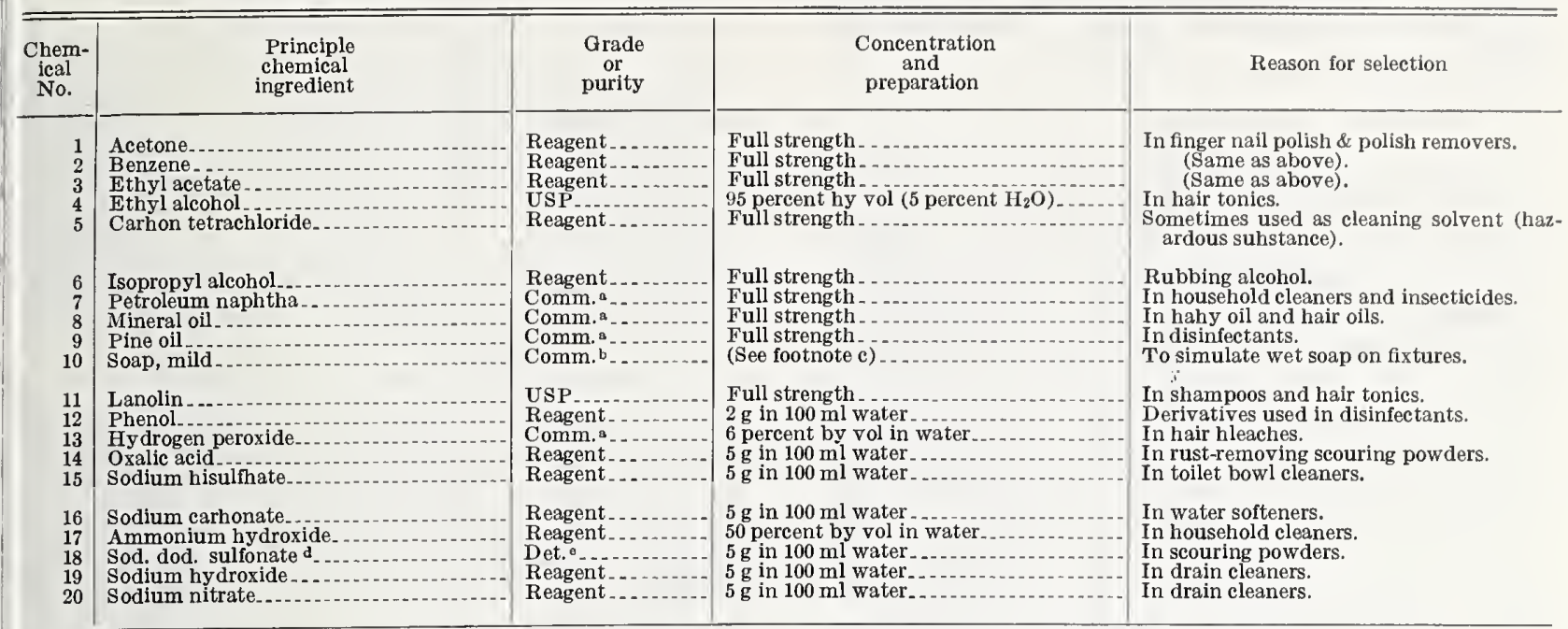

a Commercial grade.

b Ivory flakes, or equivalent.

c $0.1 \mathrm{~g}$ of soap shall he placed in Tefion ring before adding cover; $0.5 \mathrm{ml}$ of

that is not found too often in bathrooms. ASTM Procedure: D1300-53T [11] contains a section on "stain resistance" in which at least one household chemical (vinegar) is included. In this test each of eight reagents is applied to the specimen in an unspecified amount and a cover glass is placed over the reagent. The test is made for $16 \mathrm{hr}$ at $24^{\circ} \mathrm{C}$. The grading is based mostly on the presence or absence of stains.

\section{(2) Test Development}

Preliminary tests in which watch glasses were used to cover reagents indicated that this method was unsuitable because of uncontrolled evaporation rates. Volatile organic solvents such as acetone, benzene, ethyl acetate, and alcohol disappeared from under the match glass, sometimes in a matter of minutes. A tight seal was essential for reproducible results and this led to the design and use of the equipment shown in figure 2.22-1.

\section{TABLE 2.22-2. System for assigning ratings in household} chemicals test

\begin{tabular}{l|r}
\hline \hline \multicolumn{1}{c|}{ Appearance of tested areas a } & $\begin{array}{c}\text { Rating to } \\
\text { be assigned }\end{array}$ \\
\hline $\begin{array}{l}\text { No visible effect. . . } \\
\text { Fiber pattern in coating or indentation mark in coating from } \\
\text { penetration of Teflon ring. }\end{array}$ & 100 \\
Etching, dulling, pitting, or discoloration & 75 \\
Flaking, blistering, or peeling of coating & 50 \\
Exposure of suhstrate material. & 25 \\
\hline
\end{tabular}

a If more than one effect is present after treatment, the effect giving the lowest rating shall be the one used for assigning a rating to the test area. Also, all effects listed for one rating need not he present on the same test area. Thus, if a specimen showed a slight dulling of the surface with no evidence of pitting, etching or staining, the assigned rating would he 50. Likewise, if all three effects (etching, pitting, dulling, and staining) were present, the rating would be 50 . water shall he added after equipment is assemhled.

d Sodium dodecylhenzene sulfonate.

- Detergent grade.

Trials with the equipment showed that evaporation could be held to low levels even when such a volatile solvent as acetone was used as the test reagent.

The test procedure that was devised through use of this equipment is described in section $2.22 \mathrm{~b}(3)$. Test results when this procedure was used for three current fixture materials are listed in table 2.22-3. The household chemicals resistance rating

TABLE 2.22-3. Results of household chemicals test for three sanitary ware materials

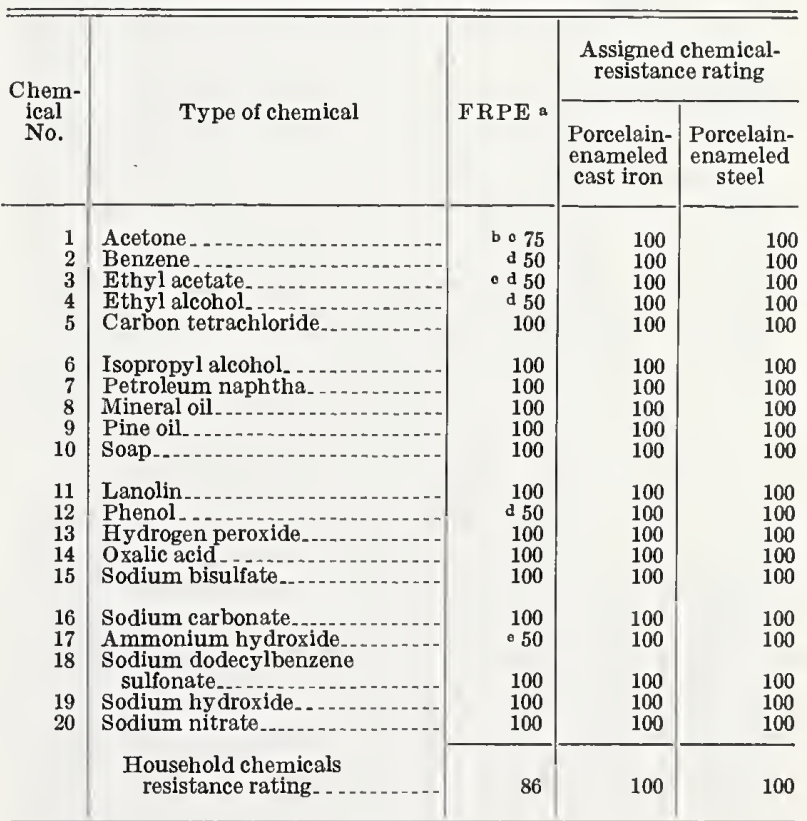

a PA Series.

b Indention mark in coating from penetration of Teflon ring.

- Fiher pattern in coating.

d Dulling of coating.

- Slight stain. 
of the FRPE fixture material was 86 and that of both porcelain-enameled materials (cast iron and steel) was 100 .

\section{(3) Rationale for Test Selection}

A test for resistance for household chemicals should incorporate a representative range of those reagents with which i bathroom fixture might come into contact during service. In selecting these reagents, staining media were not considered since a staining test is incorporated elsewhere herein (sec. 2.23).

The selection of test chemicals was established on the basis of recommendations by members of the BRAB ad hoc committee. Some of the selections may be questioned. For example, the list includes pairs of chemicals of the same type but with different reactivities or solvent properties. One such pair is ethyl and isopropyl alcohols, and another is sodium hydroxide and sodium carbonate. Also, the list does not include chlorine bleaches, which are present in scouring powders and bleaching products.

Another possible objection to the test method is that the chemical exposure occurs in a closed system. Under service conditions such volatile solvents as acetone, benzene, ethyl acetate, ethyl alcohol, and carbon tetrachloride would normally evaporate before attacking the surface. However, the rationale considered the possibility that such solvents, as well as other chemicals, might be trapped between the fixture surface and the bottom of a container. The chemical might be spilled initially on the surface of the fixture, the container might leak, or the bottom of the container might become wet due to carelessness in pouring. The container might then be set down on the surface, trapping the chemical underneath and maintaining a ring of pressure around the contour of the bottom of the container.

The test time of two hours is arbitrary. Either a longer or shorter time might have been used. However, two hours is believed to be realistic since only on very rare occasions would household chemicals (with the possible exception of wet soap) be in contact with a fixture for a longer period.

The method of grading the test areas assigns a resistance rating based on the severity of the attack. A material that shows no effect from a given chemical should obviously have a higher rating than one that shows an effect. Likewise, a material that shows only a very slight effect (fiber pattern in coating or a softening as evidenced by penetration of the Teflon ring) should be rated higher than one in which the attack is so severe that the substance is exposed after treatment. The rating system specified in table 2.22-2 incorporates this concept of differences in the degree of attack.

\section{d. Comments on Performance Requirements}

\section{(1) Suggested Format for a Performance Level}

The household chemicals resistance rating for the fixture shall be not less than __. In addition the individual resistance rating to chemical No. 10 (soap) shall be not less than 100, nor shall the ratings be less than ___ for chemicals No. 6 (isopropyl alcohol), No. 12 (phenol), No. 13 (hydrogen peroxide), No. 17 (ammonium hydroxide), No. 19 (sodium hydroxide), or No. 20 (sodium nitrate).

\section{(2) Rationale for Suggested Format}

The household chemicals resistance rating of the FRPE specimens tested was 86 . The field survey, made at the beginning of the investigation, indicated that the present gel-coat materials have a sufficient resistance to household chemicals since there was no evidence of chemical attack on any of the fixtures nor were any complaints offered by homeowners about the lack of chemical resistance.

Future sanitary ware materials may not have as good a resistance as current FRPE fixtures. Therefore, some considerations should be given to setting the performance requirement at 75 to insure that newly introduced materials will not be seriously deficient with respect to their resistance to common household chemicals.

Consideration of the 20 chemicals listed in table 2.22-1 will suggest that some of these chemicals are much more frequently encountered than others and therefore more important to the test. This is the reason for suggesting specific levels for specific chemicals. It would be unreasonable, for example, to permit the use of a fixture material that had poor resistance to attack by wet soap. A performance level requiring a resistance rating of 100 for wet soap would prevent the use of such a material. The levels for chemicals No. 6, 12, 13, 17, 19, and 20 might be set lower; possibly as low as 50 .

\subsection{Stain Resistance (C502)}

\section{a. Purpose and Scope}

The purpose of this test is to evaluate the ease of removal of stains from both "new" and "abraded" surfaces of such sanitary fixtures as bathtubs, shower stalls, and lavatories.

\section{b. Recommended Test Method}

\section{(1) Equipment and Staining Agents}

The following equipment is required for performing the stain test as herein described:

1. Brass cover blocks prepared in accordance with figure 2.23-1.

2. One-inch diameter watch glasses.

3. Rubber O-rings, $7 / 8$ in O.D. by $11 / 16$ in I.D.

In addition the following staining solutions are required: 


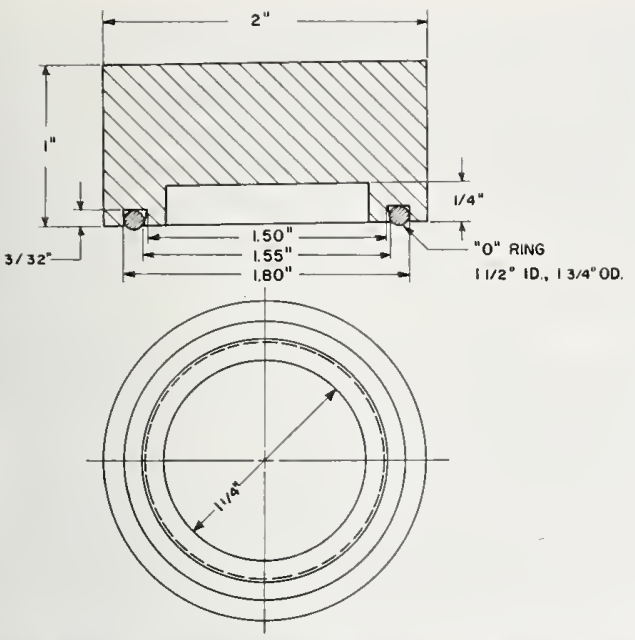

FIgURE 2.23-1. Brass cover block for stain testing.

Stain No. 1. Five-percent solution (by weight) of reagent-grade potassium permanganate in distilled water.

Stain No. 2. One-percent solution (by weight) of iodine in ethyl alcohol.

Stain No. 3. Mercurochrome in ammonia; prepare by mixing one volume of a two-percent aqueous solution of Mercurochrome (merbromin) with two volumes of concentrated ammonium hydroxide.

NoTE: The Mercurochrome solution may be that commonly sold in pharmacies as a general antiseptic.

Stain No. 4. Iron-staining medium; two ingredients are required: (1) Chemical-grade ironmetal filings, degreased, 20 mesh and finer, Allied Chemical Company, Code 1810, or equivalent, and (2) A one-percent solution (by weight) of sodium chloride in water. These two ingredients are combined immediately prior to use as specified in paragraph $2.23 \mathrm{~b}(2)$.

\section{(2) Test Procedure}

Select at random eight $11 / 2$-in-diam areas of the fixture that are substantially flat and horizontal. If the fixture has no such areas, the fixture may be tilted, or alternatively, flat specimens may be cut from the fixture. Abrade four of the selected test areas with $400 \mathrm{C}$ silicon carbide abrasive paper (Carborundum Company A955R, or equivalent). Use strips of the paper that are approximately $1 / 2$ in wide and 1 in long. Place one end of the paper under the index finger and with a firm pressure (force of approximately $10 \mathrm{lb}$ ) abrade the area to be tested for a total of 10 strokes (five forward and five backward) in one direction, and then with the index finger over the opposite end of the strip, abrade for 10 strokes in a direction at right angles to the first direction. The area where the two abrasion treatments intersect (roughly $1 / 2$ $\mathrm{in}^{2}$ ) is the area to be used for evaluating the stain resistance of an abraded surface. Prior to application of the staining solutions wash all test areas (abraded and unabraded) with soap and water, rinse thoroughly, and dry. Place approximately $0.5 \mathrm{ml}$ of Stain No. 1 solution on unabraded area No. 1 , cover with a 1 -in-diam watch glass, and finally cover with the brass cover block (fig. 2.23-1) to prevent excessive evaporation. After 2 houl's at $75 \pm 5^{\circ} \mathrm{F}$, remove the brass block and watch glass, and also remove excess staining solution by blotting. (Note: If the test area is dry on removal of watch glass, the test is void and shall be repeated). Allow the test area to stand after blotting until it is visually dry and then grade for ease of removal of residual stain in accordance with the rating system specified in table 2.23-1. Next, repeat all operations specified in the preceding paragraph for Stains No. 2 and No. 3.

Note: For Stain No. 3 cover inside surfaces of brass cover block with a layer of stop-cock grease to prevent corrosion of the brass by the ammonia vapor.

TABLE 2.23-1. Grading procedure for assigning stain ratings

(A) NUMERICAL RATING SYSTEM

\begin{tabular}{|c|c|c|}
\hline $\begin{array}{l}\text { Numerical } \\
\text { rating }\end{array}$ & $\begin{array}{c}\text { Treatment } \\
\text { identification }\end{array}$ & Treatment required for stain removal \\
\hline $\begin{array}{r}100 \\
90 \\
80 \\
70 \\
60 \\
50 \\
40 \\
30 \\
20 \\
10 \\
0\end{array}$ & $\begin{array}{l}\mathrm{A} \\
\mathrm{B} \\
\mathrm{C} \\
\mathrm{D} \\
\mathrm{E} \\
\mathrm{F} \\
\mathrm{G} \\
\mathrm{G} \\
\mathrm{H} \\
\mathrm{I} \\
\mathrm{J} \\
\mathrm{K}\end{array}$ & $\begin{array}{l}\text { Dry rub (20 strokes). } \\
\text { Wet rub with water (20 strokes). } \\
\text { Mild soapa and water rub (20 strokes). } \\
\text { Ethyl alcohol rub (20 strokes). } \\
\text { Abrasiveb and water rub (10 strokes). } \\
\text { Abrasive and ethyl-alcohol rub (10 strokes). } \\
\text { Abrasiveb and water rub ( } 20 \text { strokes). } \\
\text { Abrasiveb and ethyl-alcohol rub (20 strokes). } \\
\text { Slight staining after Treatment H. } \\
\text { Moderate staining after Treatment } \mathrm{H} \text {. } \\
\text { Severe staining after Treatment H. }\end{array}$ \\
\hline
\end{tabular}

a Ivory soap or equivalent

b Finely ground quartz mixed with 10 percent by weight of trisodium phosphate powder that has been screened through a U.S. Standard No. 100 sieve. The finely ground quartz shall conform to the following size fractions to within \pm 5 percent.

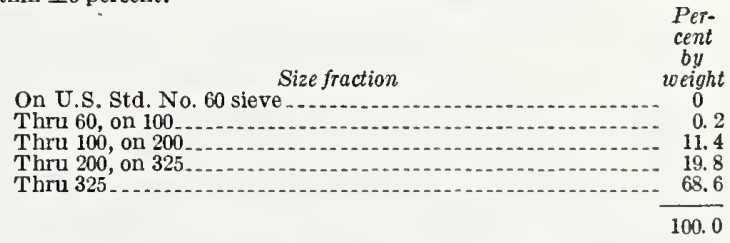

Note: Material meeting the above size requirements is available from the Pennsylvania Glass Sand Corporation, Pittsburgh, $\mathrm{Pa}$.

\section{(B) REQUIREMENTS FOR GRADING SPECIMENS}

(1) Use a fresh, unused pad of soft, lint-free cheesecloth for each rubbing treatment specified in table 2.23-1(A). Each pad shall be approximately one inch square and shall consist of not less than five layers of the cloth

(2) For each rubbing treatment, place the pad under the index finger and with a firm pressure (approximately $10 \mathrm{lb}$ total-force), rub for the specified number of strokes. One stroke shall consist of either one forward or one backward movement of the pad over the stained area.

(3) In all wet rubbing teatments, excess fluid shall be removed from the pad prior to use.

(4) Each treatment specified shall be applied to the stained area in sequence until there is no further visual evidence of discoloration, or until Treatment $I$ has been completed. The numerical rating shall correspond with the final treatment that removed the discoloration, or if some discoloration remains after Treatment $\mathrm{H}$, it shall correspond with the intensity of the residual staining.

(5) Stains retained in small scratehes that may accidentally be present on the unabraded specimens shall not be considered in assigning stain ratings. 
For Stain No. 4 (iron stain), spread $0.1 \mathrm{~g}$ of the iron filings uniformly over a $3 / 4$-in.-diam area of the test surface and surround the iron with a $7 / 8$-indiam O-ring that has been cleaned with scouring powder prior to use. Wet the iron with $0.1 \mathrm{ml}$ of the 1-percent sodium chloride solution and cover with a brass block (fig. 2.23-1). Apply an excess of stop-cock grease to the brass block O-ring to insure a tight seal. After $20 \mathrm{hrs}$ at $75 \pm 5^{\circ} \mathrm{F}$, remove the brass block and $7 / 8$-in-diam O-ring, and allow residual solution to dry without blotting. If test area is dry on removal of the brass block, improper sealing has occurred and the test shall be repeated. Grading of the iron stain shall be done within one to four hours after removal of tl:e brass block. Prior to grading, remove excess iron from test area by brushing. Assign stain rating as specified in table 2.23-1. Evaluate the stain ratings of the abraded areas by the same test procedures and the same rating system used for the unabraded surfaces.

For the abraded-area tests, the watch glass (or the O-ring for the iron stain) shall be so positioned that the outer edge of the watch glass (or O-ring) falls on the center of the abraded area. The combined stain rating shall be the sum of the rating for the eight individual stains (four stains on the unabraded and four on the abraded areas) divided by eight. This combined rating need not be reported to more than two significant figures.

\section{(3) Information to be Reported}

Include the following in the test report:

1. Assigned rating for each stain on the unabraded areas.

2. Assigned rating for each stain on the abraded areas.

3. Combined stain rating for the fixture.

\section{c. Test Results and Discussion}

\section{(1) Discussion of Existing Tests}

Two test procedures have been used for evaluating stain resistance. The first, which is for the "Fcrmica" type of material, is included in ASTM Designation: D1300-53T [11]. It specifies that tho material shall be unaffected by tea, beet juice, vinegar, bluing, dye, ink (washable), iodine (1 percent), and Mercurochrome (2 percent) except for superficial staining which can be easily removed by a light application of a mild abrasive. The test is highly qualitative and vague in its wording. In addition, it gives the test operator considerable leeway in selecting the particular proprietary products that he chooses to use.

The proposed revision of CS 221-59 [1] contains a stain test specifically designed for FRPE sanitary fixtures. Although this test has some desirable features, it was not believed suitable for a performance test since (1) it uses proprietary materials for stains, (2) the abrasive pretreatment is not sufficiently severe to have any measur- able effect on porcelain-enamel or vitreous-china finishes, (3) the material with the poorest stain resistance is assigned the highest stain rating, and (4) iron stains, which are quite common on sanitary fixtures, are not included as one of the staining media.

\section{(2) Test Development and Rationate for Test Selection}

The premises used for devising a staining test that would be free of most of the aforementioned objections were as follows:

1. Since it would be impractical to test a fixture material with every conceivable stain with which it might come into contact, it seemed necessary to select several representative types of stain for the standard test method.

2. Because proprietary products could change in composition at any time depending on the needs of the manufacturer to maintain a market, and also because these products could at some future time disappear completely from the market, the specified staining agents should be well-specified chemicals rather than proprietary products of uncertain composition.

3. With the possible exception of iron and copper discolorations, stains on fixtures are usually not the result of long-time contact but rather are caused by accidental spills or other short-time exposure to the staining agent.

4. Because the surfaces of all fixtures become roughened to varying extents during normal use, the stain resistance after a roughening treatment is of considerable interest to the user. However, it is only logical that the same roughening treatment be applied to all materials. Also, it seems logical that the selected treatment should be sufficiently severe to cause at least some roughening of the most abrasion-resistant finish.

5. The stain rating should be related to the ease with which a stain can be removed through use of common household cleaning agents.

6. The stain test should be so designed as to provide numerical ratings for stain resistance so that (a) performance levels can be more easily assigned, and (b) manufacturers can more readily ascertain when they have improved the overall stain resistance of their product.

\section{(a) Selection of Staining Agents}

One of the major problems encountered in the development of a stain test was the selection of the staining agents. The following stains were investigated:

1. Iron stain. Trials with solutions prepared from soluble iron salts all gave negative results. In no case was an adherent stain formed on any of the materials. However, when metallic iron was permitted to rust while resting on the fixture, surface stains were produced that closely resembled those that are sometimes observed on installed fixtures. The problem then became one of generating 
controlled corrosion of the iron so that reproducble stains could be obtained. After much experinental work the conditions specified in paragraph ..23b(2) were selected. A chemical grade of iron ilings was used together with a one-percent soluion of sodium chloride. The relative amounts of ach were found to be important and the amounts pecified in the recommended test method must be arefully adhered to in order to generate a reprotucible stain.

2. Copper stain. Copper stains are oftentimes pserved on fixtures in rural or suburban areas where (a) copper piping is used for the water supply, and (b) the water supply is either neutral pr slightly acid. Tenacious blue stains appear on he fixtures under these conditions, especially if here is a small leak from the hot-water faucet.

Considerable difficulty was encountered in the aboratory in reproducing these copper stains. After many trials a procedure was devised whereby copper turnings were wet with ammoium hydroxide and left on the test surface for 20 ar in a closed container. This treatment created cenacious blue stains on porcelain enamel and vitceous china that closely resembled those observed on fixtures; however, on FRPE specimens the copper stain was found to penerate deeply into the gel-coat. Additional tests showed that the ammonia was the cause of this penetration; hence, this particular test could not be considered realistic for gel-coats since any significant amount of ammonium hydroxide would never be encountered in a water supply.

Sufficient work was done with the copper stain test to show that the stain rating for enamel and vitreous china was the same for copper stains as for iron stains. Therefore, it was decided to include only the iron stain in the recommended test since the iron stain would probably give the required indication of the resistance of a material to the metal-ion type of discoloration.

3. Hair dye. The most severe staining medium in the CS-221 stain test for FRPE was the black hair dye [1]. Since this is a proprietary product, efforts were made to simulate its action through use of some easily prepared chemical solution. The hair dye was found to contain ammonium hydroxide and it was believed that the presence of this ammonium hydroxide was responsible for the iseverity of the stain on FRPE fixtures. Stain No. 3 (Mercurochrome in $\mathrm{NH}_{4} \mathrm{OH}$ ) yielded the same stain ratings on FRPE specimens as did the black hair dye. Hence, it was included in the test as one of the standard staining media.

4. Iodine. Iodine is a stain that might well come into contact with fixtures. Therefore, it seems logical to include this stain as one of the staining agents. Also, the iodine can be considered representative of many types of staining media that contain alcohol.

5. Potassium permanganate. This chemical is used occasionally in bathrooms for therapeutic purposes. A second reason for its selection is that is should be representative of the most aggressive types of water-soluble stains that might be encountered during the normal service life of a fixture.

6. Lipstick and black crayons. Stains of this general type could be removed easily from all candidate materials even after 20 hours of contact. Hence, a simulated stain of this general type was not included as one of the selected staining agents.

7. Water-soluble ink and liquid shoe poliste. These stains were also removed easily. Any material that received a high rating with respect to $\mathrm{KMnO}_{4}$ (Stain No. 1) should also be highly resistant to ink and shoe polish.

8. Rubber stains. It has been observed that some types of rubber when in contact with a plastic surface may stain the finish due to migration into the plastic of such compounding ingredients as antioxidants and sulphur that are present in the rubber.

Consideration of this problem indicated that it would be difficult, if not impossible, to simulate this type of staining by a simple laboratory test. Two ASTM tentative test methods exist for evaluation of the resistance of plastics to rubber staining: (1) ASTM Designation: D1712-60T [29] with reference to sulfide stains, and (2) ASTM Designation: D2151-63T [30] with reference to staining by rubber compounding ingredients. Since both of these tests are quite complex and since rubber stains are not reported to be a serious problem in FRPE fixtures, no requirements with respect to rubber staining were included in the recommended staining test procedure. However, if rubber staining should become a serious problem on future fixtures it would be possible at that time to incorporate the two ASTM tests into the performance requirements.

\section{(b) Test Results}

Table 2.23-2 lists the results obtained when the staining test, specified in the proposed revision of CS 221-59, was made on five fixture materials. When the same staining agents were used and the testing conducted as specified in section 2.23(1), the ratings were those listed in table $2.23-3$.

Table 2.23-4 gives the results obtained with four fixture materials using the staining agents and test procedures specified in section $2.23(\mathrm{~b})$. In all cases, the combined stain ratings were lower for the abraded specimens than for those that were not abraded. This was not the case, however, for some of the individual stains. For example, porcelain-enameled steel, porcelain-enameled cast iron, and vitreous china received a rating of 60 against iron stains in both the abraded and unabraded condition. A more severe abrasion treatment would probably have lowered the iron-stain rating of the abraded specimens; however, a more severe treatment was not indicated in view of the mild abrasion effects that are normally observed on finishes of this type after a number of years of 
ТABLE 2.23-2. Stain ratings of five sanitary ware specimens when tested in accordance with the proposed revision of CS-221 [1

\begin{tabular}{|c|c|c|c|c|c|c|c|c|c|c|c|c|c|c|c|c|c|c|c|c|c|c|c|}
\hline \multirow{3}{*}{ Specimen No. } & \multirow{3}{*}{ Specimen type } & \multirow{3}{*}{ Pre-treatment } & \multicolumn{8}{|c|}{ One percent iodine } & \multirow{2}{*}{\multicolumn{2}{|c|}{$\begin{array}{c}\begin{array}{c}\text { Liquid } \\
\text { shoo } \\
\text { polish }\end{array} \\
16 \mathrm{hr}\end{array}$}} & \multirow{2}{*}{\multicolumn{2}{|c|}{$\begin{array}{c}\frac{\begin{array}{c}\text { Blue } \\
\text { ink }\end{array}}{16 \mathrm{hr}} \\
\end{array}$}} & \multirow{2}{*}{\multicolumn{2}{|c|}{$\frac{\begin{array}{c}\text { Gen. } \\
\text { violet }\end{array}}{16 \mathrm{hr}}$}} & \multirow{2}{*}{\multicolumn{2}{|c|}{$\frac{\begin{array}{c}\mathrm{Rev} . \\
\text { lipstick }\end{array}}{16 \mathrm{hr}}$}} & \multirow{2}{*}{\multicolumn{2}{|c|}{\begin{tabular}{|c|c|c|c}
$\begin{array}{c}\text { Black } \\
\text { hair } \\
\text { dye }\end{array}$ \\
$16 \mathrm{hr}$
\end{tabular}}} & \multirow{2}{*}{\multicolumn{2}{|c|}{$\frac{\begin{array}{c}\text { Black } \\
\text { crayon }\end{array}}{16 \mathrm{hr}}$}} & \multirow{3}{*}{$\begin{array}{l}\text { Comk } \\
\text { stain } \\
\text { ratin! }\end{array}$} \\
\hline & & & \multicolumn{2}{|c|}{$5 \mathrm{~min}$} & \multicolumn{2}{|c|}{$30 \mathrm{~min}$} & \multicolumn{2}{|c|}{$4 \mathrm{hr}$} & \multicolumn{2}{|c|}{$16 \mathrm{hr}$} & & & & & & & & & & & & & \\
\hline & & & $\mathrm{C}$ & $\mathrm{U}$ & $\mathrm{C}$ & $\mathrm{U}$ & $\mathrm{C}$ & $\mathrm{U}$ & $\mathrm{C}$ & $\mathrm{U}$ & $\mathrm{C}$ & $\mathrm{U}$ & $\mathrm{C}$ & $\mathrm{U}$ & $\mathrm{C}$ & $\mathrm{U}$ & $\mathrm{C}$ & $\mathrm{U}$ & C & $\mathrm{U}$ & C & $\mathrm{U}$ & \\
\hline $\begin{array}{l}\text { PA-100_..- } \\
\text { PA-5 } \\
\text { CID-100.-. } \\
\text { VCA-99... } \\
\text { SD-79.... }\end{array}$ & $\begin{array}{l}\text { Gel-coat } \\
\text { Gel-coat- } \\
\text { P/E-cast-iron } \\
\text { Vit.-china... } \\
\text { P/E-steel }\end{array}$ & $\begin{array}{l}\text { None b- } \\
\text { Bon Ami scrub c-- } \\
\text { Bon Ami scrub d- } \\
\text { Bon Ami scrub d- } \\
\text { Bon Ami scrub d.- }\end{array}$ & \begin{tabular}{l|}
2 \\
2 \\
1 \\
1 \\
1
\end{tabular} & $\begin{array}{l}2 \\
2 \\
1 \\
1 \\
1\end{array}$ & $\begin{array}{l}2 \\
4 \\
1 \\
1 \\
1\end{array}$ & $\begin{array}{l}1 \\
3 \\
1 \\
1 \\
1\end{array}$ & \begin{tabular}{l|}
2 \\
4 \\
1 \\
1 \\
1
\end{tabular} & $\begin{array}{l}1 \\
2 \\
1 \\
1 \\
1\end{array}$ & $\begin{array}{l}3 \\
5 \\
1 \\
1 \\
1\end{array}$ & $\begin{array}{l}1 \\
3 \\
1 \\
1 \\
1\end{array}$ & $\begin{array}{l}1 \\
3 \\
1 \\
1 \\
1\end{array}$ & $\begin{array}{l}1 \\
3 \\
1 \\
1 \\
1\end{array}$ & $\begin{array}{l}1 \\
3 \\
1 \\
1 \\
1\end{array}$ & $\begin{array}{l}1 \\
3 \\
1 \\
1 \\
1\end{array}$ & $\begin{array}{r}3 \\
4 \\
1 \\
-4 \\
1\end{array}$ & $\begin{array}{l}2 \\
3 \\
1 \\
1 \\
1\end{array}$ & $\begin{array}{l}1 \\
3 \\
1 \\
1 \\
1\end{array}$ & $\begin{array}{l}1 \\
3 \\
1 \\
1 \\
1\end{array}$ & $\begin{array}{l}5 \\
5 \\
1 \\
1 \\
1\end{array}$ & $\begin{array}{l}3 \\
4 \\
1 \\
1 \\
1\end{array}$ & $\begin{array}{l}1 \\
2 \\
1 \\
1 \\
1\end{array}$ & $\begin{array}{l}1 \\
2 \\
1 \\
1 \\
1\end{array}$ & $\begin{array}{l}5 \\
6 \\
2 \\
2 \\
2\end{array}$ \\
\hline
\end{tabular}

a Ratings assigned on the following basis: No. 1, stain removed with tap water and cheesecloth by 20 scrub cycles with normal hand pressure; No. 2 , water and chesecloth by 20 for 20 cy stain removed by washing for 20 cycles with cheesecloth moistened with either (a) rubbing alcohol, or (b) lighter fluid; No. 3, stain removed by 20 scrub cycles at normal hand pressure with moistened cheesecloth and Bon
Ami; No. 4, slight stain remains after Bon Ami treatment; No. 5, severe stain remains after Bon Ami treatment. Letter " $C$ " indicates stain solution

was covered with a microscope cover glass during test, " $U$ " indicates it wa uncovered.

b Specimen tested with its initial glossy surface.

- Initial gloss mostly destroyed by pre-treatment of 20 scrub cycles wit] Bon Ami.

d No visual change in initial gloss by 20 scrub cycles with Bon Ami. - Stain penetrated pinholes in glaze.

TABLE 2.23-3. Stain ratings of specimens to CS-221 stains [1] when tested in accordance with the method specified in section $2.23(b)$

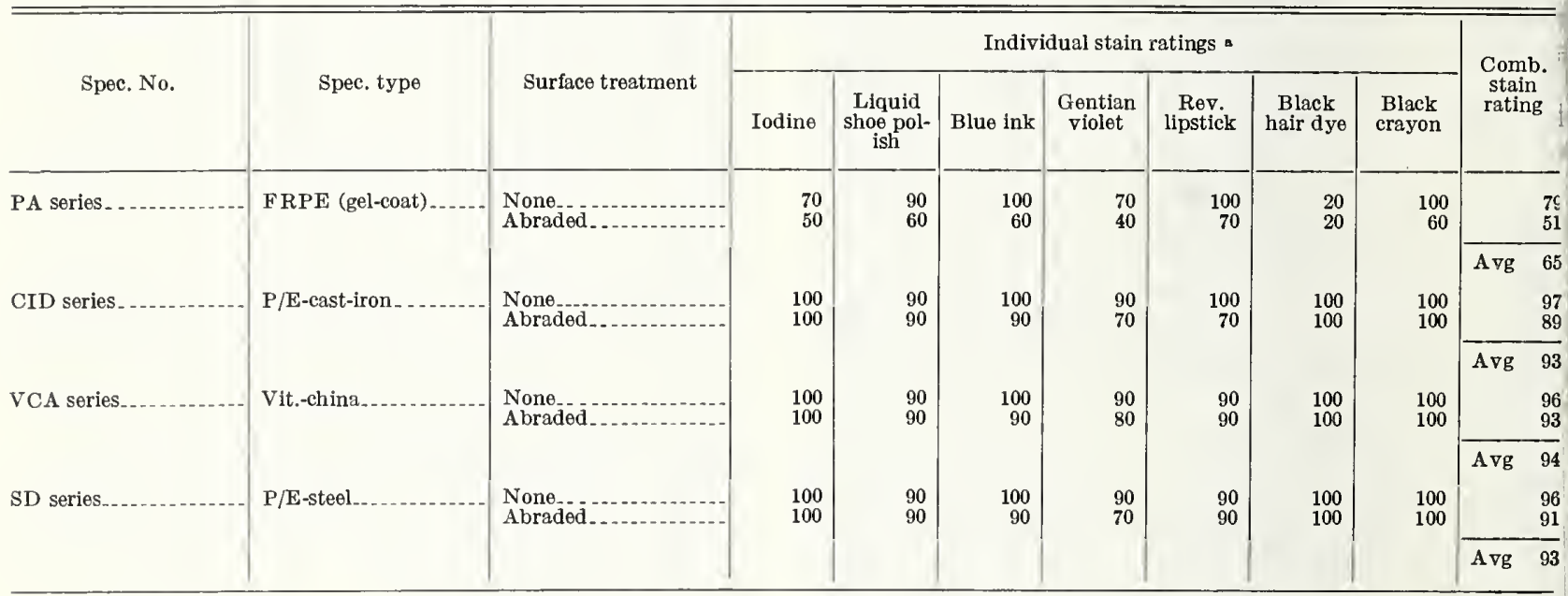

- Treatment time $2 \mathrm{hr}$.

TABLE 2. 23-4. Stain ratings of sanitary ware specimens to the four recommended stains when tested by the method specified in section $2.23(b)$

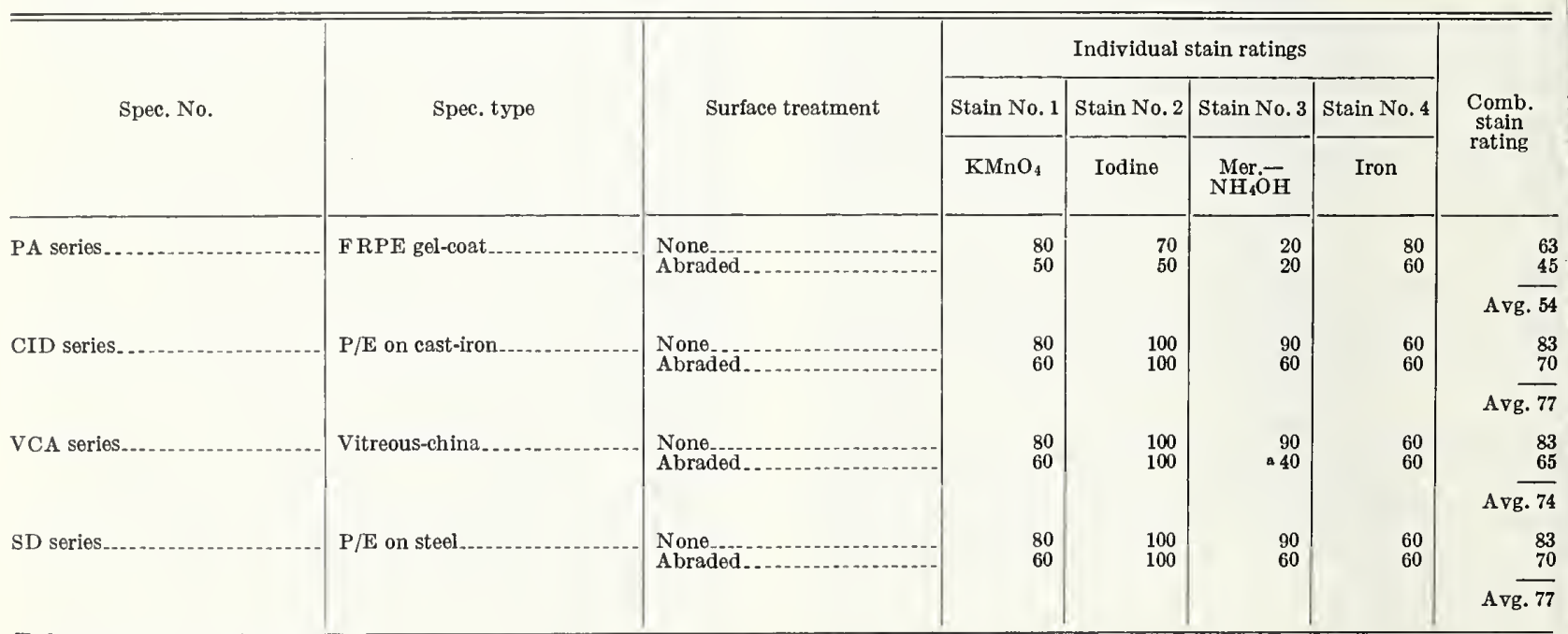

a Stain penetrated pinholes in glaze. 
service. It should also be pointed out that the specified abrasion treatment with the $400 \mathrm{C}$ silicon carbide paper roughens the surface of these materials to an extent that is comparable to the 10,000 cycle abrasion treatment in the scrub tester as specified in section 2.10 .

\section{d. Comments on Performance Requirements}

\section{(1) Suggested Format for a Performance Level}

The combined stain-resistance rating shall be not less than __ when determined as specified in section $2.23(\mathrm{~b})$.

\section{(2) Rationale for Suggested Format}

The field inspection of FRPE fixtures made in July 1964 (Appendix A) indicated that staining was not a serious problem with the FRPE material; hence, one might wish to place the performance requirement for stain resistance at a level that would permit the use of materials with a stain resistance comparable to the current types of polyester gel-coats. This purpose would be accomplished if the requirement was set at 50 .

\subsection{Color Stability (C503)}

\section{a. Purpose and Scope}

The purpose of this test is to evaluate the resistance of sanitary fixture materials to changes in color caused by exposure to solar radiation.

\section{b. Recommended Test Method}

\section{(1) Apparatus}

A 6000-W, water-cooled xenon-arc apparatus with a $373 / 4$ in-diam specimen rack shall be used. This apparatus shall be that specified in ASTM Designation: E 240-64T [31].

\section{(2) Procedure}

Cut four 4- $\mathrm{x}$ 4-in flat specimens from the fixture to be tested. Wash with soap and water, rinse thoroughly, and dry. Designate these specimens Nos. $1,2,3$, and 4 .

Place specimens Nos. 1, 2, and 3 in the xenon-arc apparatus that has been adjusted to give a blackpanel temperature of $125^{\circ} \mathrm{F} \pm 3^{\circ} \mathrm{F}$, and operate the apparatus with no water spray for a total of $200 \mathrm{hr}$. Humidity need not be controlled.

At the end of the 200 -hr exposure time, remove the three specimens, clean them by the same procedures specified above, and then place them adjacent to specimen No. 4 (untested specimen).

Finally, have an observer with normal color vision examine the specimens visually at normal reading distance and with illumination as described in section 2.8 for an immediately apparent color difference between the tested specimens and the untested specimen. If no color difference is im- mediately apparent, the specimens are adequate in color stability.

In the event of an apparent color difference by the visual examination, or in the event of a disagreement, determine color differences according to ASTM Designation D 1365-60T [38], reporting the color difference determined for each of the three tested specimens and the average of these three values, in NBS units.

\section{(3) Information to be Reported}

Include the following in the test report:

1. Type and model of xenon-are apparatus;

2. Age of both the xenon burner and the glass filters at the time of testing. Also, the wattage used during testing;

3. Operating black-panel temperature;

4. A statement as to the degree of color difference between the tested specimens and the untested specimen, in the case of visual examination. If the examination is made by the method of ASTM D 1365 , report color difference measurements in NBS units.

\section{c. Test Results and Discussion}

\section{(1) Discussion of Existing Methods}

Numerous arc tests exist for evaluating the resistance of materials to the photodegradative effects of natural sunlight. Examples are ASTM Designations: E 188-63T [32], E 42-57 [33], D 822-60 [34], and E 240-64T [31]. In general, these tests attempt to simulate rainfall as well as sunlight, since they all include a water-spray cycle as part of the test condition.

The proposed revision of CS 221-59 [1] for FRPE fixtures contains a requirement for "color fastness." A xenon arc is specified. The test time is $200 \mathrm{hr}$. The performance requirement (paragraph 6.3.2) states that the "tested specimens shall show no appreciable change in color when compared to the 'control' specimen." No explanation is given as to the interpretation to be placed on the term "appreciable change in color."

\section{(2) Test Development}

Triplicate specimens of four fixture materials were tested under both carbon-arc and xenon-arc exposure. The measured changes in color from these respective treatments are given in tables 2.24-1 and 2.24-2. In all cases the measured color changes were small.

\section{(3) Rationale for Test Selection}

The recommended test procedure is a modification of that specified in the proposed revision of CS 221-59 for FRPE fixture materials. Both the equipment and the exposure times are the same as in the test specified in the proposed revision of CS 221. The main difference in the two tests is that the test recommended herein provides an instru- 
TABLE 2.24-1. Change in color of white sanitary ware specimens after exposure to two carbon-arc treatments

\begin{tabular}{|c|c|c|c|c|}
\hline \multirow{2}{*}{ Fixture material } & \multicolumn{2}{|c|}{$\begin{array}{l}\text { Dry exposure- } \\
808 \mathrm{Hr}\end{array}$} & \multicolumn{2}{|c|}{$\begin{array}{l}\text { Wet exposure- } \\
814 \mathrm{Hr} \text { b }\end{array}$} \\
\hline & $\begin{array}{l}\text { Spec. } \\
\text { No. }\end{array}$ & $\begin{array}{l}\text { Color } \\
\text { change o }\end{array}$ & $\begin{array}{l}\text { Spec. } \\
\text { No. }\end{array}$ & $\begin{array}{l}\text { Color } \\
\text { change. }\end{array}$ \\
\hline $\begin{array}{l}\text { Porc.-Enamel on Steel................. } \\
\text { (SB Series). }\end{array}$ & $\begin{array}{l}25 \\
26 \\
34\end{array}$ & $\begin{array}{r}\text { NBS } \\
\text { units } \\
1.4 \\
1.0 \\
0.5\end{array}$ & $\begin{array}{l}13 \\
19 \\
20\end{array}$ & $\begin{array}{r}\text { NBS } \\
\text { units } \\
0.7 \\
.6 \\
.8\end{array}$ \\
\hline $\begin{array}{l}\text { A } \mathrm{A} \text { RPE } \\
\text { (PA Series). }\end{array}$ & $\begin{array}{l}27 \\
28 \\
33\end{array}$ & $\begin{array}{l}0.97 \\
1.4 \\
1.5 \\
1.9\end{array}$ & $\begin{array}{l}14 \\
15 \\
16\end{array}$ & $\begin{array}{l}.70 \\
1.8 \\
2.8 \\
2.0\end{array}$ \\
\hline $\begin{array}{l}\text { A } \begin{array}{l}\text { Prg. } \\
\text { (CID Series). }\end{array} \\
\text { (Cast-Iron. }\end{array}$ & $\begin{array}{r}29 \\
30 \\
36\end{array}$ & $\begin{array}{l}1.60 \\
1.4 \\
1.4 \\
1.6\end{array}$ & $\begin{array}{l}17 \\
18 \\
21\end{array}$ & $\begin{array}{l}2.20 \\
1.0 \\
1.3 \\
1.1\end{array}$ \\
\hline $\begin{array}{l}\text { Avg } \\
\text { Vitreous-China. } \\
\text { (VCB Series). }\end{array}$ & $\begin{array}{l}31 \\
32 \\
35\end{array}$ & $\begin{array}{l}1.47 \\
1.2 \\
1.6 \\
1.6\end{array}$ & $\begin{array}{l}-72 \\
23 \\
24\end{array}$ & $\begin{array}{l}1.10 \\
1.8 \\
1.9 \\
1.7\end{array}$ \\
\hline Avg- & & 1.47 & & 1.80 \\
\hline
\end{tabular}

a Carbon arc operated in accordance with ASTM Procedures D 822-60 and $\mathrm{E} 42-57$.

b Same as dry exposure except for a water spray striking specimens for 9 min out of each hour of operation.

o See NBS Circ. 429 (1942) [35]. Measurements made by procedure of ASTM D 1365-60T [38].

TABLE 2.24-2. Change in color of white sanitary ware specimens after 200 hours exposure in xenon-arc apparatus ${ }^{\mathrm{a}}$

\begin{tabular}{|c|c|c|c|}
\hline $\begin{array}{l}\text { Spec. } \\
\text { No. }\end{array}$ & Specimen type & $\begin{array}{l}\text { Change in } \\
\text { color }\end{array}$ & $\begin{array}{l}\text { Average color } \\
\text { change }\end{array}$ \\
\hline $\begin{array}{l}1 \\
2 \\
3\end{array}$ & Porce.-Enamel on Steel (SB Series) ... & $\begin{array}{r}\text { NBS units } \\
0.5 \\
.3 \\
.3\end{array}$ & $\begin{array}{r}\text { NBS units b } \\
0.37\end{array}$ \\
\hline $\begin{array}{l}4 \\
5 \\
6\end{array}$ & FRPE (PA Series) & $\begin{array}{r}0.7 \\
1.1 \\
.6\end{array}$ & 0.80 \\
\hline $\begin{array}{l}7 \\
8 \\
9\end{array}$ & $\begin{array}{l}\text { Porce.-Enamel on Cast-Iron (CID } \\
\text { Series). }\end{array}$ & $\begin{array}{r}0.2 \\
.6 \\
.5\end{array}$ & 0.43 \\
\hline $\begin{array}{l}10 \\
11 \\
12\end{array}$ & Vitreous-China (VCB Series) ... & $\begin{array}{r}1.0 \\
.7 \\
1.0\end{array}$ & 0.90 \\
\hline
\end{tabular}

s $6000-W$, water-cooled xenon are with a 373/4-in-diam specimen rack. Apparatus operated dry. Black panel temperature was $125^{\circ} \mathrm{F}$.

b See NBS Circ. 429 (1942) [35]. Measurements made by procedure of ASTM D $1365-60 \mathrm{~T}^{\mathrm{T}}[38]$.

mental method for determining the degree of color change.

The following reasoning influenced the selection of the recommended xenon-are test method:

1. Sanitary fixtures in normal installations are exposed to only very short periods of sunlight. This would occur when the fixture was installed near a window. Some exposure to direct sunlight occurs when fixtures are stored temporarily out-of-doors by manufacturers, distributors, or plumbing contractors. Thus, a test exposure to simulated sunlight seems reasonable. Because of window shades, translucent glass, cloudy days, and dirty windows, $200 \mathrm{hr}$ seen a reasonable testing time.
2. The xenon-arc has been shown to have a spectral energy distribution, when properly filtered, that more closely simulates sunlight at the earth's surface than does the distribution from any other available light source. Hence, the filtered xenon are is preferable to the carbon arc.

3. A xenon-arc test is already specified in the proposed revision of CS 221-59. There does not appear to be any good reason to change to a completely new test for color stability except to be more specific about the magnitude and measurement of the color change that will be permissible after the $200-\mathrm{hr}$ treatment.

\section{d. Comments on Performance Requirements}

\section{(1) Suggested Format for a Performance Level}

The average color difference between three untested specimens and three specimens from the same lot exposed for $200 \mathrm{hr}$ to the xenon arc specified in section $2.24 \mathrm{~b}$ shall be less than __ NBS units.

\section{(2) Rationale for Suggested Format}

The largest average color change reported in table 2.24-2 is 0.90 NBS units. This is not a noticeable change, since 1.0 NBS unit, as described in NBS Circ. 429 [35], is generally considered to be an excellent color match. This means that the presently manufactured white-fixture materials have acceptable color stability with respect to solar radiation. Colored fixtures, however, might not have this same stability. Also, future candidate materials might be lacking in this respect. Therefore, it seems desirable to include a color-stability requirement. Possibly the performance level should be set higher than 1.0 NBS unit. A color change of 5.0 NBS units would be readily dectable, but would not detract from the serviceability of the fixture.

\subsection{Surface Texture Aging (C4)05}

The purpose of this test is to evaluate the ability of a sanitary plumbing fixture to maintain its original appearance and other important surface properties without deterioration from natural changes through passage of time under normal ambient conditions, as contrasted to changes from external influences associated with use.

The principal difficulty in developing a suitable aging test is the correlation between effects observed in an accelerated laboratory test and the anticipated changes over a long period of time under normal conditions. If it is anticipated that normal temperature, humidity, daylight, etc., cause aging, it is impossible, without extensive experimentation, to compress the time scale by a known factor using selected increases in the severity of these environmental factors.

A test for color fastness of FRPE sanitary ware is described in paragraph 6.3.1 of the proposed revision of CS 221-59 [1], involving exposure for 
$200 \mathrm{hr}$ to ultraviolet radiation. A similar test for evaluating color stability, using apparatus specified in ASTM E 240-64T [35], is recommended in section 2.24 herein. However, it is not the purpose of either of these tests to evaluate surface texture aging effects.

Weatherometer tests, such as described in ASTM D 1499-59T [36], generally combine ultraviolet radiation and water spray. Other accelerated tests for plastics, such as ASTM D 756 [37], employ cycles involving different degrees of humidity and heat. Still other accelerated tests involve exposure to elevated temperatures in an oven.

None of the existing tests referred to approximates the conditions of service exposure for sanitary plumbing fixtures sufficiently well to warrant their recommendation as performance tests for surface texture aging without correlation with effects observed in service.

ithe ad hoc committee was of the opinion that the development of an aging test for sanitary plumbing fixtures was not practical during the present investigation.

\subsection{Odor (C505)}

The ad hoc committee established a functional requirement on odors that stated that sanitary plumbing fixture materials should not emit objectionable odors, either their own inherent odor or others which they might acquire during normal use. While evaluation of odors is not within the scope of technical investigations of the National Bureau of Standards, the problem of odor emission by materials used for sanitary plumbing fixtures was brought to the attention of the Chairman of ASTM Committee E-18 on Sensory Evaluation of Materials and Products. Although no formal reply was received from this Commit- tee, it is recommended that further contact be made with this ASTM Committee for assistance and guidance in the evaluation of this property.

It was observed during the study of FRPE bathtubs at the National Bureau of Standards, that some specimens produce a pronounced odor when stored in a confined space. Flat specimens, stored overnight in closed glass jars, caused odors to develop in the jars; some specimens having more pronounced odor than others. 'The odors were generally characteristic of styrene, a constituent used in manufacture of the FRPE material. The same odor was detected during the Hot-Water Resistance Test (sec. 2.18) and the RadiantHeater Resistance Test (sec. 2.20).

\subsection{Noise Control (Bathtub) (N401) and (N402)}

The damping characteristics of a bathtub for the noise generated by falling water and the sound-attenuation characteristics of an integral surround were considered to be significant functional characteristic of a bathtub. However, study of these factors was not included in the approved project proposal.

\subsection{Biological Characteristics (B601) (B602) (B603)}

There was general agreement in the ad hoc committee that a sanitary plumbing fixture should be cleanable with respect to micro-organisms, that the materials in the fixture should not sensitize human skin on repeated contact, and that the materials should be resistant to attack by rodents or insects. However, investigation of these characteristics was not included in the approved project proposal.

\section{Tests Requiring Further Development}

Several needed test methods discussed in section 2 herein are not sufficiently complete for recommendation in their present stage of development for application to the bathtubs in particular, nor to sanitary plumbing fixtures in general, as performance tests. Special attention is directed to three of these tests requiring further work.

\subsection{Cieanability and Soilability (M203A)}

A suitable test method for these characteristics cannot be recommended at this time, principally because of (1) the lack of a representative soiling medium, and (2) inadequacies in the means for simulating scrubbing procedures and for evaluating residual soil. These deficiencies and recommendations for further development work are discussed in section 2.11. Cleanability and soilability may be considered as separate characteristics.
However, they are closely related and could probably be evaluated, in sequence, during a single test procedure.

\subsection{Surface Slip Resistance (M207)}

A suitable test method for this characteristic cannot be recommended at this time, principally because of (1) poor simulation of use conditions in the existing tests, and (2) lack of correlation between test results and slipping in service. These deficiencies and recommendations for further development work are discussed in section 2.15.

\subsection{Resistance to Thermal Shock (T304)}

A test method for resistance to thermal shock was not recommended herein, principally because of (1) poor simulation of service temperature ex- 
posure in existing tests, and (2) lack of information to correlate temperature levels and the number of cycles to produce failure. It is recommended that further work be directed toward the development of a suitable test that would replace both the hot-water resistance tests described in section 2.18 and the existing thermal-shock tests described in section 2.21. A discussion of these matters is given in section 2.21 .

The blistering of FRPE bathtubs observed during the hot-water resistance tests described in section 2.18 was probably not the result of thermal shock. It may have been the caused by differential expansion of the gel-coat and the substrate, or more likely by volatile products given off by the substrate at the elevated temperatures. Therefore, the combination test procedure proposed above should incorporate a cumulative long-term exposure of a bathtub to warm water, together with a cyclic thermal-shock test at different temperatures.

\subsection{Other Characteristics Requiring Test Development}

There was a number of performance characteristics for sanitary plumbing fixtures that were considered important by the ad hoc committee, but which were excluded from the present test development effort either because (1) accounting for all the relevant parameters made the investigation too complex and costly or (2) the particular scientific discipline principally involved was not available at the National Bureau of Standards. These characteristics include the following:

Dimensional Stability (M205)

Noise Control (N401) (N402)

Surface Texture Aging (C504)

Odor (C505)

Biological characteristics (B601)

(B602) (B603)

These characteristics should be considered in any future program of test development for sanitary plumbing fixtures.

\section{References}

[1] Standard for gel-coated glass-fiber reinforced polyester resin bathtub units, a proposed revision of Commercial Standard CS 221-59 (Aug. 1964).

[2] Gel-coated glass-fiber reinforced polyester resin bathtubs, Commercial Standard CS 221-59.

[3] Plumbing fixtures, land use, Federal Specification WW-P-541b (4) (1962).

[4] Enameled cast iron plumbing fixtures, Commercial Standard CS 77-63.

[5] Method of test for water absorption of plastics, ASTM designation : D 570-63.

[6] Vitreous china plumbing fixtures, Commercial Standard CS 20-63.

[7] Earthenware (vitreous-glazed) plumbing fixtures, Commercial Standard CS $111-43$.

[8] Standard methods of test for abrasion resistance of porcelain enamels, ASTM designation : C 448-61.

[9] Schiefer, H. F., Crean, L. E., and Krasny, J. F., Improved single-unit Schiefer abrasion testing machine, Research Paper RP 1988, NBS J. Research, 42 (May 1949).

[10] Richey, G. G., McKenna, E. H., and Hobbs, R. H.; Methods and equipment for testing printed-enamel felt-base floor covering, NBS Building Materials and Structures Report No. 130 (1952).

[11] Tentative specifications and methods of test for laminated thermosetting decorative sheets, ASTM designation : D 1300-53T.

[12] Standard method of test for mar resistance of plasties, ASTM designation : D 673-44.

[13] Standard method of test for abrasion resistance of paint, varnish, lacquer, and related products by the falling sand method, ASTM designation: D 968-51.

[14] Standard method of test for abrasion resistance of coatings of paint, varnish, lacquer, and related products with the air blast abrasion tester, ASTM designation : D 658-44.

[15] Marra, Dorothea, and Osipow, Lloyd I., A review of Snells's soiled cloth, Detergent Age (Oct. 1964, p. 52).

[16] Enamel; interior, semigloss, tints and white, Federal Specification TT-E-508(4) (1953).
[17] Shelberg, Wesley E., Mackin, James L., and Fuller, Ross K., Artificial surface dirts for detergency studies with painted surfaces, Ind. Eng. Chem., 46, No. 12, 2572 (Dec. 1954).

[18] Ridenour, G. M., and Armbruster, E. H., Bacterial cleanability of various types of eating surfaces, Am. J. Public Health, 43, No. 2, 138 (Feb. 1953).

[19] Armbruster, E. H., and Ridenour, G. M., Field test procedures for cleanliness measurement of multiple use of eating utensils, The Sanitarian 23, No. 2, 103, (Sept.-Oct. 1960).

[20] Wells, Louis E. Jr., A progress report, Part II, Test methods for evaluating liquid detergents for hand dishwashing, Proc., 43rd Annual Meeting, Chemical Specialties Manufacturers Association, Washington, D.C., (Dec. 3-5, 1956). pages 189-191.

[21] Weatherby, Robert J., The measurement of floor dirt, J. Environmental Health, 26, No. 4 (Jan.Feb. 1964).

[22] Standard method of salt spray (fog) testing, ASTM designation : B 117-61.

[23] Causes and measurement of walkway slipperiness, Federal Construction Council Technical Report No. 43, Report of Task Group T-41, Building Research Advisory Board, National Academy of Sciences-National Research Council, Washington, D.C., 1961.

[24] Causes and measurement of walkway slipperiness, Publication No. 899, National Academy of Sciences-National Research Council, Washington, D.C., 1961.

[25] Giles, C. G., Sabey, B. E., and Cardew, K. H. F., Development and performance of the portable skid-resistance tester, Road Research Paper No. 66, Department of Scientific and Industrial Research, London, England (1964).

[26] Tentative specifications for standard tire for pavement tests, ASTM designation: E 249-64T.

[27] Test for resistance of porcelain enamels to gouging, Bulletin T-1, Porcelain Enamel Institute, Inc., Washington, D.C. (1942).

[28] Formed metal porcelain-enameled sanitary ware, Commercial Standard CS 144-47 (under revision). 
[29] Tentative method of test for resistance of plastics to sulfide staining, ASTM designation D 1712 $60 \mathrm{~T}$.

[30] Tentative method of test for staining of poly-(vinyl chloride) compositions by rubber compounding ingredients, ASTM designation: D 2151-63T.

[31] Tentative recommended practice for operating watel-cooled xenon-arc type apparatus for artificial light exposure tests, ASTM designation: E $240-64 \mathrm{~T}$.

[32] Tentative recommended practice for operating enclosed carbon-are type apparatus for artificial light exposure tests, ASTM designation : E 188-63T.

[33] Recommended practice for operating light- and water-exposure apparatus (carbon-arc type) for artificial weathering test, ASTM designation: E 42-57.
[34] Recommended practice for operating light- and water-exposure apparatus (carbon-arc type) for testing paint, varnish lacquer, and related products, ASTM designation : D 822-60.

[35] Hunter, R. S., Photoelectric tristimulus colorimetry with three filters, NBS Circular C429 (1942).

[36] Tentative recommended practice for operating lightand watel-exposure apparatus (carbon-are type) for exposure of plastics, ASTM designation: D $1499-59 \mathrm{~T}$.

[37] Standard methods of test for resistance of plastics to accelerated service conditions, ASTM designation: D 756-56.

[38] Method of test for color difference using colordifference meters of the Hunter-lab or Gardner types, ASTM designation: D 1365-60T. 


\section{Appendix A. Inspection of FRPE Manufacturing Processes, Installed Fixtures, and Test Facilities}

\section{a. Purpose and Scope}

A five-man inspection team from NBS, assisted by BRAB consultants and FHA representatives, visited three plants engaged in the manufacture of FRPE sanitary plumbing fixtures and made on-site field inspections of 37 fixtures that had been in use for periods ranging up to three years. Test facilities were also observed. The field observations on FRPE fixtures were limited to bathtubs and shower receptors.

The purpose of the trip was twofold: (a) to become familiar with current manufacturing and testing processes for FRPE plumbing fixtures, and (b) to inspect as many installed fixtures as time would allow. The overall goal was to permit the NBS team to obtain a background on FRPE plumbing fixtures before embarking on the BRABsponsored program to select or develop performance tests for sanitary plumbing fixtures fabricated from any material.

\section{b. Manufacturing Processes}

There were many similarities in the operations observed at the three plants that were visited. All three used a highly-polished black plastic mold, which is a male image of the desired fixtures. A wax parting compound was first lubbed on the mold surface, after which a polyester gel-coat was applied by hand-spraving with a special spray gun to a thickness of approximately $0.020 \mathrm{in}$. The required amount of catalyst was metered in the gun so as to provide hardening of the gel-coat within 30 to 45 min after spraying. The white gel-coats appeared to be opacified with titanium dioxide. The appearance of the finish was similar to porcelain enamel. Its smoothness and gloss depended on the polish imparted to the mold prior to spraying.

After the gel-coat hardened, the fiberglass backing was applied. Two of the three plants used the sprayed-glass process. In this process, glass yarn was fed into a special spray gun where it was chopped into fibers $5 / 8$ to $3 / 4$ in long before being propelled along with the polyester and catalyst against the previously gel-coated mold. The resincoated fibers did not flatten out against the back of the gel-coat, but rather deposited as a loose mat. This required a hand-rolling operation in which the operators used steel rollers to compact the layer. This was done periodically throughout the spraying operation. The thickness of the backing as well as thickness unifornity appeared to depend to a considerable extent on the skills of the spraygun and roller operators with the methods and equipment being used.

In the glass-fabric process the gel-coated mold was first brushed with a polyester varnish to which the proper amount of catalyst had been added. Sheets of glass mat and glass fabric were then placed over the polyester and hand rolled into position.

The total thickness of the walls of the fixtures manufactured at all three plants was of the order of $1 / 8$ to $1 / 4$ in. Since this was insufficient to provide the required rigidity, reinforcements were glued to the back surfaces before removal of the fixtures from each mold. Each manufacturer used a different type of backing reinforcement such as plywood, pressed hardboard, gypsum wallboard, or plastic ribs.

Mold removal occurred as a final operation. This was done by applying air pressure at the edges.
All three plants manufactured bathtubs of the same basic design, i.e., a tub with an integral front apron and a wall surround extending above the top of the tub to a maxi. mum of approximately 4 feet. The wall surround was flanged with an edging strip about $1 / 2$ in wide for nailing to the studs during installation. A few bathtubs with no wall surround were being produced, but this type of fixture represented only a small percentage of the total production.

\section{c. Inspection of Installed Fixtures}

A total of 37 plastic fixtures was inspected in the geographical areas adjacent to the manufacturing plants. However, all units inspected in a given area were not necessarily manufactured by the plant that was visited in that area. The age of the fixtures inspected ranged from a few months to approximately three years. Producticn methods and quality control procedures had been changed in some instances since the first of these fixtures was manufactured.

The inspections were intended as spot checks. They were not arranged by the manufacturers except in one midwestern area where time limitations prevented a more objective selection of installations.

The help of local FHA officials was used in locating housing developments where plastic fixtures had been installed. The selection of installations was largely random after the development was reached. Normally, three teams of two persons each made the inspections. Arrangements for the inspections were made in most cases by one of the team members talking to one of the occupants of each of the selected houses. Detailed observations were recorded by the NBS team for the information of BRAB staff and the project staff. From this information, several comments can be made:

\section{(1) Installation Method}

The plastic bathtubs were attached to the wall studding by nailing through the edge strip provided for this purpose on both the front apron and on the wall surrounds. In some cases cracking of the edge strip was observed. The observed cracks did not extend into the part of the fixture intended to be visible after installation of the bathroom walls. One manufacturer recommended screws for this purpose and predrilled the edging strip. However, one such fixture inspected in a house under construction showed that the installer had nevertheless used nails rather than screws.

All of the plastic fixtures inspected had a bottom slope adequate to provide complete draining of cold water introduced into them. The bottom slopes varied from 0.2 to 4.2 percent with a median of 2.5 percent. The top ledges showed slopes of -0.6 to +1.1 percent, but most were installed level.

\section{(2) Cleaning Methods and Cleanability}

Although all manufacturers recommended that the tubs not be cleaned with harsh scouring powders, about 80 percent of the occupant interviewed reported that they used proprietary brands of scouring powders. A cleanability test convenient for field use was made during each inspection in which a $3 \mathrm{~B}$ drawing pencil was used to make marks on the surface of the fixture. On a newly installed bathtub 
the pencil marks could normally be removed by dry rubbing. Once the gloss had disappeared, however, it was necessary to use soap (Ivory) and water to obtain removal. On about 19 percent of the fixtures it was necessary to use scouring powder (Bon Ami). In no case was it inpossible to remove the marks with the scouring powder.

\section{(3) Scratching of Gel-Coat}

Almost all of the fixtures inspected had one or more visible scratches. In general, these scratches were visible only on close inspection and did not appear to affect cleanability as determined by the $3 \mathrm{~B}$ pencil test.

\section{(4) Cracking of Gel-Coat}

About half of the fixtures showed one or more fine cracks in the gel-coat. The depth of the cracks was not ascertained.

\section{(5) Gouging of Gel-Coat}

Small gouges in the gel-coat were observed in three of 37 fixtures.

\section{(6) Chemical Stains}

Chemical staining was observed on four of the 37 fixtures. In one case the staining apparently had resulted from use of a rubber mat in the bottom of the tub, while in the other three, the stain had probably been caused by rusting of iron objects (possibly hobby pins or metal toys).

\section{(7) Cigarette Burns}

Three tubs showed cigarette burns on the outer ledge. Two of these were in motel units and the third in a private home. It was found in the home fixture (F'HA repossessed) that the discolored area could be removed by a vigorous and prolonged localized scouring with "Bon Ami."

\section{(8) Impact Damage}

There was no positive evidence in any of the inspected plastic fixtures of complete loss or penetration of gel-coat from impact of a falling object. However, one fixture was found where a star-shaped crack pattern in the gel-coat on the wall surround suggested that an impact from the reverse side might have occurred previously.

\section{(9) Rigidity and Strength}

Several fixtures (two or three years old) exhibited considerable flexibility, especially in the wall surround, and some fixtures exhibited a "cracking noise" when pressed firmly with a foot or a hand. This condition suggested either a possible separation of the reinforcement strips from the fiber-glass-resin backing, or insufficient rigidity of the reinforcement as designed. No structural failures were observed in any of the fixtures.

\section{(10) Spalls and Pits}

Small spalls or pits, approximately $1 / 16$ in to $1 / 8$-in diam, were detected on the bottom of about 80 percent of the bathtubs which had been installed for periods of two to three years. This percentage decreased to 35 percent on the fixtures installed from one to two years while none of these defects was observed on the fixtures installed for one year or less.

\section{(11) Lifting of Gel Layer (Delamination)}

Several examples of separation of the gel layer from the fiberglass-resin backing were observed. In one case water could be squeezed out of a break in the coating by pressing down on the raised portion of the gel-coat.

\section{(12) Apparent Slip Resistance of Gel-Coat}

Two members of the inspection team who took baths in FRPE tubs installed in their motel rooms reported a feeling that the tubs were less slippery than conventional porcelain-enameled fixtures.

The manager" of a development for retired people reported no injuries from falls in bathrooms since the development started. He ascribed this absence of injury to the plastic fixtures. All of these homes (est. $1,000 \mathrm{com}$ pleted) were equipped with deep shower receptors with integral seats.

\section{(13) Field Repairs of Plastic Fixtures}

Several field-repaired fixtures were inspected. Some owners reported reappearance of defects after a relatively short period of service following repair.

\section{(14) Comments on Customer Acceptance}

Although no comments from occupants were solicited during the field inspections, opinions and comments were nevertheless frequently volunteered. Some dissatisfaction was evidenced in a number of cases where defects requiring field repairs had appeared. One comment, volunteered during many of the inspections, was that the FRPE fixtures were not only more difficult to clean than porcelain-enameled fixtures, but that even after cleaning they did not look as "clean" as a porcelain-enameled fixture. On the other hand, many favorable comments were heard on the absence of a tub-to-tile seam with the FRPE fixture. Some users commented favorably about apparent slip resistance.

\section{d. Suggestions Regarding Needed Test Based on Field Observations}

The comments given below regarding needed tests for sanitary plumbing fixtures were developed immediately following the field inspection trip as a result of the field observations, and preceded the initiation of laboratory work. In fact, the substance of these comments was later found quite useful as guideline material in actual test development work and in formulating recommendations. For these reasons, it is appropriate to present the comments here.

\section{(1) Delamination}

Separation of the gel-coat from the fiber-glass-resin backing, if it occurs, is a serious defect from the standpoint of sanitation and fixture usability. A suitable hotwater resistance test might reveal tendencies to delamination and spalling of the gel-coat.

\section{(2) Cracking or Crazing of Gel-Coat}

Cracking of crazing of the gel-coat is undesirable from the standpoint of sanitation and ease of cleaning, and may permit water entry into the fiber-glass-reinforced plastic. A hot-water resistance test might reveal susceptibility to crack or craze.

\section{(3) Gel-Coat Thickness}

In a performance specification a gel-coat thickness requirement does not seem appropriate. Instead it might be better to require that the coating withstand a minimum number of abrasion cycles under specified conditions.

\section{(4) Bond Between Fiber-Glass-Resin Backing and Rein- forcing Strips}

A test of the bond strength of reinforcing strips should not be a part of a performance specification. The integrity of the bond could probably best be evaluated by specify- 
ing maximum permissible deflection during localized loading and measuring the deflection with respect to the immediate vicinity of the loading point.

\section{(5) Abrasion Resistance}

This is an important property, since the field inspection indicated that owners continue to use scouring powder for cleaning in spite of instructions to the contrary from the manufacturer. A suitable abrasion test should take into account the portable number and severity of scouring treatments during the desired period of service life.

\section{(6) Stain Resistance}

The field inspection indicated that stains had not been a serious problem with FRPE tubs except possibly stains from cigarette burns. The criterion for stain resistance might possibly be related to the thickness of coating that would have to be removed to eliminate the stain.

\section{(7) Aging}

No installations were inspected that had been in service for longer than three years. It might be desirable to have an accelerated test to indicate whether or not the properties of the material would change appreciably with time at approximately room temperature.

\section{(8) Hardness and Scratch Resistance}

One of the unexpected findings from the field inspection was that scratches, while present, were not especially noticeable and, furthermore, they had little effect on the pencil cleanability test employed in the field inspections. Nevertheless, it seems important that a scratch test be included in a performance specification.

\section{(9) Cleanability}

The field inspections indicated that cleanability is important to the user. A suitable test should measure the ease with which a standard soiling agent can be removed.

\section{e. Test Facilities}

The NBS inspection team risited one commercial testing laboratory, one industry research laboratory, and one fixture manufacturer's laboratory. The impression obtained was that each of these laboratories had been conducting several of the tests called for under CS 22159 , and had become familiar with these tests. The manufacturer's laboratory was set up for the primary purpose of quality control of FRPE fixtures, and was well equipped for this purpose. The industry research laboratory was concerned with evaluating or developing tests for a broad spectrum of building products and materials, and was well equipped for making several of the important tests called for by CS 221-59. The commercial testing laboratory visited evidently made only certain tests on plumbing fixtures, principally the structural and mechanical tests.

Two of the three manufacturing plants visited evidently did not make on the premises the test described in CS 221-59, but conducted inspection and made empirical process control adjustment. These two plants did not conduct routine tests on the quality of the gel-coat materials, but purchased the product from well-known suppliers according to specification.

This brief inspection of test facilities should not in any sense be construed to indicate an evaluation of the laboratories visited. The only purpose was to obtain some familiarity with the test apparatus and procedures used in evaluating FRPE fixtures made to existing standards. 


\section{Appendix B. Telephone Survey of Pressed-Steel Bathtubs}

In two of the performance tests for bathtubs (Dynamic Load, Sec. 2.4, and Surface-Impact Resistance, Sec. 2.12), relatively low values were obtained in the laboratory tests for the pressed-steel bathtubs. Therefore, it appeared desirable to conduct a survey of field damage due to impact for tubs of this type. However, since available resources were limited, it became necessary to select a type of survey that could provide statistically significant data in a reasonable time and at a reasonable cost.

The procedure decided upon was a telephone survey. Two housing developments were first selected from the Washington, D.C., area, where it was known with certainty that only porcelain-enameled pressed-steel bathtubs had been installed by the developers. The two developments selected were:

1. Development "A": This is a very large mediumpriced housing development located approximately 15 miles from the District of Columbia. Occupancies from 1 to 3 years.

2. Development "B": This is a medium-sized development located almost adjacent to the District of Columbia. Homes, which are from 6 to 15 years old, are in the medium-price range.

Telephone numbers were chosen at random from the street names and house numbers known to be a part of these two developments. Secretaries in the NBS Building Research Division then placed the calls requesting the information specified on a survey sheet, a sample of which is included with this Appendix (table B-1).

Table B-2 lists the results of the survey. In interpreting the results the following comments appear to be pertinent:
(1) The homes contacted in Development " $A$ " were built by mass-production techniques. Information was obtained indirectly indicating that extra precautions against chipping damage were not exercised when installing bathtubs, since the builder had found that it was more economical to repair chipped areas after installation than to require elaborate protective procedures by the workmen. This may account for the high incidence of damaged areas reported at the time of occupancy (see table B-2).

(2) The survey indicated that a serious fall had occurred in only 0.9 percent of the pressed-steel bathtubs. The falls that did occur were reported to have caused no noticeable damage to the fixtures.

(3) A total of 20 percent of the 324 tubs was reported to have one or more chips, while 80 percent ( 258 tubs) were reported as having no impact damage. Most of the chipped areas were small; 60 per cent of the damaged areas were described as less than $1 / 4$-in in diameter.

(4) No field inspections were made by the project personnel. A few spot checks would have been desirable, but these could not be made because of time limitations. Therefore, since the results were based entirely on the replies of the housewives, the reference level for judging damage probably varied and, for this reason, uncertainties exist in the data. On the other hand, it seems very unlikely that the reported percentages could be in error by any sizable amount since there would appear to be no logical reason for a housewife to supply either a dishonest or an incorrect answer to the questions. 


\section{NBS TELEPHONE SURVEY OF SHEET STEEL BATHTUBS}

Date of Call Initials of NBS Interviewer

Name Telephone No.

Subdivision

1. How old is your house? years.

2. How many bathtubs in house?

3. Does your bathtub have any chipped areas: places where the white finish has come off and you can see the black material underneath?

Yes No

3.b. If so, how many places are there like this?

3.c. Are they on one tub only?

3.d. Are they on bottom? Rim?

3.e. About how large are they?

3.f. Were they present when you moved into house? Yes

Both tubs

. Has anyone ever fallen while taking a bath or shower in your tub?

Yes No

4.b. If so, were they injured? Yes

4.c. Was there any damage to the tub? Yes No

If no chipping or falls are reported, complete the call by thanking them for their assistance.

If either chipping or a fall has occurred, ask if it would be all right for a team of two people from the Bureau of Standards to stop by to look at the tub sometime during the next month. These people would not come without first calling and making an appointment.

Volunteered comments of interest (if any)

TABLE B-2. Summary of results of telephone survey of pressed-steel bathtubs

\begin{tabular}{|c|c|c|c|c|c|c|c|}
\hline \multirow{2}{*}{ Question } & \multirow{2}{*}{ Description } & \multicolumn{2}{|c|}{ Development " $\mathrm{A}$ "a } & \multicolumn{2}{|c|}{ Development “ $\mathrm{B}$ "b } & \multicolumn{2}{|c|}{ Both developments } \\
\hline & & Number & Percentage & Number & Percentage & Number & Percentage \\
\hline \multirow[t]{3}{*}{$\begin{array}{l}1 . \\
2 . \\
3 . \\
4 .\end{array}$} & $\begin{array}{l}\text { Bathtubs reported } \\
\text { Serious falls reported } \\
\text { Bathtubs with no chips } \\
\text { Bathtubs with one or more chips } \\
\text { a. Chips present when dwelling was occupied } \\
\text { b. Chips occurred after occupancy } \\
\text { c. Average number of chips per fixture } \\
\text { d. Location of chips: } \\
\quad \text { Bottom } \\
\quad \text { Rim }\end{array}$ & $\begin{array}{r}273 \\
\circ 2 \\
218 \\
55 \\
40 \\
15 \\
1.15 \\
\\
39 \\
23 \\
2\end{array}$ & $\begin{array}{r}100 \\
0.7 \\
80 \\
20 \\
15 \\
5 \\
- \\
61 \\
36 \\
3\end{array}$ & $\begin{array}{r}51 \\
01 \\
40 \\
11 \\
\mathrm{~d} \\
\mathrm{~d} \\
1.36 \\
\\
5 \\
9 \\
1\end{array}$ & $\begin{array}{r}100 \\
1 \\
78 \\
22 \\
\\
\\
60 \\
73\end{array}$ & $\begin{array}{r}324 \\
3 \\
258 \\
66\end{array}$ & $\begin{array}{r}100 \\
0.9 \\
80 \\
20 \\
\\
- \\
\\
56 \\
40 \\
4\end{array}$ \\
\hline & $\begin{array}{l}\text { Total } \\
\text { Approx. size of chips: } \\
\text { A } 1 / 4 \text { in diam } \\
\text { About } 1 / 4 \text { in diam } \\
\text { About } 1 \text { in diam } \\
>1 \text { in diam }\end{array}$ & $\begin{array}{r}64 \\
40 \\
9 \\
8 \\
4 \\
3\end{array}$ & $\begin{array}{r}100 \\
63 \\
14 \\
12 \\
6 \\
5\end{array}$ & $\begin{array}{r}15 \\
7 \\
0 \\
5 \\
3 \\
0\end{array}$ & $\begin{array}{r}100 \\
47 \\
0 \\
33 \\
20 \\
0\end{array}$ & $\begin{array}{r}79 \\
47 \\
9 \\
13 \\
7 \\
3\end{array}$ & $\begin{array}{r}100 \\
60 \\
11 \\
16 \\
9 \\
4\end{array}$ \\
\hline & Total & 64 & 100 & 15 & 100 & 79 & 100 \\
\hline
\end{tabular}

a Medium-priced homes that had been occupied from 1 to 3 years.

$\checkmark$ Medium-priced homes that had been occupied from 6 to 15 years (average age of fixture 9.8 years).

- No damage reported to fixture.

d In most cases, occupant was unable to answer this question. 


\section{Announcement of New Publications in Building Science Series}

Superintendent of Documents, Government Printing Office, Washington, D.C., 20402

\section{Dear Sir:}

Please add my name to the announcement list of new publications to be issued in the series: National Bureau of Standards Building Science Series.

Name

Company

Address

City State Zip Code

(Notification key N-339) 



\section{NATIONAL BUREAU OF STANDARDS}

The National Bureau of Standards ' was established by an act of Congress March 3, 1901. Today, in addition to serving as the Nation's central measurement laboratory, the Bureau is a principal focal point in the Federal Government for assuring maximum application of the physical and engineering sciences to the advancement of technology in industry and commerce. To this end the Bureau conducts research and provides central national services in four broad program areas. These are: (1) basic measurements and standards, (2) materials measurements and standards, (3) technological measurements and standards, and (4) transfer of technology.

The Bureau comprises the Institute for Basic Standards, the Institute for Materials Research, the Institute for Applied Technology, the Center for Radiation Research, the Center for Computer Sciences and Technology, and the Office for Information Programs.

THE INSTITUTE FOR BASIC STANDARDS provides the central basis within the United States of a complete and consistent system of physical measurement; coordinates that system with measurement systems of other nations; and furnishes essential services leading to accurate and uniform physical measurements throughout the Nation's scientific community, industry, and commerce. The Institute consists of an Office of Measurement Services and the following technical divisions:

Applied Mathematics-Electricity-Metrology-Mechanics-Heat-Atomic and Molecular Physics-Radio Physics "-Radio Engineering "-Time and Frequency - - Astrophysics "-Cryogenics. ${ }^{2}$

THE INSTITUTE FOR MATERIALS RESEARCH conducts materials research leading to improved methods of measurement standards, and data on the properties of well-characterized materials needed by industry, commerce, educational institutions, and Government; develops, produces, and distributes standard reference materials; relates the physical and chemical properties of materials to their behavior and their interaction with their environments; and provides advisory and research services to other Government agencies. The Institute consists of an Office of Standard Reference Materials and the following divisions:

Analytical Chemistry-Polymers-Metallurgy-Inorganic Materials-Physical Chemistry.

THE INSTITUTE FOR APPLIED TECHNOLOGY provides technical services to promote the use of available technology and to facilitate technological innovation in industry and Government; cooperates with public and private organizations in the development of technological standards, and test methodologies; and provides advisory and research services for Federal, state, and local government agencies. The Institute consists of the following technical divisions and offices:

Engineering Standards-Weights and Measures - Invention and Innovation - Vehicle Systems Research-Product Evaluation-Building Research-Instrument Shops-Measurement Engineering-Electronic Technology-Technical Analysis.

THE CENTER FOR RADIATION RESEARCH engages in research, measurement, and application of radiation to the solution of Bureau mission problems and the problems of other agencies and institutions. The Center consists of the following divisions:

Reactor Radiation-Linac Radiation-Nuclear Radiation-Applied Radiation.

THE CENTER FOR COMPUTER SCIENCES AND TECHNOLOGY conducts research and provides technical services designed to aid Government agencies in the selection, acquisition, and effective use of automatic data processing equipment; and serves as the principal focus for the development of Federal standards for automatic data processing equipment, techniques, and computer languages. The Center consists of the following offices and divisions:

Information Processing Standards-Computer Information - Computer Services - Systems Development-Information Processing Technology.

THE OFFICE FOR INFORMATION PROGRAMS promotes optimum dissemination and accessibility of scientific information generated within NBS and other agencies of the Federal government; promotes the development of the National Standard Reference Data System and a system of information analysis centers dealing with the broader aspects of the National Measurement System, and provides appropriate services to ensure that the NBS staff has optimum accessibility to the scientific information of the world. The Office consists of the following organizational units:

Office of Standard Reference Data-Clearinghouse for Federal Scientific and Technical Information :-Office of Technical Information and Publications-Library-Office of Public Information-Office of International Relations.

\footnotetext{
Headquarters and Laboratories at Gaithersburg. Maryland, unless otherwise noted: mailing address Washington, D.C. 20234.

3 Located at 5285 Port Royal Road. Springfield. Virginia 22151.
} 
U.S. DEPARTMENT OF COMMERCE Washington, D.C. 20230

OFFICIAL BUSINESS

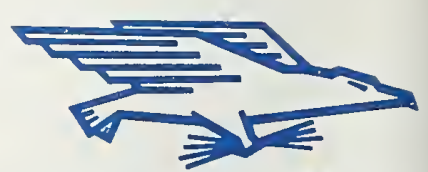

POSTAGE AND FEES PAID U.S. DEPARTMENT OF COMMERCE 